



\section{Dietary Epicatechin and Quercetin in}

Cardiovascular Health and Disease

James I. Dower 


\section{THESIS COMMITTEE}

\section{Promotors}

Prof. Dr D. Kromhout

Professor of Public Health Research

Wageningen University

Prof. Dr J.M. Geleijnse

Personal chair at the Division of Human Nutrition

Wageningen University

\section{Co-promotor}

Dr P.C.H. Hollman

Senior Researcher RIKILT Wageningen UR

Associate Professor, Division of Human Nutrition

Wageningen University

\section{Other members}

Prof. Dr I.C.W Arts, Maastricht University Prof. A. Cassidy, Norwich Medical School

Prof. Dr A. Bast, Maastricht University

Prof. Dr J. Keijer, Wageningen University 


\title{
Dietary Epicatechin and Quercetin in Cardiovascular Health and Disease
}

\author{
James I. Dower
}

Thesis

submitted in fulfillment of the requirements for the degree of doctor at Wageningen University by the authority of the Rector Magnificus

Prof. Dr A.P.J. Mol,

in the presence of the

Thesis Committee appointed by the Academic Board

to be defended in public

on Monday 27 June 2016

at 1:30 in the Aula. 
James I. Dower

Dietary Epicatechin and Quercetin in Cardiovascular Health and Disease 164 pages.

PhD thesis, Wageningen University, Wageningen, NL (2016)

With references and summary in English

ISBN 978-94-6257-786-2

DOI: $10.18174 / 378696$ 


\section{TABLE OF CONTENTS}

1. General Introduction 7

2. Dietary Epicatechin Intake and 25-year Risk of Cardiovascular Mortality: The Zutphen Elderly Study

(Accepted)

3. Effects of the Pure Flavonoids Epicatechin and Quercetin on Vascular

Function and Cardiometabolic Health: a Randomised Double-Blind, Placebo-Controlled, Crossover Trial

(Am J Clin Nutr. 2015;101(5):914-921)

4. Supplementation of the Pure Flavonoids Epicatechin and Quercetin Affects Some Biomarkers of Endothelial Dysfunction and Inflammation in (Pre)Hypertensive Adults: A Randomised Double-Blind, PlaceboControlled, Crossover Trial (U Nutr. 2015;145(7):1459-1463)

5. Pure Epicatechin and Inflammatory Gene Expression Profiles in Circulating Immune Cells in (Pre)Hypertensive Adults: A Randomised, Double-Blind, Placebo-Controlled, Crossover Trial (In preparation)

6. Does Epicatechin Contribute to the Acute Vascular Function Effects of Dark Chocolate? A Randomised, Crossover Study

(Under review)

7. General Discussion

English Summary

Dankwoord

About the Author

Curriculum Vitae

List of Publications 

General Introduction 
Cardiovascular disease (CVD) is one of the leading causes of deaths and is responsible for approximately $30 \%$ of all deaths worldwide [1]. CVD is the term used to encompass a wide range of diseases of the cardiovascular system, such as coronary heart disease (CHD), stroke and heart failure. Tobacco use, physical activity and diet are major modifiable risk factors for CVD [2]. For example, dietary components such as cocoa and tea are associated with a lower risk of CVD. A meta-analysis of cohort studies showed that cocoa/chocolate intake was associated with a 37\% lower risk of CVD and 29\% lower risk of stroke [3]. Metaanalyses of tea showed that those who drank 1-3 cups of green tea per day had a $36 \%$ lower relative risk of stroke [4], and that those who drank 3 cups of green or black tea per day had a $21 \%$ lower risk of stroke [5]. An increase in green tea consumption of $1 \mathrm{cup} / \mathrm{d}$ was also associated with a $10 \%$ lower risk of CHD [6].

\section{Pathophysiology of Cardiovascular Disease}

Atherosclerosis is a chronic disorder characterized by the accumulation of lipids and fibrous elements in large arteries and is one of the main underlying causes of CVD [7]. The endothelium, a thin layer of cells that line the interior of blood vessels in the circulatory system, plays an important role in the development of atherosclerosis [7].

Hyperlipidaemia, smoking and hypertension, classic risk factors for atherosclerosis, lead to an increase in oxidised products of lipoproteins such as LDL, and angiotensin II [8]. This stimulates endothelial cells to produce inflammatory cytokines such as TNF-a, C-reactive protein (CRP), and interleukins (IL-1 $\beta, I L-6$, and IL-8). In response to these cytokines, adhesion molecules such as soluble endothelial selectin (sE-selectin), soluble vascular cell adhesion molecule-1 (sVCAM-1), soluble intercellular adhesion molecule-1 (sICAM-1), and von Willebrand factor ( $\mathrm{VWf}$ ) are synthesized by endothelial cells and induce adhesion of leukocytes to the endothelium. After adhesion, monocyte chemoattractant protein-1 (MCP1) induces the transendothelial migration of monocytes into the intima [9]. Once in the intima, monocytes may differentiate into macrophages and scavenge oxidized LDL. This leads to the formation of foam cells, resulting in chronic inflammation and progression into fatty streaks and fibrous plaques, which in turn leads to atherosclerosis. Studies have shown that inflammatory cytokines (e.g. CRP, TNF-a, and IL-6) and adhesion molecules (e.g. sVCAM-1, sICAM-1, and SE-selectin) are predictors of CVD risk [10-12].

Chronic inflammation is not only heavily involved in the development of atherosclerosis, but is also linked to the development of insulin resistance [13-15]. It is suggested, for example, that cytokines such as TNF-a may induce insulin resistance [16]. Insulin resistance is associated with an increased risk of type II diabetes mellitus and atherosclerosis [17], as well as CVD $[18,19]$.

Inflammatory processes and insulin resistance play a role in maintaining normal endothelial and vascular function. By controlling the release of vasoactive compounds such as nitric 
oxide (a vasodilator) and endothelin-1 (a vasoconstrictor), the endothelium helps to control vascular tone and normal endothelial function. An imbalance in vasoactive compounds can lead to a deterioration in the flexibility of the vascular wall, causing a progressive increase in blood pressure. As such, endothelial dysfunction is positively associated with hypertension [20]. A widely used measure of endothelial function is flow- mediated dilation (FMD), which measures the change in arterial diameter in response to reactive hyperaemia [21]. Prospective cohort studies showed that every $1 \%$ increase in FMD is associated with an $8-13 \%$ lower risk of future cardiovascular events $[22,23]$. Likewise, the risk of CVD mortality doubles with every $20 \mathrm{~mm} \mathrm{Hg}$ increase in systolic blood pressure [24].

Cardiometabolic health encompasses the underlying processes involved in developing type II diabetes and CVD [25, 26]. Endothelial dysfunction, inflammation, insulin resistance and hypertension are all major determinants of cardiometabolic health [22, 23, 27]. There is evidence that cocoa and tea protect against CVD by positively influencing these cardiometabolic risk factors [28-32].

\section{Cocoa, Tea and Cardiometabolic Health}

Interest in the cardioprotective effects of cocoa stems, in part, from observations of an ecological study carried out in Central America. The Kuna Indians who live on the San Blas Islands, off the coast of Panama, have low blood pressure which does not rise with age [33]. Interestingly, the Kuna Indians who migrate to mainland Panama do see an age-dependent increase in blood pressure. This excludes the possibility that Kuna Indians are genetically protected against hypertension and suggests that the protective factor is local to the island environment, for example the diet. The most striking difference in diet between the two populations is what they drink. On the islands, there is little drinking water and the supply from the mainland is unpredictable. For this reason, the Kuna Islanders consume up to 5 cups per day of a raw cocoa drink whereas the mainland Kuna Indians consume only 0.5 cups per day [34].

The effect of cocoa on blood pressure has been demonstrated since then in a number of randomised, placebo-controlled, clinical trials (RCTs). A meta-analysis of these cocoa RCTs showed that cocoa consumption reduced systolic blood pressure (SBP) by $3.2 \mathrm{mmHg}$ and diastolic blood pressure (DBP) by $2.0 \mathrm{mmHg}$ [35].

RCTs have also investigated the effects of cocoa on other markers of cardiometabolic health. A meta-analysis by Hooper et al. showed that cocoa consumption improved FMD chronically (2-18 weeks) by $1.3 \%$, as well as acutely ( 2 hours) by $3.2 \%$ [28]. Based on this evidence, the European Food Safety Authority (EFSA) approved a health claim that cocoa flavan-3-ols help to maintain normal endothelial function [36]. In the meta-analysis of Hooper et al, chronic cocoa consumption was also related to improvements in insulin resistance [28]. 
Similar to cocoa, results from RCTs also showed that chronic tea consumption (median daily intake of $500 \mathrm{~mL} / \mathrm{d}$ ) improved FMD by 2.6\% [31]. Likewise, green tea or green tea extracts reduced SBP/DBP by $2.1 / 1.7 \mathrm{mmHg}$ in healthy subjects [37], and improved insulin resistance in obese type II diabetes patients [29].

There is some evidence from RCTs that cocoa and tea can favourably influence biomarkers of endothelial function and inflammation, however, studies are still limited and results are conflicting. For example, consuming a cocoa beverage decreased plasma levels of SVCAM-1, but did not change sICAM-1 [38]. In contrast, another cocoa study found no change in SVCAM-1, but found a decrease in SICAM-1 [39]. Other biomarkers of endothelial function changed after cocoa consumption - NO increased [40,41], and endothelin-1 production decreased [42]. To our knowledge, inflammation markers have only been studied in one cocoa study, which did not find an effect on IL-6 or CRP [39]. Black tea had no effect on E-selectin, P-selectin, sICAM-1 and SVCAM-1 [43], as well as CRP, IL-1 $\beta$, IL-6, and TNF- $\alpha$ [44]. Other studies did show, however, that chronic tea consumption reduced the levels of MCP1 and CRP [30, 32].

\section{Flavonoids in Cocoa and Tea}

Cocoa and tea are both rich sources of flavonoids. Flavonoids are a group of secondary plant metabolites that belong to the larger group of polyphenolic compounds (Figure 1). The first research into flavonoids began in the 1930's when Szent-Györgyi reported a substance in citrus fruits that was thought to influence the permeability of capillaries, and called it vitamin P [45]. Later on, this substance proved to be a mixture of flavonoids [46]. No deficiency disease was ever linked to vitamin P, and hence it lost its vitamin status. Nowadays, over 4000 different flavonoids have been identified, and based on their chemical structure they can be divided into 6 subclasses; flavan-3-ols, flavonols, flavanones, flavones, isoflavones and anthocyanidins. As shown in Figure 2, flavonoids are characterised by two benzene rings ( $A$ and $B$ rings) that are linked by a heterocyclic pyran ring ( $C$ ring). Differences in saturation and oxidation states of the $C$ ring and the position of the $\mathrm{B}$ ring determine the subclass.

Flavonoids can be found in a wide range of plant-based foods, including cocoa, tea, apples, citrus fruits, red wine, berries and legumes (Figure 1). The average intake of all flavonoids together, in a French population, was approximately $500 \mathrm{mg} / \mathrm{d}$ [47]. Tea is the major dietary source of monomeric flavan-3-ols as well as flavonols. In the Netherlands, tea contributes more than $65 \%$ of monomeric flavan-3-ol intake as well as $50 \%$ of flavonol intake $[48,49]$. Of the flavonols in tea, quercetin (Figure 2) is the most abundant - approximately $50 \%$ of the flavonol content of black tea is from quercetin [50].

Cocoa is a rich source of flavan-3-ols and contains both monomeric and oligomeric flavan3-ols. Because oligomeric flavan-3-ols have a much lower bioavailability than monomeric 


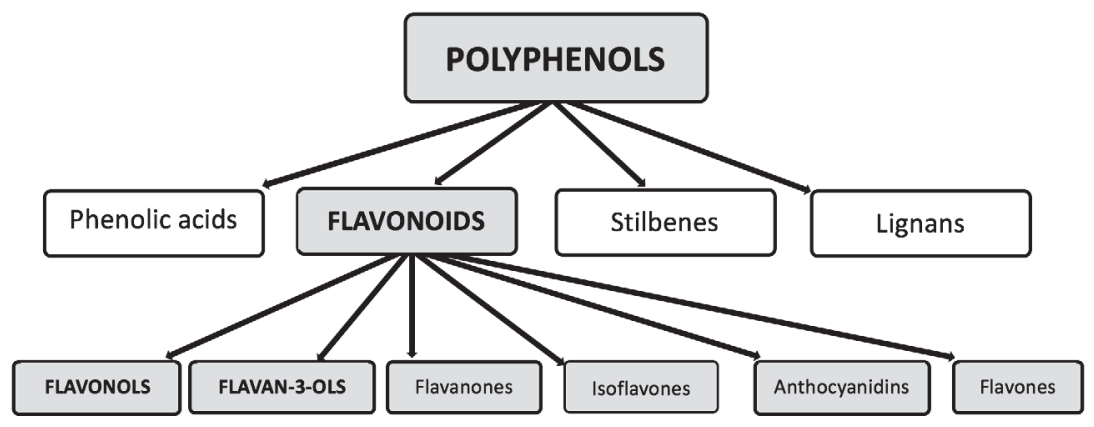

\begin{tabular}{|c|c|c|c|c|c|c|}
\hline Examples & $\begin{array}{l}\text { Quercetin } \\
\text { Kaempferol }\end{array}$ & $\begin{array}{l}\text { Proantho- } \\
\text { cyanidins } \\
\text { Epicatechin }\end{array}$ & $\begin{array}{l}\text { Hesperetin } \\
\text { Naringenin }\end{array}$ & $\begin{array}{l}\text { Daidzein } \\
\text { Gensitein }\end{array}$ & $\begin{array}{l}\text { Delphinidin } \\
\text { Malvidin }\end{array}$ & $\begin{array}{l}\text { Apigenin } \\
\text { Luteolin }\end{array}$ \\
\hline Main & Tea & Tea & Grapefruit & Soy & Blackberry & Chicory \\
\hline dietary & Apples & Apples & Orange & Legumes & Blackcurrant & Artichoke \\
\hline Sources & Onion & Cocoa & & & & Olive \\
\hline
\end{tabular}

FIGURE 1. Categorisation of polyphenol subclasses, with examples and main dietary sources of all flavonoid subclasses.

flavan-3-ols [51], they are not thought to contribute directly to the cardioprotective effects of cocoa. Of the monomeric flavan-3-ols in cocoa, epicatechin (Figure 2) is by far the most abundant. A bar of $100 \mathrm{~g}$ dark chocolate (54\% cocoa) provides $33 \mathrm{mg}$ of epicatechin - more than twice the mean daily intake in the Netherlands [48]. Interestingly, epicatechin is also a major monomeric flavan-3-ol in tea [52], and tea is its major dietary source [48].

Epicatechin is the major monomeric flavan-3-ol in cocoa, and tea is not only the major dietary source of epicatechin, but also the flavonol quercetin (Figure 3). For this reason, we highlighted epicatechin and quercetin as two dietary flavonoids which could mediate the cardioprotective effects of cocoa and tea. Evidence of the effects of epicatechin and quercetin on CVD incidence, as well as markers of CVD risk, is limited. Hence, it remains unclear if, and how, the dietary flavonoids epicatechin and quercetin protect against CVD.

\section{Epicatechin, Quercetin and Cardiovascular Disease}

\section{Cohort Studies on Cardiovascular Disease}

Associations between the intake of flavonoid subclasses and CVD have been investigated. McCullough et al. showed that the highest quintile of monomeric flavan-3-ol intake was significantly associated with a 17\% lower risk of CVD mortality in 98,469 American men and women [53]. Likewise, in the Zutphen Elderly Study, a higher intake of monomeric flavan-3-ols was associated with a 51\% lower risk of CHD mortality in 805 elderly Dutch 
<smiles>[R5]c1cc(C2Oc3cc(O)c([R6])c([R6])c3C2([R4])C([R])C)cc([R5])c1[R6]</smiles><smiles>Oc1cc(O)c2c(c1)OC(c1ccc(O)c(O)c1)C(O)C2</smiles><smiles>O=c1c(O)c(-c2ccc(O)c(O)c2)oc2cc(O)cc(O)c12</smiles>

FIGURE 2. Structures of flavonoids. i) Flavonoid skeleton, ii) (-)-epicatechin, iii) Quercetin. The various R-groups of the flavonoid skeleton can be: $\mathrm{H}, \mathrm{OH}, \mathrm{OCH} 3$ or $\mathrm{O}-\mathrm{Glycoside}$. The $\mathrm{A}$ and $\mathrm{B}$ rings are linked by a heterocyclic pyrane ring ( $\mathrm{C}$ ring). Differences in saturation and oxidation states of the $\mathrm{C}$ ring and the position of the $\mathrm{B}$ ring determine the subclass.

men [54]. Other studies, however, showed no significant association. In the European Prospective Investigation into Cancer and Nutrition, monomeric flavan-3-ol intake was not significantly associated with CVD mortality in 40,622 Spanish [55], or 24,885 British men and women [56]. Likewise, flavan-3-ol intake was not significantly associated with CVD mortality or ischaemic stroke in 1,950 Finnish men [57], or with CVD, CHD or stroke mortality in 34,489 post-menopausal women [58]. For flavonols, McCullough et al. showed that the highest quintile of intake was associated with a $16 \%$ lower risk of CVD mortality [56]. In the Zutphen Elderly Study, the highest tertile of flavonol intake was also associated with a 58\% lower risk of CHD mortality [59].

Cohort studies have not assessed the association between epicatechin intake and CVD mortality. A number of cohort studies have, however, investigated the association between quercetin and CVD mortality. One study reported that a higher quercetin intake was significantly associated with a 12\% lower risk of CHD mortality in 10,054 Finnish men and women [60]. Other cohort studies, however, reported no significant association between 


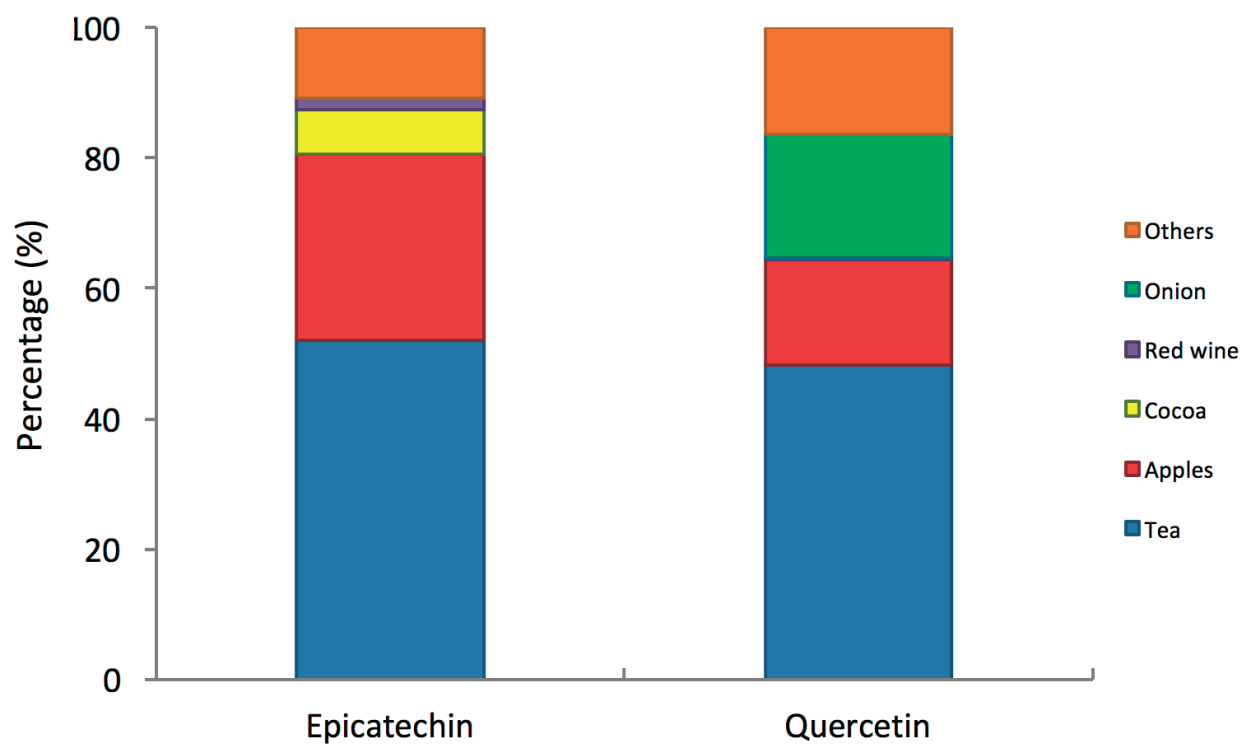

FIGURE 3. Dietary sources of epicatechin and quercetin intake. Mean epicatechin intake $=15.1 \mathrm{mg} / \mathrm{d}$, mean quercetin intake = $15.5 \mathrm{mg} / \mathrm{d}$. Based on data from the Zutphen Elderly Study (Chapter 2).

quercetin intake and stroke incidence in 9,208 Finnish men and women [61], or with CHD mortality in 66,289 women [62], or CHD incidence in 34,789 male health professionals [63].

\section{Randomised-Controlled Trials on Cardiometabolic Health}

A number of trials have investigated the effects of pure quercetin, and to a lesser extent epicatechin, on markers of CVD risk. Chronic supplementation of quercetin dihydrate (150 $\mathrm{mg} / \mathrm{d}$ ) for 8 weeks did not improve endothelial function in 49 healthy male subjects [64]. It is important to note that in this study, endothelial function was measured by means of reactive hyperemia with finger plethysmography using the Endo-PAT2000 system, instead of the more commonly used measure of endothelial function; FMD. An acute study showed that pure epicatechin (70 - $140 \mathrm{mg}$ ) improved FMD, however, this was only tested in a small sample of 6 healthy individuals [41]. This effect could be explained by changes in vasoactive compounds as the increase in FMD coincided with an increase in NO. Relatively high dosages of pure epicatechin (200 mg) and quercetin (200 mg) supplementation augmented NO products and reduced endothelin-1 acutely in 12 healthy men [65]. 
Three RCTs reported positive effects of pure quercetin supplementation on blood pressure. Egert et al. showed that $150 \mathrm{mg} / \mathrm{d}$ of pure quercetin for 6 weeks reduced systolic blood pressure in 93 overweight/obese men and women [66]. Likewise, Edwards et al. showed that $730 \mathrm{mg} / \mathrm{d}$ of quercetin for 4 weeks reduced systolic and diastolic blood pressure in hypertensive subjects, but not in prehypertensive subjects [67]. Chronic supplementation of quercetin dihydrate $(150 \mathrm{mg} / \mathrm{d})$ for 8 weeks decreased systolic blood pressure in healthy male subjects [64]. Other studies investigated the effects of quercetin supplementation on markers of inflammation. Supplementation of quercetin-3-glucoside (1000 mg/d) for 1 week did not attenuate IL-6 levels after sprint exercise in recreationally active adult men [68]. In contrast, supplementation of $4 \times 500 \mathrm{mg}$ of quercetin over a period of 24 -hours did lower markers of inflammation in sarcoidosis patients [69].

\section{Molecular Mechanisms of Epicatechin and Quercetin}

Due to recent developments and reductions in cost, gene expression analyses have become more feasible and reliable. It has been suggested that cocoa flavan-3-ols may protect against CVD via the inhibition of mitogen-activated protein kinases (MAPKs) and transcriptions factors NF-kB and AP-1 [70], as well as activation of the Nrf2 transcription factor [71].

NF-kB is a transcription factor involved in normal cell function and helps regulate the expression of genes involved in inflammation, innate immunity and cell survival [72]. Interestingly, NF-KB is mediated by the stimulation of TNF- $\alpha$ and IL-1 $\beta$. In vitro studies showed that cocoa flavan-3-ols modulated the secretion and transcription of IL-1 $\beta$ and TNF-a in peripheral blood mononuclear cells (PBMCs) collected from healthy volunteers $[73,74]$. In an animal study, Morrison et al. showed that pure epicatechin supplementation prevented diet-induced activation of aortic NF-kB in ApoE*3-Leiden mice fed an atherogenic diet [75].

Nrf2 is a transcription factor which protects cells against oxidative stress by maintaining active antioxidant pathways [72]. To our knowledge, there is no current evidence of the effects of pure flavonoids on Nrf2 activation in humans. Animal studies did, however, show that epicatechin increased the activation of Nrf2 and Nrf2 target genes in aortas from rats [76], and that the cardioprotective effects of epicatechin were abolished in mice lacking the Nrf2 transcriptional factor [77]. The activation of Nrf2 has also been linked to an increased $\mathrm{PI3K} / \mathrm{Akt}$ activity [78]. Interestingly, improvements in insulin resistance as a result of cocoa flavan-3-ol consumption is thought to be mediated through the induction of the PI3K/Akt and ERK1/2 pathways [72].

Peripheral blood mononuclear cells are a mixture of T-cells, B-cells and monocytes which are relatively easy to collect. Human nutrition studies also show that they are sensitive to diet-induced changes in gene expression [79]. Nevertheless, evidence of the effects 
of flavonoids or flavonoid-rich foods on PBMC gene expression in humans is lacking. One RCT did, however, report that acute cocoa consumption significantly decreased NFKB activation in PBMCs [80]. To our knowledge, no human study has yet investigated the effects of pure flavonoids on gene-expression in PBMCs, specifically looking at endothelial function and inflammation.

\section{Thesis Outline}

Cohort studies showed a lower risk of CVD mortality with higher intakes of flavonoid-rich foods such as cocoa and tea. Results from RCTs showed that cocoa and tea consumption improved vascular and endothelial function, as well as insulin resistance. Cocoa and tea are complex mixtures of many flavonoids and other substances. The effects of specific flavonoids in cocoa and tea on cardiovascular health are, therefore, unclear. A major favan-3-ol in cocoa is epicatechin, whereas tea is a major dietary source of epicatechin and quercetin. We hypothesize that epicatechin and quercetin are major contributors to the cardioprotective effects of cocoa and tea. The aim of this thesis is to gain insight into the effects of epicatechin and quercetin on cardiovascular health and disease.

Since we are not aware of any cohort studies that have studied the association between epicatechin intake and CVD mortality, we first carried out an epidemiological analysis. In Chapter 2, the association between epicatechin intake and cardiovascular mortality was investigated using data from the Zutphen Elderly Study - a cohort of 744 elderly Dutch men who were followed for a period of 25 years.

Whether epicatechin and quercetin affect cardiometabolic health was investigated in a clinical trial with the pure compounds. First, the effects of pure epicatechin and quercetin3-glucoside supplementation on cardiometabolic risk factors were evaluated by means of a double-blind, randomised, crossover trial in 37 healthy adults (Chapter 3). To gain more mechanistic insight, the effects of epicatechin and quercetin supplementation on a comprehensive set of biomarkers of endothelial dysfunction and inflammation were evaluated (Chapter 4). In the same study, the effects of pure epicatechin supplementation on PBMC gene expression were also studied (Chapter 5).

In Chapter 6 the contribution of epicatechin to the vascular effects of dark chocolate was investigated by comparing the acute effects of dark chocolate and pure epicatechin supplementation on vascular function. This was done by means of a, randomisedcontrolled trial in 20 healthy adult men. Finally, in Chapter $\mathbf{7}$ the main findings of this thesis are summarised and discussed in a broader context in the general discussion. 


\section{REFERENCES}

1. Lozano R, Naghavi M, Foreman K, et al. Global and regional mortality from 235 causes of death for 20 age groups in 1990 and 2010: A systematic analysis for the Global Burden of Disease Study 2010. Lancet. 2012;380(9859):2095-2128.

2. World Health Organisation. Cardiovascular Disease Fact Sheet, 2015.

3. Buitrago-Lopez A, Sanderson J, Johnson L, et al. Chocolate consumption and cardiometabolic disorders: Systematic review and meta-analysis. BMJ (Online). 2011;343.

4. Pang J, Zhang Z, Zheng TZ, et al. Green tea consumption and risk of cardiovascular and ischemic related diseases: A meta-analysis. Int J Cardiol. 2016;202:967-974.

5. Arab L, Liu W, Elashoff D. Green and black tea consumption and risk of stroke: A meta-analysis. Stroke. 2009;40(5):1786-1792.

6. Wang ZM, Zhou B, Wang YS, et al. Black and green tea consumption and the risk of coronary artery disease: A meta-analysis. Am J Clin Nutr. 2011;93(3):506-515.

7. Libby P. Inflammation in atherosclerosis. Nature. 2002;420(6917):868-874.

8. Libby P. Inflammation in Atherosclerosis. Arterioscler Thromb Vasc Biol. 2012;32(9):2045-2051.

9. Libby P. Vascular biology of atherosclerosis: Overview and state of the art. Am J Cardiol. 2003;91(S3):3A-6A.

10. Mulvihill NT, Foley JB, Murphy RT, Curtin R, Crean PA, Walsh M. Risk stratification in unstable angina and non-Q wave myocardial infarction using soluble cell adhesion molecules. Heart. 2001;85(6):623-627.

11. Tuomisto K, Jousilahti P, Sundvall J, Pajunen P, Salomaa V. C-reactive protein, interleukin-6 and tumor necrosis factor alpha as predictors of incident coronary and cardiovascular events and total mortality. A population-based, prospective study. Thromb Haemost. 2006;95(3):511-518.

12. Tzoulaki I, Murray GD, Lee AJ, Rumley A, Lowe GDO, Fowkes FGR. Relative value of inflammatory, hemostatic, and rheological factors for incident myocardial infarction and stroke: The Edinburgh artery study. Circulation. 2007;115(16):2119-2127.

13. Hotamisligil GS. Inflammation and metabolic disorders. Nature. 2006;444(7121):860-867.

14. Shoelson SE, Lee J, Goldfine AB. Inflammation and insulin resistance. J Clin Invest. 2006;116(7):17931801.

15. Xu H, Barnes GT, Yang Q, et al. Chronic inflammation in fat plays a crucial role in the development of obesity-related insulin resistance. J Clin Invest. 2003;112(12):1821-1830.

16. Nieto-Vazquez I, Fernández-Veledo S, Krämer DK, Vila-Bedmar R, Garcia-Guerra L, Lorenzo M. Insulin resistance associated to obesity: The link TNF-alpha. Arch Physiol Biochem. 2008;114(3):183194.

17. DeFronzo RA, Ferrannini E. Insulin resistance: A multifaceted syndrome responsible for NIDDM, obesity, hypertension, dyslipidemia, and atherosclerotic cardiovascular disease. Diabetes Care. 1991;14(3):173-194.

18. Bonora E, Kiechl S, Willeit J, et al. Insulin resistance as estimated by homeostasis model assessment predicts incident symptomatic cardiovascular disease in caucasian subjects from the general population: The Bruneck study. Diabetes Care. 2007;30(2):318-324. 
19. Hanley AJG, Williams K, Stern MP, Haffner SM. Homeostasis model assessment of insulin resistance in relation to the incidence of cardiovascular disease: The San Antonio heart study. Diabetes Care. 2002;25(7):1177-1184.

20. Benjamin EJ, Larson MG, Keyes MJ, et al. Clinical Correlates and Heritability of Flow-Mediated Dilation in the Community: The Framingham Heart Study. Circulation. 2004;109(5):613-619.

21. Celermajer DS, Sorensen KE, Gooch VM, et al. Non-invasive detection of endothelial dysfunction in children and adults at risk of atherosclerosis. Lancet. 1992;340(8828):1111-1115.

22. Inaba Y, Chen JA, Bergmann SR. Prediction of future cardiovascular outcomes by flow-mediated vasodilatation of brachial artery: A meta-analysis. Int J Cardiovasc Imaging. 2010;26(6):631-640.

23. Ras RT, Streppel MT, Draijer R, Zock PL. Flow-mediated dilation and cardiovascular risk prediction: A systematic review with meta-analysis. Int J Cardiol. 2013;168(1):344-351.

24. Lewington S, Clarke R, Qizilbash N, Peto R, Collins R. Age-specific relevance of usual blood pressure to vascular mortality: A meta-analysis of individual data for one million adults in 61 prospective studies. Lancet. 2002;360(9349):1903-1913.

25. Després JP, Lemieux I. Abdominal obesity and metabolic syndrome. Nature. 2006;444(7121):881887.

26. Eckel RH, Kahn R, Robertson RM, Rizza RA. Preventing cardiovascular disease and diabetes: A call to action from the American Diabetes Association and the American Heart Association. Circulation. 2006;113(25):2943-2946.

27. Cannon CP. Cardiovascular disease and modifiable cardiometabolic risk factors. Clin Cornerstone. 2007;8(3):11-28.

28. Hooper L, Kay C, Abdelhamid A, et al. Effects of chocolate, cocoa, and flavan-3-ols on cardiovascular health: A systematic review and meta-analysis of randomized trials. Am J Clin Nutr. 2012;95(3):740751.

29. Hsu CH, Liao YL, Lin SC, Tsai TH, Huang CJ, Chou P. Does supplementation with green tea extract improve insulin resistance in obese type 2 diabetics? A randomized, double-blind, and placebocontrolled clinical trial. Altern Med Rev. 2011;16(2):157-163.

30. Oyama JI, Maeda T, Kouzuma K, et al. Green tea catechins improve human forearm endothelial dysfunction and have antiatherosclerotic effects in smokers. Circ J. 2010;74(3):578-588.

31. Ras RT, Zock PL, Draijer R. Tea consumption enhances endothelial-dependent vasodilation; a meta-analysis. PLOS ONE. 2011;6(3).

32. Steptoe A, Gibson EL, Vuononvirta R, et al. The effects of chronic tea intake on platelet activation and inflammation: A double-blind placebo controlled trial. Atherosclerosis. 2007;193(2):277-282.

33. Hollenberg NK. Vascular action of cocoa flavanols in humans: The roots of the story. J Cardiovasc Pharmacol. 2006;47(SUPPL. 2):S99-S102.

34. McCullough ML, Chevaux K, Jackson L, et al. Hypertension, the Kuna, and the epidemiology of flavanols. J Cardiovasc Pharmacol. 2006;47(SUPPL. 2):S103-S109.

35. Ried K, Sullivan T, Fakler P, Frank OR, Stocks NP. Does chocolate reduce blood pressure? A metaanalysis. BMC Med. 2010;8(39). 
36. EFSA Panel on Dietetic Products NaAN. Scientific Opinion on the modification of the authorisation of a health claim related to cocoa flavanols and maintenance of normal endothelium-dependent vasodilation pursuant to Article 13(5) of Regulation (EC) No 1924/20061 following a request in accordance with Article 19 of Regulation (EC) No 1924/2006. EFSA Journal. 2014;12(5):3654.

37. Khalesi S, Sun J, Buys N, Jamshidi A, Nikbakht-Nasrabadi E, Khosravi-Boroujeni H. Green tea catechins and blood pressure: a systematic review and meta-analysis of randomised controlled trials. EurJ Nutr. 2014;53(6):1299-1311.

38. Wang-Polagruto JF, Villablanca AC, Polagruto JA, et al. Chronic consumption of flavanolrich cocoa improves endothelial function and decreases vascular cell adhesion molecule in hypercholesterolemic postmenopausal women. J Cardiovasc Pharmacol. 2006;47(S2):S177-S186.

39. Monagas M, Khan N, Andres-Lacueva C, et al. Effect of cocoa powder on the modulation of inflammatory biomarkers in patients at high risk of cardiovascular disease. Am J Clin Nutr. 2009;90(5):1144-1150.

40. Heiss $C$, Finis $D$, Kleinbongard $P$, et al. Sustained increase in flow-mediated dilation after daily intake of high-flavanol cocoa drink over 1 week. J Cardiovasc Pharmacol. 2007;49(2):74-80.

41. Schroeter H, Heiss C, Balzer J, et al. (-)-Epicatechin mediates beneficial effects of flavanol-rich cocoa on vascular function in humans. Proc Natl Acad Sci U S A. 2006;103(4):1024-1029.

42. Grassi D, Desideri G, Necozione $S$, et al. Cocoa consumption dose-dependently improves flowmediated dilation and arterial stiffness decreasing blood pressure in healthy individuals. J Hypertens. 2015;33(2):294-303.

43. Hodgson JM, Puddey IB, Mori TA, Burke V, Baker RI, Beilin LJ. Effects of regular ingestion of black tea on haemostasis and cell adhesion molecules in humans. Eur J Clin Nutr. 2001;55(10):881-886.

44. De Maat MPM, Pijl H, Kluft C, Princen HMG. Consumption of black and green tea has no effect on inflammation, haemostasis and endothelial markers in smoking healthy individuals. Eur J Clin Nutr. 2000;54(10):757-763.

45. Rusznyák S, Szent-Györgyi A. Vitamin P: Flavonols as vitamins [5]. Nature. 1936;138(3479):27.

46. Bruckner V, Szent-Györgyi A. Chemical nature of citrin [10]. Nature. 1936;138(3503):1057.

47. Perez-Jimenez J, Fezeu L, Touvier M, et al. Dietary intake of 337 polyphenols in French adults. Am J Clin Nutr. 2011;93(6):1220-8.

48. Arts ICW, Hollman PCH, Feskens EJM, Bueno De Mesquita HB, Kromhout D. Catechin intake and associated dietary and lifestyle factors in a representative sample of Dutch men and women. Eur J Clin Nutr. 2001;55(2):76-81.

49. Hertog MGL, Hollman PCH, Katan MB, Kromhout D. Intake of potentially anticarcinogenic flavonoids and their determinants in adults in The Netherlands. Nutr Cancer. 1993;20(1):21-29.

50. Hertog MGL, Hollman PCH, Van de Putte B. Content of potentially anticareinogenic flavonoids of tea infusions, wines, and fruit juices. J Agric Food Chem. 1993;41(8):1242-1246.

51. Ottaviani Jl, Kwik-Uribe C, Keen CL, Schroeter H. Intake of dietary procyanidins does not contribute to the pool of circulating flavanols in humans. Am J Clin Nutr. 2012;95(4):851-858.

52. Arts ICW, Van De Putte B, Hollman PCH. Catechin contents of foods commonly consumed in The Netherlands. 2. Tea, wine, fruit juices, and chocolate milk. J Agric Food Chem. 2000;48(5):1752-1757. 
53. McCullough ML, Peterson JJ, Patel R, Jacques PF, Shah R, Dwyer JT. Flavonoid intake and cardiovascular disease mortality in a prospective cohort of US adults. Am J Clin Nutr. 2012;95(2):454464.

54. Arts ICW, Hollman PCH, Feskens EJM, Bueno de Mesquita HB, Kromhout D. Catechin intake might explain the inverse relation between tea consumption and ischemic heart disease: The Zutphen Elderly Study. Am J Clin Nutr. 2001;74(2):227-232.

55. Zamora-Ros R, Jiménez C, Cleries R, et al. Dietary flavonoid and lignan intake and mortality in a Spanish cohort. Epidemiology. 2013;24(5):726-733.

56. Vogiatzoglou A, Mulligan AA, Bhaniani A, et al. Associations between flavan-3-ol intake and CVD risk in the Norfolk cohort of the European Prospective Investigation into Cancer (EPIC-Norfolk). Free Radic Biol Med. 2015;841-10.

57. Mursu J, Voutilainen S, Nurmi T, Tuomainen TP, Kurl S, Salonen JT. Flavonoid intake and the risk of ischaemic stroke and CVD mortality in middle-aged Finnish men: The Kuopio Ischaemic Heart Disease Risk Factor Study. Br J Nutr. 2008;100(4):890-895.

58. Mink PJ, Scrafford CG, Barraj LM, et al. Flavonoid intake and cardiovascular disease mortality: A prospective study in postmenopausal women. Am J Clin Nutr. 2007;85(3):895-909.

59. Hertog MGL, Feskens EJM, Hollman PCH, Katan MB, Kromhout D. Dietary antioxidant flavonoids and risk of coronary heart disease: The Zutphen Elderly Study. Lancet. 1993;342(8878):1007-1011.

60. Knekt P, Kumpulainen J, Järvinen R, et al. Flavonoid intake and risk of chronic diseases. Am J Clin Nutr. 2002;76(3):560-568.

61. Knekt $\mathrm{P}$, Isotupa $\mathrm{S}$, Rissanen $\mathrm{H}$, et al. Quercetin intake and the incidence of cerebrovascular disease. Eur J Clin Nutr. 2000;54(5):415-417.

62. Lin J, Rexrode KM, Hu F, et al. Dietary intakes of flavonols and flavones and coronary heart disease in US women. Am J Epidemiol. 2007;165(11):1305-1313.

63. Rimm EB, Katan MB, Ascherio A, Stampfer MJ, Willett WC. Relation between Intake of Flavonoids and Risk for Coronary Heart Disease in Male Health Professionals. Ann Intern Med. 1996;125(5):384389.

64. Pfeuffer M, Auinger A, Bley U, et al. Effect of quercetin on traits of the metabolic syndrome, endothelial function and inflammation in men with different APOE isoforms. Nutr Metab Cardiovasc Dis. 2013;23(5):403-9.

65. Loke WM, Hodgson JM, Proudfoot JM, McKinley AJ, Puddey IB, Croft KD. Pure dietary flavonoids quercetin and (-)-epicatechin augment nitric oxide products and reduce endothelin-1 acutely in healthy men. Am J Clin Nutr. 2008;88(4):1018-1025.

66. Egert S, Bosy-Westphal A, Seiberl J, et al. Quercetin reduces systolic blood pressure and plasma oxidised low-density lipoprotein concentrations in overweight subjects with a high-cardiovascular disease risk phenotype: A double-blinded, placebo-controlled cross-over study. Br J Nutr. 2009;102(7):1065-1074.

67. Edwards RL, Lyon T, Litwin SE, Rabovsky A, Symons JD, Jalili T. Quercetin reduces blood pressure in hypertensive subjects. J Nutr. 2007;137(11):2405-2411.

68. Abbey EL, Rankin JW. Effect of quercetin supplementation on repeated-sprint performance, xanthine oxidase activity, and inflammation. Int J Sport Nutr Exerc Metab. 2011;21(2):91-6. 
69. Boots AW, Drent M, de Boer VC, Bast A, Haenen GR. Quercetin reduces markers of oxidative stress and inflammation in sarcoidosis. Clin Nutr. 2011;30(4):506-12.

70. Ali F, Ismail A, Kersten S. Molecular mechanisms underlying the potential antiobesity-related diseases effect of cocoa polyphenols. Mol Nutr Food Res. 2014;58(1):33-48.

71. Fraga CG, Oteiza PI. Dietary flavonoids: Role of (-)-epicatechin and related procyanidins in cell signaling. Free Radic Biol Med. 2011;51(4):813-823.

72. Kerimi A, Williamson G. The cardiovascular benefits of dark chocolate. Vascul Pharmacol. 2015;7111-5.

73. Mao TK, Powell J, Van De Water J, et al. The effect of cocoa procyanidins on the transcription and secretion of interleukin $1 \beta$ in peripheral blood mononuclear cells. Life Sci. 2000;66(15):1377-1386.

74. Mao TK, Van de Water J, Keen CL, Schmitz HH, Gershwin ME. Modulation of TNF-a secretion in peripheral blood mononuclear cells by cocoa flavanols and procyanidins. Dev Immunol. 2002;9(3):135-141.

75. Morrison M, van der Heijden R, Heeringa $P$, et al. Epicatechin attenuates atherosclerosis and exerts anti-inflammatory effects on diet-induced human-CRP and NFKB invivo. Atherosclerosis. 2014;233(1):149-156.

76. Gomez-Guzman M, Jimenez R, Sanchez M, et al. Epicatechin lowers blood pressure, restores endothelial function, and decreases oxidative stress and endothelin-1 and NADPH oxidase activity in DOCA-salt hypertension. Free Radic Biol Med. 2012;52(1):70-9.

77. Shah ZA, Li RC, Ahmad AS, et al. The flavanol (-)-epicatechin prevents stroke damage through the Nrf2/HO1 pathway. J Cereb Blood Flow Metab. 2010;30(12):1951-61.

78. Granado-Serrano AB, Martín MA, Haegeman G, Goya L, Bravo L, Ramos S. Epicatechin induces NF-KB, activator protein-1 (AP-1) and nuclear transcription factor erythroid 2p45-related factor-2 (Nrf2) via phosphatidylinositol-3-kinase/protein kinase B (PI3K/AKT) and extracellular regulated kinase (ERK) signalling in HepG2 cells. BrJ Nutr. 2010;103(2):168-179.

79. Esser D, van Dijk SJ, Oosterink E, Lopez S, Muller M, Afman LA. High fat challenges with different fatty acids affect distinct atherogenic gene expression pathways in immune cells from lean and obese subjects. Mol Nutr Food Res. 2015;59(8):1563-72.

80. Vázquez-Agell M, Urpi-Sarda M, Sacanella E, et al. Cocoa consumption reduces NF-kB activation in peripheral blood mononuclear cells in humans. Nutr Metab Cardiovasc Dis. 2013;23(3):257-263. 




\section{Dietary Epicatechin Intake and 25-year Risk of Cardiovascular Mortality: The Zutphen Elderly Study}

James I Dower

Johanna M Geleijnse

Peter $\mathrm{CH}$ Hollman

Sabita S Soedamah-Muthu

Daan Kromhout

Accepted 


\section{ABSTRACT}

\section{Background}

Prospective cohort studies showed that the consumption of cocoa and tea was associated with a lower risk of cardiovascular diseases (CVD) and cocoa and tea improved cardiovascular risk factors in randomised-controlled trials. Cocoa and tea are major dietary sources of the flavan-3-ol epicatechin. We investigated the associations of dietary epicatechin intake with 25-year CVD mortality in elderly Dutch men.

\section{Design}

We used data from the Zutphen Elderly Study, a prospective cohort study of 774 men aged 65-84 years in 1985. Epicatechin intake was estimated with the cross-check dietary history method four times in 15 years. Time-dependent Cox proportional hazards models were used to investigate repeated measures of epicatechin intake in relation to 25-year CVD mortality.

\section{Results}

The mean intake of epicatechin was $15.2 \pm 7.7 \mathrm{mg} / \mathrm{d}$, and the major dietary sources were tea (51\%), apples (28\%) and cocoa (7\%). During 25 years of follow-up, 329 men died from CVD, 148 from coronary heart disease (CHD) and 72 from stroke. The risk of CHD mortality was 38\% lower in men in the top compared to the bottom tertile of epicatechin intake (HR: $0.62 ; 95 \% \mathrm{Cl}: 0.39,0.98)$. Similar results were found for men with and without prevalent CVD at baseline, although they were not statistically significant. Epicatechin intake was significantly associated with a 46\% lower risk of CVD mortality in men with prevalent CVD (HR: $0.54 ; 95 \% \mathrm{Cl}: 0.31,0.96)$ but not in men free of CVD.

\section{Conclusions}

We showed for the first time that epicatechin intake was inversely related to CHD mortality in elderly men and to CVD mortality in prevalent cases of CVD. More studies are needed before conclusions can be drawn. 


\section{INTRODUCTION}

Cardiovascular disease (CVD) is the leading cause of death and is responsible for approximately $30 \%$ of all deaths worldwide [1]. Diet is an important determinant of CVD [2]. Consumption of plant-based foods, which are a rich source of flavan-3-ols, was inversely associated with CVD risk [3]. Flavan-3-ols are a subclass of flavonoids and cocoa (Theobroma cacao), tea (Camellia sinensis) and apples are their major dietary sources.

A meta-analysis of 7 observational studies $(n=114009)$ showed that the highest level of chocolate consumption was associated with a $37 \%$ (HR: 0.63; $95 \% \mathrm{Cl}: 0.44,0.90)$ lower risk of CVD and a 29\% (HR:0.71; 95\% Cl:0.52, 0.98) lower risk of stroke [4]. In a meta-analysis of 14 cohort studies, 3 cups of black or green tea consumption per day was associated with a $13 \%$ (HR: $0.87 ; 95 \%$ Cl: $0.81,0.94)$ lower risk of stroke [5]. A meta-analysis of 5 additional observational studies ( $n=35808$ ) showed that those who drank 1-3 cups of green tea per day had a $36 \%$ (HR: 0.64; 95\% Cl: 0.47, 0.86) lower risk of stroke [6]. Black tea consumption was not associated with CHD [7].

Clinical trials showed that chocolate/cocoa improved endothelial function, blood pressure and insulin resistance [8]. Likewise, meta-analyses of tea trials showed that black or green tea consumption improved endothelial function [9] and that black [10] and green tea reduced blood pressure [11]. Randomized controlled trials also found that green tea reduced fasting glucose and insulin concentrations [12], thus reducing insulin resistance - an important risk factor for type 2 diabetes and CVD [13-15]. Indeed, a meta-analysis of prospective cohort studies showed that tea consumption was inversely related to the incidence of type 2 diabetes [16].

Epicatechin is the most abundant flavan-3-ol in cocoa. Black and green tea are also rich in epicatechin, and contribute approximately $40 \%$ of the epicatechin intake in European populations [17]. Recently, we showed that a supplement of pure epicatechin of 100mg/d decreased SE-selectin, a marker of endothelial dysfunction [18], and improved insulin resistance [19]. These results suggest that epicatechin contributes to the cardioprotective effects of chocolate/cocoa.

Previously we showed in the Zutphen Elderly Study that cocoa intake was inversely associated with CVD mortality [20] and that tea intake was inversely related to CHD mortality [21]. In the present study, we investigated the associations of repeated measures of epicatechin intake with 25-year CVD mortality risk also in the Zutphen Elderly Study. 


\section{METHODS}

\section{Study population}

The Zutphen Elderly Study is a prospective cohort study that investigated risk factors of chronic diseases in elderly men. It is an extension of the Zutphen Study that started in 1960 as the Dutch contribution to the Seven Countries Study. In 1985, 555 men of the original cohort were still alive and were invited to participate in the Zutphen Elderly Study. A random sample of all other men of the same age group also living in Zutphen, but who did not take part in the original Zutphen Study, were also invited to participate. This resulted in a total target population of 1266 men aged 65-84 years. Of these 1266 men, 939 (74\%) agreed to participate in the study. After excluding subjects with missing information on diet ( $n=63$ ) and/or risk factors (smoking: $n=53$; physical activity: $n=75$ ), complete data was available for 807 men. After excluding prevalent cancer cases $(n=63)$, a study population of 744 remained (Supplemental Figure 1).

The study was conducted according to the guidelines of the Declaration of Helsinki and was approved by the medical ethics committees of the University of Leiden (1985 and 1990) and of the Netherlands Organisation for Applied Scientific Research (1995 and 2000). All participants provided written informed consent.

\section{Dietary assessment}

The habitual diet during the month preceding the interview was assessed between March and June in 1985, 1990, 1995 and 2000, using the cross-check dietary history method, adapted for the Dutch setting [22]. Participants were interviewed by trained dieticians about their usual pattern of food intake during weekdays and weekends, with the person usually preparing the meals also present. Based on these patterns, the dieticians asked the respondents to indicate the frequency of consumption and serving size of each food using a checklist. This information was used to estimate the average weekly food consumption, which was checked against the quantities of foods bought each week. The food intake data were encoded by the dieticians and converted into energy and nutrient data using time-specific food composition tables as well as flavan-3-ol data. The monomeric flavan3-ol content of 120 commonly consumed plant foods and beverages were determined by Reverse Phase HPLC with ultraviolet and fluorescence detection. For each food product, the (-)-epicatechin, (+)-catechin, (-)epigallocatechin, (-)-epicatechin gallate, (-)-epigallocatechin gallate and (+)-gallocatechin concentrations were determined [23, 24]. Epicatechin intake in 1985 correlated strongly with epicatechin intake in 1990 ( $r=0.59)$, in $1995(r=0.51)$ and in $2000(r=0.46)$.

\section{Risk factors and lifestyle factors}

Body Mass Index (BMI) was calculated as weight $(\mathrm{kg})$ divided by height squared $\left(\mathrm{m}^{2}\right)$, which were measured at baseline according to standardised protocols. Blood pressure (BP) was 
measured at baseline while participants were in the supine position, and was calculated as the mean of two measurements. Subjects were considered hypertensive if they had a systolic BP greater than $160 \mathrm{mmHg}$, diastolic BP greater than $95 \mathrm{mmHg}$ or were prescribed anti-hypertensive medication. Non-fasting blood samples were collected to determine serum total and HDL-cholesterol enzymatically [25, 26]. A medical history was used to collect information about diagnosis of myocardial infarction, stroke, heart failure, cancer and diabetes, as well as use of aspirin, antihypertensive and lipid-lowering medication at baseline and in follow-up surveys. A lifestyle questionnaire was used to collect information about social economic status (professionals, non-manual workers, small business owners or manual workers) at baseline (1985), and smoking status (former, current or never) at repeated intervals $(1985,1990,1995,2000)$. Physical activity was also assessed at repeated intervals using a validated questionnaire designed for retired men [27], and was categorised according to the average time spent per week doing physical activities with an intensity of at least 3 metabolic equivalents (METs). Men were called physically active if they spent at least 150 minutes/week on activities of at least moderate intensity.

\section{Case ascertainment}

Participants were followed until death or censored on 30 June 2010. Causes of death were determined based on official death certificates, medical histories collected by the examining physician or by interviewing relatives of the deceased person, and abstracts of medical records from the hospital and general practitioners in Zutphen. Primary causes of death were coded according to the ninth edition of the International Classification of Diseases by a clinical epidemiologist. ICD-codes 390-459 refer to CVD, codes 410-414 refer to CHD and codes 430-438 refer to stroke mortality. Sudden death (ICD-code 798.2) was also included as a cause of death for CVD and CHD. After 25 years of follow-up, 32 (4\%) of the men were still alive. Two subjects were lost to follow-up and censored at the date of their last examination.

\section{Statistical analysis}

Baseline characteristics were compared among tertiles of epicatechin intake. One-way analysis of variance was used for normally distributed variables, Kruskal-Wallis test for skewed variables and Chi-square test for categorical variables. The individual contributions of tea, cocoa and apples to total epicatechin intake were calculated. To better represent long-term intake, the cumulative mean of epicatechin intake was calculated. Mortality between 1985 and 1990 was related to epicatechin intake estimated in 1985; mortality between 1990 and 1995 was related to the mean epicatechin intake of 1985 and 1990; mortality between 1995 and 2000 was related to the mean epicatechin intake of 1985, 1990, and 1995; and mortality between 2000 and 2010 was related to the mean epicatechin intake of 1985, 1990, 1995 and 2000. 
Hazard ratios of cardiovascular mortality were estimated with Cox proportional hazard models using the SAS PHREG procedure (SAS 9.3, SAS Institute, North Carolina, USA). Proportional hazard assumptions were examined by a log-minus-log plot and the assumptions were met. Model 1 was adjusted for age. Model 2 was additionally adjusted for prevalence of myocardial infarction, stroke, heart failure or diabetes at baseline as well as aspirin use, anti-hypertensive medication, smoking status, alcohol intake and physical activity. Model 3 was additionally adjusted for dietary factors that are related to CVD (energy, saturated fat, trans fat, n-3 fatty acids, n- 6 fatty acids, dietary fibre, potassium, $\beta$-carotene and coffee). A stratified analysis was conducted for prevalence of CVD. Additionally, hazard ratios of CVD mortality for total flavan-3-ol monomer intake as well as intake of catechin, epicatechin gallate (ECg) and epigallocatechin gallate (EGCg) were calculated. Associations were considered statistically significant if $p<0.05$.

\section{RESULTS}

The mean age of the study population at baseline was $71.9 \pm 5.2$ years. In total, $56 \%$ of the men had a BMI of at least $25 \mathrm{~kg} / \mathrm{m}^{2}, 31 \%$ were current smokers, $25 \%$ did not consume alcohol and $26 \%$ were physically active. At baseline, 22\% had a history of CVD and $10 \%$ had diabetes, 50\% were hypertensive, $1 \%$ used lipid-lowering medication and $10 \%$ aspirin. The cumulative mean of epicatechin intake was $15.2 \pm 7.7 \mathrm{mg} / \mathrm{d}$ (range: 0.01-60.6 mg/d). The major dietary sources of epicatechin intake were tea $(51 \%=7.8 \mathrm{mg} / \mathrm{d})$, apples $(28 \%$ $=4.3 \mathrm{mg} / \mathrm{d})$ and cocoa $(7 \%=1.1 \mathrm{mg} / \mathrm{d})$. Subjects with higher epicatechin intake were generally more physically active, less likely to be smokers and drank less coffee (Table 1). Total energy intake and intake of protein, carbohydrates, potassium and fibre were also higher in subjects with higher epicatechin intake.

The median survival time over the 25-year period was 10.7 years (IQR: 5.9-16.0). Of the 712 men who died, 329 died from CVD, 148 from CHD and 72 from stroke. CVD mortality was inversely associated with epicatechin intake in the age-adjusted model (Table 2, model 1). This association was no longer statistically significant after adjustment for lifestyle and dietary factors, with a hazard ratio of $0.79(95 \% \mathrm{Cl}: 0.58,1.08)$ in the top compared to the bottom tertile. CHD mortality was inversely associated with epicatechin intake in all three models. The hazard ratio of CHD mortality was $0.62(95 \% \mathrm{Cl}: 0.39,0.98)$ in the fully-adjusted model (Model 3). Although not statistically significant, similar associations were obtained for men with and without prevalent CVD at baseline (Table 3). For men with prevalent CVD, epicatechin intake was associated with a 46\% lower CVD mortality risk (HR: 0.54; 95\% Cl: $0.32,0.96)$.

Besides epicatechin, also the intake of other flavan-3-ol monomers was investigated in relation to CVD mortality (Table 4). The mean intake of catechin was $4.2 \pm 2.5 \mathrm{mg} / \mathrm{d}$. 
TABLE 1. Baseline characteristics of 744 men in the Zutphen Elderly Study, by tertile of epicatechin intake in 1985.

\begin{tabular}{|c|c|c|c|c|}
\hline Characteristics & $\mathrm{T} 1$ & $\mathrm{~T} 2$ & T3 & P-value ${ }^{1}$ \\
\hline Range of epicatechin intake, $\mathrm{mg} / \mathrm{d}$ & $<11.1$ & $11.1-18.0$ & $>18.0$ & \\
\hline Number & 248 & 248 & 248 & \\
\hline Age, $y$ & $71.7 \pm 5.2$ & $72.4 \pm 5.3$ & $71.7 \pm 5.1$ & 0.27 \\
\hline $\mathrm{BMI}, \mathrm{kg} / \mathrm{m}^{2}$ & $25.6 \pm 3.5$ & $25.8 \pm 3.2$ & $25.4 \pm 2.8$ & 0.41 \\
\hline Physical activity $\geq 3$ METs, $n$ (\%) & & & & 0.003 \\
\hline 0 mins/week & $152(61)$ & $131(53)$ & $109(44)$ & \\
\hline 1-150 mins/week & $42(17)$ & $49(20)$ & $66(27)$ & \\
\hline$>150$ mins/week & $54(22)$ & $68(27)$ & $73(29)$ & \\
\hline Social economic status, $n$ (\%) & & & & 0.37 \\
\hline Professionals & $18(7)$ & $21(9)$ & $32(13)$ & \\
\hline Non-manual workers & $102(42)$ & $108(44)$ & $108(44)$ & \\
\hline Small business owners & $56(23)$ & $49(20)$ & $44(18)$ & \\
\hline Manual workers & $70(28)$ & $68(28)$ & $64(26)$ & \\
\hline Smoking Status, $n(\%)$ & & & & $<0.001$ \\
\hline Never & $34(14)$ & $35(14)$ & $44(18)$ & \\
\hline Former & $114(46)$ & $132(53)$ & $158(64)$ & \\
\hline Current & $100(40)$ & $81(33)$ & $46(19)$ & \\
\hline Alcohol intake, $n$ (\%) & & & & 0.07 \\
\hline$g / d$ & $64(26)$ & $65(26)$ & $55(22)$ & \\
\hline$>0-20 \mathrm{~g} / \mathrm{d}$ & $110(44)$ & $133(54)$ & $134(54)$ & \\
\hline$>20 \mathrm{~g} / \mathrm{d}$ & $74(30)$ & $50(20)$ & $59(24)$ & \\
\hline Systolic blood pressure, $\mathrm{mm} \mathrm{Hg}$ & $151.2 \pm 21.5$ & $150.8 \pm 21.2$ & $150.4 \pm 21.0$ & 0.93 \\
\hline Diastolic blood pressure, $\mathrm{mm} \mathrm{Hg}$ & $84.3 \pm 11.1$ & $86.3 \pm 11.8$ & $85.7 \pm 11.2$ & 0.13 \\
\hline Serum total cholesterol, $\mathrm{mmol} / \mathrm{L}$ & $6.2 \pm 1.1$ & $6.2 \pm 1.2$ & $6.0 \pm 1.0$ & 0.16 \\
\hline Serum total/HDL cholesterol & $5.7 \pm 1.6$ & $5.8 \pm 1.60$ & $5.7 \pm 1.6$ & 0.51 \\
\hline Total energy, kcal/d & $2010 \pm 496$ & $2147 \pm 493$ & $2283 \pm 505$ & $<0.001$ \\
\hline Protein, g/d & $79.8 \pm 20.6$ & $82.2 \pm 16.3$ & $84.9 \pm 17.9$ & 0.009 \\
\hline Total carbohydrates, $g / d$ & $211.1 \pm 59.4$ & $235.3 \pm 64.8$ & $258.3 \pm 65.2$ & $<0.001$ \\
\hline Total fat, $g / d$ & $94.1 \pm 31.3$ & $97.4 \pm 28.8$ & $101.2 \pm 29.8$ & 0.03 \\
\hline Saturated fatty acids, $g / d$ & $40.9 \pm 14.8$ & $42.9 \pm 13.9$ & $44.4 \pm 14.3$ & 0.03 \\
\hline Trans fat, $g / d$ & $10.2 \pm 5.8$ & $10.8 \pm 6.4$ & $10.8 \pm 6.0$ & 0.38 \\
\hline n-3 fatty acids, $g / d$ & $1.4(1.1-1.8)$ & $1.3(1.1-1.7)$ & $1.4(1.0-1.7)$ & 0.88 \\
\hline n-6 fatty acids, $g / d$ & $10.5(7.1-16.0)$ & $11.0(7.4-15.8)$ & $11.7(8.6-16.9)$ & 0.07 \\
\hline Calcium, $m g / d$ & $991 \pm 410$ & $1028 \pm 376$ & $1043 \pm 364$ & 0.31 \\
\hline Potassium, $m g / d$ & $3394 \pm 911$ & $3520 \pm 726$ & $3676 \pm 743$ & $<0.001$ \\
\hline$\beta$-carotene, $m g / d$ & $1.4(1.0-1.9)$ & $1.5(1.0-2.0)$ & $1.5(1.1-2.2)$ & 0.11 \\
\hline Dietary fibre, $g / d$ & $22.2 \pm 6.9$ & $24.2 \pm 6.2$ & $28.1 \pm 7.0$ & $<0.001$ \\
\hline Coffee, $\mathrm{ml} / \mathrm{d}$ & $456(300-660)$ & $427(300-560)$ & $346(215-480)$ & $<0.001$ \\
\hline
\end{tabular}


TABLE 1. Continued

\begin{tabular}{lcccc}
\hline Characteristics & T1 & T2 & T3 & P-value $^{1}$ \\
\hline Tea, $m / / d$ & $175(0-297)$ & $425(271-542)$ & $620(464-861)$ & $<0.001$ \\
Cocoa, g/d & $0.4(0-1.9)$ & $0.9(0-3.0)$ & $2.0(0-4.8)$ & $<0.001$ \\
Apple, g/d & $8(0-48)$ & $56(8-112)$ & $112(64-148)$ & $<0.001$ \\
\hline
\end{tabular}

Data are mean \pm SD or median (IQR).

1 Test for differences among tertiles of epicatechin intake. Chi-square test for categorical variables, one-way analysis of variance for normally distributed variables and Kruskal-Wallis test for skewed variables ( $n-3$ fatty acids, $n-6$ fatty acids, $\beta$-carotene, coffee tea, cocoa and apple intake).

Abbreviations: BMI: body mass index; HDL: high density lipoprotein.

Catechin intake was inversely related to CHD mortality and the strength of the association was similar to that of epicatechin. The intake of catechin was strongly correlated with that of epicatechin $(r=0.80)$. Therefore the intake of catechin and epicatechin was combined. The daily intake of epicatechin gallate (ECg) was $24.4 \pm 16.7 \mathrm{mg} / \mathrm{d}$ and that of epigallocatechin gallate (EGCg) was $18.2 \pm 12.4 \mathrm{mg} / \mathrm{d}$. These two flavan-3-ols were very strongly correlated $(r=0.99)$. For this reason, the intake of these two flavan-3-ols was also combined and related to CVD mortality. The intake of ECg plus EGCg was not significantly associated with CVD mortality.

The major dietary sources of epicatechin, tea, apples and cocoa were not associated with CHD mortality (data not shown). 
TABLE 2. Tertiles of epicatechin intake and 25-year cardiovascular mortality, in 744 elderly Dutch men free of cancer at baseline.

\begin{tabular}{|c|c|c|c|}
\hline & \multicolumn{3}{|c|}{ Tertiles of Epicatechin Intake (mg/d) } \\
\hline & $\mathrm{T} 1$ & $\mathrm{~T} 2$ & T3 \\
\hline Number & 227 & 266 & 251 \\
\hline Median survival time, $y^{1}$ & $8.8(5.1-13.7)$ & $11.8(6.3-16.1)$ & $11.9(6.5-22.9)$ \\
\hline Median epicatechin intake, $m g / d^{1}$ & $7.5(5.1-9.4)$ & 14.5 (12.5-15.9) & $21.9(19.5-25.6)$ \\
\hline \multicolumn{4}{|l|}{ CVD } \\
\hline Cases & 106 & 116 & 107 \\
\hline Model 1 & 1.00 & $0.78(0.60,1.02)^{2}$ & $0.72(0.55,0.95)$ \\
\hline Model 2 & 1.00 & $0.88(0.67,1.15)$ & $0.75(0.56,0.99)$ \\
\hline Model 3 & 1.00 & $0.90(0.68,1.19)$ & $0.79(0.58,1.08)$ \\
\hline \multicolumn{4}{|l|}{$\mathrm{CHD}$} \\
\hline Cases & 47 & 57 & 44 \\
\hline Model 1 & 1.00 & $0.76(0.52,1.12)$ & $0.59(0.39,0.89)$ \\
\hline Model 2 & 1.00 & $0.81(0.55,1.20)$ & $0.57(0.37,0.87)$ \\
\hline Model 3 & 1.00 & $0.85(0.57,1.27)$ & $0.62(0.39,0.98)$ \\
\hline \multicolumn{4}{|l|}{ Stroke } \\
\hline Cases & 25 & 23 & 24 \\
\hline Model 1 & 1.00 & $0.81(0.45,1.46)$ & $0.88(0.49,1.58)$ \\
\hline Model 2 & 1.00 & $0.92(0.50,1.67)$ & $0.93(0.51,1.70)$ \\
\hline Model 3 & 1.00 & $0.81(0.43,1.51)$ & $0.78(0.40,1.53)$ \\
\hline
\end{tabular}

1 Values are median (IQR).

2 Values are hazard ratios with 95\% confidence intervals, obtained by Cox proportional hazard analysis, using the lower tertile as the reference (all such values).

Model 1: Adjusted for age

Model 2: Adjusted for model 1 plus prevalence of myocardial infarction, stroke, heart failure or diabetes at baseline as well as anti-hypertensive medication, aspirin, smoking status (categories), alcohol intake (categories) and physical activity (categories).

Model 3: Adjusted for model 2 plus, total energy, saturated fat, trans fat, n-3 fatty acids, n- 6 fatty acids, dietary fibre, potassium, $\beta$-carotene and coffee.

Abbreviations: CVD: cardiovascular disease; CHD: coronary heart disease 
TABLE 3. Tertiles of epicatechin intake and 25-year cardiovascular mortality in 744 elderly Dutch men free of cancer at baseline, stratified by prevalence of cardiovascular diseases.

\begin{tabular}{|c|c|c|c|c|}
\hline & \multirow{2}{*}{$\begin{array}{c}\text { Mortality case } \\
\text { Yes / No (n) }\end{array}$} & \multicolumn{3}{|c|}{ Epicatechin Intake (mg/d) } \\
\hline & & T1 & $\mathrm{T} 2$ & T3 \\
\hline \multicolumn{5}{|l|}{ CVD mortality } \\
\hline Prevalent CVD & $93 / 73$ & 1.00 & $0.56(0.31-1.03)$ & $0.54(0.31-0.96)$ \\
\hline CVD-free & $236 / 342$ & 1.00 & $1.03(0.73-1.43)$ & $0.90(0.61-1.33)$ \\
\hline \multicolumn{5}{|l|}{ CHD mortality } \\
\hline Prevalent CVD & $46 / 120$ & 1.00 & $0.34(0.14-0.84)$ & $0.46(0.20-1.05)$ \\
\hline CVD-free & $102 / 476$ & 1.00 & $1.08(0.67-1.75)$ & $0.63(0.34-1.16)$ \\
\hline \multicolumn{5}{|l|}{ Stroke Mortality } \\
\hline Prevalent CVD & $17 / 149$ & 1.00 & $1.17(0.25-5.46)$ & $0.50(0.11-2.27)$ \\
\hline CVD-free & $55 / 523$ & 1.00 & $0.70(0.34-1.44)$ & $0.92(0.41-2.05)$ \\
\hline
\end{tabular}

Values are hazard ratios with $95 \%$ confidence intervals, obtained by Cox proportional hazard analysis, using the lower tertile as the reference; adjusted for age, physical activity (categories); anti-hypertensive medication; aspirin; smoking status (categories); alcohol intake (categories); prevalent diabetes at baseline; total energy; saturated fat; trans fat; $n-3$ fatty acids; n- 6 fatty acids; dietary fibre; potassium; $\beta$-carotene and coffee.

Abbreviations: CVD: cardiovascular disease; CHD: coronary heart disease 
TABLE 4. Tertiles of intake of different flavan-3-ol monomers and 25-year cardiovascular mortality in 744 elderly Dutch men free of cancer at baseline.

\begin{tabular}{|c|c|c|c|}
\hline & \multicolumn{3}{|c|}{ Tertiles of Intake (mg/d) } \\
\hline & $\mathrm{T} 1$ & $\mathrm{~T} 2$ & T3 \\
\hline \multicolumn{4}{|l|}{ CVD Mortality } \\
\hline Catechin & 1.00 & $0.84(0.63-1.13)$ & $0.78(0.57-1.05)$ \\
\hline Catechin + epicatechin & 1.00 & $0.92(0.69-1.21)$ & $0.77(0.56-1.05)$ \\
\hline$E C g+E G C g$ & 1.00 & $0.93(0.70-1.23)$ & $0.92(0.68-1.23)$ \\
\hline Total flavan-3-ols & 1.00 & $0.87(0.66-1.15)$ & $0.80(0.59-1.08)$ \\
\hline \multicolumn{4}{|l|}{ CHD Mortality } \\
\hline Catechin & 1.00 & $0.76(0.50-1.15)$ & $0.60(0.38-0.93)$ \\
\hline Catechin + epicatechin & 1.00 & $0.94(0.63-1.41)$ & $0.62(0.39-1.00)$ \\
\hline$E C g+E G C g$ & 1.00 & $0.94(0.62-1.43)$ & $0.95(0.61-1.47)$ \\
\hline Total flavan-3-ols & 1.00 & $0.95(0.63-1.43)$ & $0.74(0.47-1.16)$ \\
\hline \multicolumn{4}{|l|}{ Stroke Mortality } \\
\hline Catechin & 1.00 & $0.88(0.48-1.63)$ & $0.68(0.35-1.31)$ \\
\hline Catechin + epicatechin & 1.00 & $0.84(0.45-1.55)$ & $0.72(0.37-1.41)$ \\
\hline $\mathrm{ECg}+\mathrm{EGCg}$ & 1.00 & $0.80(0.44-1.46)$ & $0.80(0.42-1.50)$ \\
\hline Total flavan-3-ols & 1.00 & $0.75(0.40-1.38)$ & $0.73(0.39-1.38)$ \\
\hline
\end{tabular}

Values are hazard ratios with 95\% confidence intervals, obtained by Cox proportional hazard analysis, using the lower tertile as the reference; adjusted for age; prevalence of myocardial infarction, stroke, or diabetes at baseline; anti-hypertensive medication; aspirin; smoking status (categories); alcohol intake (categories); physical activity (categories); total energy; saturated fat; trans fat; $n-3$ fatty acids; n-6 fatty acids; dietary fibre; potassium; $\beta$-carotene and coffee.

Abbreviations: CVD: cardiovascular disease; CHD: coronary heart disease; ECg: epicatechin gallate; EGCg: epigallocatechin gallate. 


\section{DISCUSSION}

In this study of elderly Dutch men, the risk of long-term CHD mortality was 38\% lower in men in the highest tertile of epicatechin (median intake $22 \mathrm{mg} / \mathrm{d}$ ) compared to the lowest (median $8 \mathrm{mg} / \mathrm{d}$ ). In men with prevalent CVD, the highest tertile of epicatechin intake was associated with a $44 \%$ lower long-term CVD mortality risk compared to those in the lowest tertile.

Major strengths of the present study are the long duration (25 years) and the complete mortality follow-up. Using repeated measures of dietary assessment and covariates (every 5 years between 1985 and 2000) provided a more accurate assessment compared to a single baseline assessment because of reduction in intra-individual variation. Furthermore, the epicatechin intake was assessed with the cross-check dietary history, a reproducible dietary survey method [22]. Although, the strength of validity for assessing epicatechin intake is currently unknown, the 5-year repeated estimate of epicatechin intake was strongly correlated $(r=0.59)$. A limitation of our study is the relatively small study population, resulting in a limited power for the studied associations. Furthermore, our cohort included only elderly Dutch men and is, therefore, not generalisable to younger men and women. Finally, although we adjusted for a wide range of risk factors related to cardiovascular disease, we cannot exclude the possibility of residual confounding.

To our knowledge, this is the first prospective cohort study to examine specifically the association between dietary epicatechin intake and CVD mortality. Previous cohort studies focused on total flavan-3-ol monomer intake and showed conflicting results [28-31]. An explanation could be that individual flavan-3-ol monomers differ in their metabolic effects. Epicatechin is of particular interest because it is the major flavan-3-ol monomer of cocoa, and a meta-analysis of randomised controlled cocoa trials showed that cocoa/chocolate improved blood pressure and endothelial function in adults [8].

Tea, apples and cocoa are rich in both epicatechin and catechin. The strong correlation between epicatechin and catechin intake in our study $(r=0.80)$ could explain the association between catechin and CHD mortality. A study in rats showed that the vasodilatory effect of catechin was only $20 \%$ of that of epicatechin, suggesting that epicatechin is the most biologically active compound of the two [32]. There was also a strong correlation between epicatechin and tea intake $(r=0.75)$. This makes it difficult to separate the effects of epicatechin from that of tea in observational studies due to multi-collinearity. Ideally, RCTs using pure flavonoids are needed to fully elucidate the role of flavonoids in the cardioprotective effects of tea. The correlation between ECg and EGCg intake was also extremely high $(r>0.99)$, because both are exclusively present in tea. For this reason, we combined the intake of ECg and EGCg and found that these compounds were not associated with CHD mortality risk. 
The inverse association of epicatechin with CVD mortality could be mediated through changes in endothelial function. Chocolate/cocoa RCTs have consistently shown improvements in flow-mediated dilation (FMD), a measure of endothelial function [8]. In addition, pure epicatechin (200 mg) acutely (after $2 \mathrm{~h}$ ) increased nitric oxide bioavailability and decreased endothelin-1 [33], two important mediators of endothelial function. However, in our previous clinical trial, supplementation of $100 \mathrm{mg}$ pure epicatechin per day for four weeks did not affect these markers [19], suggesting that dose and duration of exposure are critical. A link of FMD with future CVD events was firmly established in prospective studies, and there were indications for a stronger association in diseased populations [34]. This is consistent with the results of the present study which suggested that epicatechin intake was more strongly inversely related to CVD mortality risk in prevalent cases of CVD compared to those free of CVD.

The inverse association of epicatechin with CVD mortality could also be mediated through changes in insulin resistance, a risk factor for diabetes and CVD [13-15]. A meta-analysis of RCTs showed that chocolate/cocoa improved insulin resistance [8]. In addition, a metaanalysis of cohort studies showed that tea was inversely associated with type 2 diabetes [16]. We showed in a double-blind crossover RCT that pure epicatechin improved insulin resistance (19). These results point to a protective role of epicatechin in the aetiology of diabetes and CVD.

In the present study, elderly men with a median epicatechin intake of $22 \mathrm{mg} / \mathrm{d}$ had a $38 \%$ lower risk of CHD mortality compared to those with a median intake of $8 \mathrm{mg} / \mathrm{day}$. This suggests that the beneficial effects of epicatechin on CHD mortality may be achieved at relatively low levels of intake. A daily intake of $22 \mathrm{mg}$ of epicatechin is equivalent to approximately 6 cups of black tea ( 1 cup $=125 \mathrm{ml}), 54 \mathrm{~g}$ of dark chocolate ( $54 \%$ cocoa) or $2-3$ apples (1 apple $=120 \mathrm{~g})(24,25)$.

In conclusion, our findings suggest that a higher epicatechin intake is associated with a lower risk of long-term CHD mortality, in a population-based study of elderly men, and to CVD mortality in men with prevalent CVD. More and larger studies are needed to confirm these associations before statements can be made about the strength of the association of epicatechin with CVD mortality. 


\section{ACKNOWLEDGEMENTS}

We are grateful to Prof. dr. Hendriek Boshuizen for statistical advice.

\section{FUNDING SOURCES}

The Zutphen Elderly Study was supported by grants from the Netherlands Prevention Foundation (the Hague) and by the Royal Netherlands Academy of Arts and Sciences. The current analysis was co-funded by Top Institute Food and Nutrition (TIFN), a public-private partnership on pre-competitive research in food and nutrition. The sponsors provided funding but had no role in the design of the study, collection, management, analysis, and interpretation of the data; and preparation, review or approval of the manuscript.

\section{DISCLOSURES}

No authors declare a conflict of interest 


\section{REFERENCES}

1. Lozano R, Naghavi M, Foreman K, et al. Global and regional mortality from 235 causes of death for 20 age groups in 1990 and 2010: A systematic analysis for the Global Burden of Disease Study 2010. Lancet. 2012;380(9859):2095-2128.

2. Knoops KTB, De Groot LCPGM, Kromhout $D$, et al. Mediterranean diet, lifestyle factors, and 10year mortality in elderly European men and women: The HALE project. JAMA. 2004;292(12):14331439.

3. Wang $X$, Ouyang $Y$, Liu J, et al. Fruit and vegetable consumption and mortality from all causes, cardiovascular disease, and cancer: Systematic review and dose-response meta-analysis of prospective cohort studies. BMJ. 2014;349.

4. Buitrago-Lopez A, Sanderson J, Johnson L, et al. Chocolate consumption and cardiometabolic disorders: Systematic review and meta-analysis. BMJ (Online). 2011;343.

5. Shen L, Song LG, Ma H, Jin CN, Wang JA, Xiang MX. Tea consumption and risk of stroke: A doseresponse meta-analysis of prospective studies. J Zhejiang Univ Sci B. 2012;13(8):652-662.

6. Pang J, Zhang Z, Zheng TZ, et al. Green tea consumption and risk of cardiovascular and ischemic related diseases: A meta-analysis. Int J Cardiol. 2016;202:967-974.

7. Wang ZM, Zhou B, Wang YS, et al. Black and green tea consumption and the risk of coronary artery disease: A meta-analysis. Am J Clin Nutr. 2011;93(3):506-515.

8. Hooper L, Kay C, Abdelhamid A, et al. Effects of chocolate, cocoa, and flavan-3-ols on cardiovascular health: A systematic review and meta-analysis of randomized trials. Am J Clin Nutr. 2012;95(3):740751.

9. Ras RT, Zock PL, Draijer R. Tea consumption enhances endothelial-dependent vasodilation; a meta-analysis. PLOS ONE. 2011;6(3).

10. Greyling A, Ras RT, Zock PL, et al. The effect of black tea on blood pressure: A systematic review with meta-analysis of randomized controlled trials. PLOS ONE. 2014;9(7).

11. Khalesi S, Sun J, Buys N, Jamshidi A, Nikbakht-Nasrabadi E, Khosravi-Boroujeni H. Green tea catechins and blood pressure: a systematic review and meta-analysis of randomised controlled trials. EurJ Nutr. 2014;53(6):1299-1311.

12. Liu K, Zhou R, Wang B, et al. Effect of green tea on glucose control and insulin sensitivity: A metaanalysis of 17 randomized controlled trials. Am J Clin Nutr. 2013;98(2):340-348.

13. Bonora E, KiechIS, Willeit J, et al. Insulin resistance as estimated by homeostasis model assessment predicts incident symptomatic cardiovascular disease in caucasian subjects from the general population: The Bruneck study. Diabetes Care. 2007;30(2):318-324.

14. DeFronzo RA, Ferrannini E. Insulin resistance: A multifaceted syndrome responsible for NIDDM, obesity, hypertension, dyslipidemia, and atherosclerotic cardiovascular disease. Diabetes Care. 1991;14(3):173-194.

15. Hanley AJG, Williams K, Stern MP, Haffner SM. Homeostasis model assessment of insulin resistance in relation to the incidence of cardiovascular disease: The San Antonio heart study. Diabetes Care. 2002;25(7):1177-1184. 
16. Huxley R, Lee CMY, Barzi F, et al. Coffee, decaffeinated coffee, and tea consumption in relation to incident type 2 diabetes mellitus: A systematic review with meta-analysis. Arch Intern Med. 2009;169(22):2053-2063.

17. Zamora-Ros R, Forouhi NG, Sharp SJ, et al. Dietary intakes of individual flavanols and flavonols are inversely associated with incident type 2 diabetes in European populations.J Nutr. 2014;144(3):335343.

18. Dower JI, Geleijnse JM, Gijsbers L, Schalkwijk C, Kromhout D, Hollman PC. Supplementation of the pure flavonoids epicatechin and quercetin affects some biomarkers of endothelial dysfunction and inflammation in (pre)hypertensive adults: A randomized double-blind, placebo-controlled, crossover trial. J Nutr. 2015;145(7):1459-1463.

19. Dower Jl, Geleijnse JM, Gijsbers L, Zock PL, Kromhout D, Hollman PCH. Effects of the pure flavonoids epicatechin and quercetin on vascular function and cardiometabolic health: A randomized, double-blind, placebo-controlled, crossover trial. Am J Clin Nutr. 2015;101(5):914-921.

20. Buijsse B, Feskens EJM, Kok FJ, Kromhout D. Cocoa intake, blood pressure, and cardiovascular mortality: The Zutphen Elderly Study. Arch Intern Med. 2006;166(4):411-417.

21. Hertog MGL, Feskens EJM, Hollman PCH, Katan MB, Kromhout D. Dietary antioxidant flavonoids and risk of coronary heart disease: The Zutphen Elderly Study. Lancet. 1993;342(8878):1007-1011.

22. Bloemberg BPM, Kromhout D, Obermann-De Boer GL, Van Kampen-Donker M. The reproducibility of dietary intake data assessed with the cross-check dietary history method. Am J Epidemiol. 1989;130(5):1047-1056.

23. Arts ICW, Van De Putte B, Hollman PCH. Catechin contents of foods commonly consumed in The Netherlands. 2. Tea, wine, fruit juices, and chocolate milk. J Agric Food Chem. 2000;48(5):1752-1757.

24. Arts ICW, Van De Putte B, Hollman PCH. Catechin contents of foods commonly consumed in The Netherlands. 1. Fruits, vegetables, staple foods, and processed foods. J Agric Food Chem. 2000;48(5):1746-1751

25. Siedel J, Hagele EO, Ziegenhorn J, Wahlefeld AW. Reagent for the enzymatic determination of serum total cholesterol with improved lipolytic efficiency. Clin Chem. 1983;29(6):1075-1080.

26. Warnick GR, Benderson J, Albers JJ. Dextran sulfate-Mg2+ precipitation procedure for quantitation of high-density-lipoprotein cholesterol. Clin Chem. 1982;28(6):1379-1388.

27. Caspersen CJ, Bloemberg BPM, Saris WHM, Merritt RK, Kromhout D. The prevalence of selected physical activities and their relation with coronary heart disease risk factors in elderly men: The Zutphen Study, 1985. Am J Epidemiol. 1991;133(11):1078-1092.

28. Arts ICW, Hollman PCH, Feskens EJM, Bueno de Mesquita HB, Kromhout D. Catechin intake might explain the inverse relation between tea consumption and ischemic heart disease: The Zutphen Elderly Study. Am J Clin Nutr. 2001;74(2):227-232.

29. McCullough ML, Peterson JJ, Patel R, Jacques PF, Shah R, Dwyer JT. Flavonoid intake and cardiovascular disease mortality in a prospective cohort of US adults. AmJ Clin Nutr. 2012;95(2):454464.

30. Mink PJ, Scrafford CG, Barraj LM, et al. Flavonoid intake and cardiovascular disease mortality: A prospective study in postmenopausal women. Am J Clin Nutr. 2007;85(3):895-909. 
31. Zamora-Ros R, Jiménez C, Cleries R, et al. Dietary flavonoid and lignan intake and mortality in a Spanish cohort. Epidemiology. 2013;24(5):726-733.

32. Ottaviani Jl, Momma TY, Heiss C, Kwik-Uribe C, Schroeter H, Keen CL. The stereochemical configuration of flavanols influences the level and metabolism of flavanols in humans and their biological activity in vivo. Free Radic Biol Med. 2011;50(2):237-244.

33. Loke WM, Hodgson JM, Proudfoot JM, McKinley AJ, Puddey IB, Croft KD. Pure dietary flavonoids quercetin and (-)-epicatechin augment nitric oxide products and reduce endothelin-1 acutely in healthy men. Am J Clin Nutr. 2008;88(4):1018-1025.

34. Ras RT, Streppel MT, Draijer R, Zock PL. Flow-mediated dilation and cardiovascular risk prediction: A systematic review with meta-analysis. Int J Cardiol. 2013;168(1):344-351. 


\section{6}

Elderly men (65-84 y) invited

555 Survivors Seven Countries Study

711 Randomly sampled in Zutphen

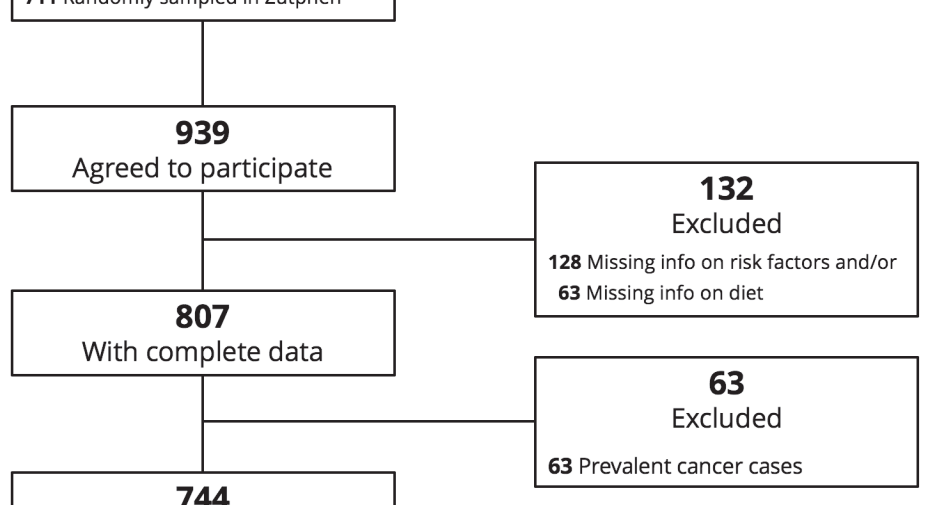

Final study population

SUPPLEMENTARY FIGURE 1. Flow-chart of participants included in the analysis. 


Effects of the Pure Flavonoids Epicatechin and Quercetin on Vascular Function and Cardiometabolic Helath: A Randomised Double-Blind, PlaceboControlled, Crossover Trial

\author{
James I Dower \\ Johanna M Geleijnse \\ Lieke Gijsbers \\ Peter L Zock \\ Daan Kromhout \\ Peter CH Hollman
}

Am J Clin Nutr. 2015;101(5):914-921 


\section{ABSTRACT}

\section{Background}

Prospective cohort studies showed inverse associations between the intake of flavonoidrich foods (cocoa and tea) and cardiovascular disease (CVD). Intervention studies showed protective effects on intermediate markers of CVD. This may be due to the protective effects of the flavonoids epicatechin (in cocoa and tea) and quercetin (in tea). We investigated the effects of supplementation of pure epicatechin and quercetin on vascular function and cardiometabolic health.

\section{Methods}

Thirty-seven apparently healthy men and women aged $40-80$ years with a systolic blood pressure (BP) between 125 and $160 \mathrm{~mm} \mathrm{Hg}$ at screening were enrolled in a randomised, double-blind, placebo-controlled, crossover trial. CVD risk factors were measured before and after 4 weeks of daily flavonoid supplementation. Participants received (-)-epicatechin (100 mg/d), quercetin-3-glucoside $(160 \mathrm{mg} / \mathrm{d})$, or placebo capsules for 4 weeks, in random order. The primary outcome was the change in flow-mediated dilation from pre- to postintervention. Secondary outcomes included other markers of CVD risk and vascular function.

\section{Results}

Epicatechin supplementation did not change flow-mediated dilation significantly $(1.1 \%$ absolute; 95\% Cl: -0.1 , 2.3; $\mathrm{p}=0.07)$. Epicatechin supplementation improved fasting plasma insulin ( $\Delta$ insulin: $-1.46 \mathrm{mU} / \mathrm{L} ; 95 \% \mathrm{Cl}$ : $-2.74,-0.18 ; \mathrm{p}=0.03$ ) and insulin resistance $(\Delta$ homeostasis model assessment of insulin resistance (HOMA-IR): -0.38 ; $95 \% \mathrm{Cl}:-0.74,-0.01$; $\mathrm{p}=0.04$ ) and had no effect on fasting plasma glucose. Epicatechin did not change BP (office BP and 24-h ambulatory BP), arterial stiffness, nitric oxide, endothelin-1, or blood lipid profile. Quercetin-3-glucoside supplementation had no effect on flow-mediated dilation, insulin resistance, or other CVD risk factors.

\section{Conclusions}

Our results suggest that epicatechin may in part contribute to the cardioprotective effects of cocoa and tea by improving insulin resistance. It is unlikely that quercetin plays an important role in the cardioprotective effects of tea. This study was registered at clinicaltrials.gov as NCT01691404. 


\section{INTRODUCTION}

Prospective cohort studies showed inverse associations between the intake of flavonoidrich foods (cocoa and tea) and cardiovascular disease (CVD). Meta-analyses of observational studies showed a 37\% lower risk of CVD with increasing chocolate consumption [1], a 21\% lower risk of stroke with increasing tea consumption [2], and a 15\% lower risk of diabetes with higher tea consumption [3].

Cocoa and tea may change CVD risk factors, including vascular function, insulin sensitivity, blood pressure (BP), and blood lipids. Cocoa/chocolate consumption improved flowmediated dilation (FMD), a measure of endothelial function, by $1.34 \%$ relative to controls in a meta-analysis of 11 randomised-controlled trials (RCTs) and also insulin resistance (HOMA-IR) [4]. Similarly, 13 RCTs found a reduction of $3.2 \mathrm{~mm} \mathrm{Hg}$ in systolic BP (SBP) and of $2.0 \mathrm{~mm} \mathrm{Hg}$ in diastolic BP (DBP) relative to controls after cocoa or chocolate consumption [5]. Few studies have investigated cocoa and arterial stiffness, a novel marker of CVD risk [6-8]; only improvements in augmentation index were reported [9, 10]. In 10 RCTs, cocoa/ chocolate reduced serum LDL and total cholesterol compared with controls [11].

Similarly, 9 RCTs found an increase in FMD of 2.6\% (absolute) after tea consumption [12]. Consuming decaffeinated green tea extract improved HOMA-IR in obese patients with type 2 diabetes, despite no change in body weight [13]. Following consumption of green tea or green tea extracts, 13 RCTs showed a reduction in SBP of $2.08 \mathrm{~mm} \mathrm{Hg}$ and DBP of $1.71 \mathrm{~mm}$ $\mathrm{Hg}$ [14], and 19 RCTs showed improvements in total and LDL cholesterol [15].

Cocoa is high in flavan-3-ols (a subclass of flavonoids) and in particular epicatechin. A bar of $100 \mathrm{~g}$ dark chocolate (54\% cocoa) provides $33 \mathrm{mg}$ of epicatechin - 3 times the mean daily intake in The Netherlands [16, 17], but the main dietary source of epicatechin is tea [16]. Besides epicatechin, tea is also a major source of flavonols (another subclass of flavonoids), of which quercetin is the most abundant [18]. For Dutch males, tea provides $16 \mathrm{mg}$ quercetin/d (47\% of the mean daily intake) as well as $11.5 \mathrm{mg}$ epicatechin/d (69\% of the intake) [18-20].

The above-mentioned cardioprotective effects were only demonstrated with cocoa and tea, complex mixtures of many flavonoids and other substances. The specific role of flavonoids remains unclear until the effects of pure flavonoids are studied. Only a few studies investigated the effects of high doses of pure flavonoids on a limited number of cardioprotective markers [21-24]. We, therefore, investigated whether pure epicatechin and quercetin could account for the cardioprotective effects of cocoa and tea by performing an intervention study in 37 subjects who ingested supplements with a relatively low dose of pure (-)-epicatechin or quercetin-3-glucoside daily for 4 weeks. 


\section{METHODS}

\section{Subjects}

Apparently healthy men and women aged 40-80 years were recruited from Wageningen and surroundings, in The Netherlands. Eligible for participation were non-smoking men and women, with a BMI (in $\mathrm{kg} / \mathrm{m}^{2}$ ) between 20 and 40 and SBP between 125 and $160 \mathrm{~mm}$ $\mathrm{Hg}$ on 2 separate occasions. Exclusion criteria included the presence of diabetes mellitus; cardiovascular, gastrointestinal, or liver disease; usage of antihypertensive or cholesterollowering medication or corticosteroids; adherence to a prescribed diet; unstable weight in the past 2 months; $\geq 10$ h/week moderate to vigorous physical activity ( $\geq 3$ metabolic equivalent tasks); and pregnancy or lactation. All participants (Table 1) gave written informed consent, and the study was approved by the Medical Ethics Committee of Wageningen University.

\section{Intervention}

The study was conducted as a randomised, double-blind, placebo-controlled, crossover study between October 2012 and March 2013 (Figure 1). After enrolment, subjects were randomly allocated into 6 intervention sequences using computer-generated block randomisation by a staff member not involved in the study. All supplements were encapsulated in non-transparent capsules that were identical in appearance and coded A, B, or C. Encoding was performed by an external pharmacist not involved in the study. Encoding was broken after all data analysis had been performed. Participants ingested (-)-epicatechin $(n=35)$, quercetin-3-glucoside ( $n=35)$, and placebo capsules ( $n=35$ ) for 4-week periods, separated by 4 weeks of washout. Outcome variables were measured at the research centre at the start and end of each 4-week intervention period. Measurements of endothelial function (FMD), BP, arterial stiffness, body weight (wearing minimal clothing), and blood samples were taken in the morning following an overnight fast (from 22:00). To assess acute-onchronic effects of flavonoid supplementation, FMD measurements were repeated on the final day of each intervention period, 2 hours after ingestion of the total daily dosage of the supplements. For the 24 hours before each measurement day, subjects were asked to avoid physical activity and alcohol consumption. The day before each measurement day, subjects underwent 24-hour ambulatory BP monitoring (24-h ABPM), collected 24-hour urine samples, and in the evening consumed a standardised low-flavonoid meal provided by the research team.

During the run-in week and throughout the study, subjects were asked to avoid consumption of epicatechin- and quercetin-rich foods, such as cocoa-containing products, red wine, apples, and onion-rich foods, and to drink no more than one cup of tea per day. Subjects ingested 2 capsules/d, with a glass of water: one during breakfast and one during dinner. Subjects reported capsules that were not ingested and non-adherence to the dietary 


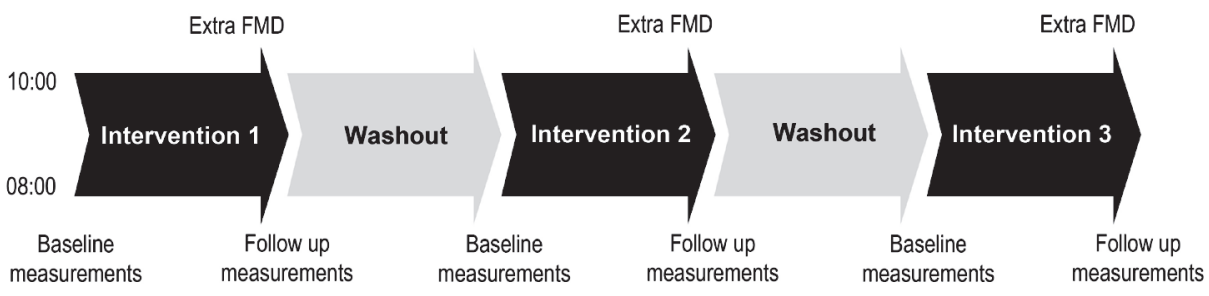

FIGURE 1. Study design. Participants ingested 2 capsules/d, one during breakfast and one during dinner, for 4 wk. Measurements of blood pressure, vascular function, and insulin resistance were taken at the start and end of each intervention period. Additional FMD measurements were taken on the final day of each intervention period, 2 h after consumption of 2 capsules. Participants received interventions (epicatechin, quercetin-3-glucoside, and placebo) in random order. FMD, flow-mediated dilation.

guidelines in a diary. Compliance was checked by asking participants to return all unused capsules. In addition, plasma and urinary flavonoid concentrations were determined.

The daily dosage of epicatechin used $(100 \mathrm{mg}=345 \mu \mathrm{mol})$ was in line with the amount of epicatechin present in previous cocoa/chocolate intervention studies (46-107 mg) [25-28]. In contrast to epicatechin, quercetin is present in foods only as glycosides. Quercetin3-glucoside was chosen because of its superior bioavailability [29]. For quercetin-3glucoside, an equimolecular dose was used (160 mg quercetin-3-glucoside $=345 \mu \mathrm{mol}$ ). A supplemental file (Supplemental Material 1) describes details on capsules and isolation and purification of the flavonoids.

\section{Functional and Biochemical Markers of Vascular Function}

Endothelial function (FMD) was measured non-invasively in the right brachial artery by the same researcher, who was blinded to treatment allocation. An ultrasound transducer (7.5 MHz) was positioned proximal to the antecubital fossa. Baseline arterial diameter was measured for $3 \mathrm{~min}$. Subsequently, reactive hyperaemia was induced by 5 min of lower arm occlusion through inflation of a cuff to $200 \mathrm{~mm} \mathrm{Hg}$. FMD images were processed automatically using custom-written software (MyFMD; APG Hoeks, Department of Biomedical Engineering, Maastricht University). During analysis, 11\% (34/309) of recordings were removed due to movement of arm after cuff release or unclear image of the arterial wall. FMD was calculated as peak change in arterial diameter following reactive hyperemia relative to baseline. Endothelium-independent vasodilation was calculated as peak change in arterial diameter over a 5-min period following sublingual administration of $400 \mathrm{mg}$ glyceryl trinitrate.

Pulse wave analysis and pulse wave velocity were measured by applanation tonometry on the radial artery, in triplicate, with the SphygmoCor system (version 8; Atcor Medical). 
TABLE 1. Baseline characteristics of 37 healthy subjects randomised at the start of the study.

\begin{tabular}{lc}
\hline & Mean \pm SD \\
\hline Age $(\mathrm{yrs})$ & $66.4 \pm 7.9$ \\
$\mathrm{BMI}\left(\mathrm{kg} / \mathrm{m}^{2}\right)$ & $26.7 \pm 3.3$ \\
Office SBP $(\mathrm{mmHg})$ & $129.3 \pm 14.1$ \\
Office DBP $(\mathrm{mmHg})$ & $74.8 \pm 9.8$ \\
Pulse Wave Velocity (m/s) & $12.9 \pm 1.9$ \\
Alx (\%) & $25.9 \pm 7.6$ \\
Plasma glucose (mmol/L) & $5.71 \pm 0.65$ \\
Serum insulin (mU/L) & $6.10 \pm 3.77$ \\
HOMA-IR & $1.57 \pm 0.97$ \\
Fasting serum lipids (mmol/L) & \\
Total cholesterol & $5.63 \pm 0.90$ \\
$\quad$ LDL cholesterol & $3.49 \pm 0.80$ \\
HDL cholesterol & $1.54 \pm 0.41$ \\
Triglycerides & $1.29 \pm 0.57$ \\
\hline
\end{tabular}

Alx, augmentation index corrected for a heart rate of 75 bpm; BMI, body mass index; DBP, diastolic blood pressure; HDL, high-density lipoprotein; HOMA-IR, homeostasis model assessment of insulin resistance; LDL, low-density lipoprotein; SBP, systolic blood pressure.

Central aortic waveforms were derived using a validated transfer function [30, 31]. Subsequently, central SBP, central DBP, subendocardial viability ratio and heart rate (HR)corrected central augmentation index were estimated using integrated software. Carotidfemoral pulse wave velocity was calculated as the measured carotid-femoral distance divided by the pulse transit time between the 2 sites.

Office BP and HR (beats/min) were measured as the mean of the last 3 of 4 measurements using an automated oscillometric device (Dinamap Pro 100; KP Medical). Measurements were taken in a temperature-controlled room (20-248C), in the supine position, after 10 min of rest. Twenty-four-hour ABPM was performed using Spacelabs 90217 devices (Spacelabs Medical Inc.). Daytime BP (07:00-23:00) was recorded every 30 min and nighttime BP (2300-07:00) every 60 min. Weighted 24-h mean ABPM and mean daytime (08:0022:00) and night-time (00:00-06:00) BP were calculated.

Plasma insulin concentrations were determined by ELISA from EDTA-plasma. Blood glucose, total and HDL cholesterol, and triglycerides were analysed with standard kits using an autoanalyzer (Hitachi 917; Roche Diagnostics). Insulin resistance was calculated by HOMA-IR, as described previously [32]. LDL cholesterol was calculated according to the Friedewald equation [33]. 
Heparin-plasma was used to determine the nitric oxide (NO) concentration by the estimation of NO by chemiluminescence formed after the release of NO from NO2, NO2-, and nitrosated and nitrosylated species. To minimize NOx contamination, measurements of NO were performed when air NOx concentrations were $<40 \mathrm{mg} / \mathrm{m3}$. Detection limit was $10 \mathrm{nmol} / \mathrm{L}$ [34]. Endothelin-1 was measured in EDTA-plasma by ELISA. Flavonoid concentrations were analysed in 24-hour urine and plasma samples after enzymatic hydrolysis of the conjugates by means of HPLC-electrochemical detection [35]. Detection limit for epicatechin and quercetin was $300 \mathrm{nmol} / \mathrm{L}$.

\section{Statistical Analysis}

FMD was defined as the primary outcome. Because no previous studies have assessed the effects of pure flavonoids on FMD, the power calculation was based on results from cocoa studies [4]. Assuming an SD in absolute FMD change of 2.7\%, 35 participants would provide sufficient power to detect an absolute change in FMD of 1.3\% (2-sided a of 5\%, power $=0.80$ ).

Data were analysed according to a pre-defined statistical analysis plan using SAS software version 9.2 (SAS Institute). Pre- and post-intervention data are shown in Supplemental Table 1. Treatment effects were calculated as the changes between values at the start and the end of each 4-week intervention period. Treatment effects were tested by comparing changes during epicatechin and quercetin supplementation with changes during placebo. Data were checked for normality of distribution, and all variables were considered normally distributed. Using the SAS PROC MIXED statement, a linear mixed model for repeated measures with compound symmetry as covariant structure was used to compare changes. Treatment and period were set as fixed effects and subject as random effect. To test for a carryover effect, we also included previous treatment in the model. No carryover effect was apparent, however, and was therefore excluded from the final model. Numerical data are expressed as means \pm SDs, medians with IQRs, or treatment effects (least squares means) with $95 \% \mathrm{Cls}$. Statistical significance was set at a 2 -sided p-value of 0.05 . 


\section{RESULTS}

\section{Study Population}

Of the 37 subjects ( 25 men, 12 women) who participated, 33 completed all interventions (Figure 2). Two subjects experienced an adverse event: one had a non-fatal acute myocardial infarction, and another had a fatal stroke. Both events took place during washout periods. The Medical Ethics Committee judged that these events were unrelated to the intervention, and this was confirmed by an independent Data and Safety Monitoring Board of a previous study [36].

The age of the study population ranged from 48 to 79 years, and BMI was between 20 and 35 (Table 1). Subjects had a mean SBP/DBP of $129 / 75 \mathrm{~mm} \mathrm{Hg}$, and $22 \%$ were hypertensive (SBP $\geq 140$ and/or DBP $\geq 90 \mathrm{~mm} \mathrm{Hg}$ ). Missing treatments due to dropout did not affect baseline characteristics between the quercetin and epicatechin groups (Supplemental Table 2). Body weight remained stable throughout the study period, and no omission of capsule ingestion was reported.

\section{Absorption and Compliance}

Plasma epicatechin was not detectable in fasting samples at the start or end of all 4-week interventions but was detectable 2 hours after acute-on-chronic epicatechin supplementation, with a mean concentration of $1950 \pm 2070 \mathrm{nmol} / \mathrm{L}$. At baseline, before each intervention, all urine samples were below the detection limit for epicatechin (300 nmol/L). After 4 weeks of epicatechin supplementation, $51 \%$ of urine samples had urinary epicatechin concentrations above the detection limit. After placebo and quercetin interventions, no urine samples had epicatechin concentrations above the detection limit. Fasting plasma quercetin concentrations increased from a mean of $381 \pm 205 \mathrm{nmol} / \mathrm{L}$ to $707 \pm 517 \mathrm{nmol} / \mathrm{L}(\mathrm{p}<0.001)$ after 4 weeks of quercetin supplementation, with a further increase to $2060 \pm 1370 \mathrm{nmol} / \mathrm{L} 2$ hours after acute supplementation $(p<0.001)$. Fasting plasma quercetin concentration in the placebo group was $393 \pm 217 \mathrm{nmol} / \mathrm{L}$ at baseline and did not change during placebo intervention. At baseline, before each intervention, all urine samples but one were below the detection limit for quercetin $(300 \mathrm{nmol} / \mathrm{L})$. After 4 weeks of quercetin supplementation, $71 \%$ of urine samples had urinary quercetin concentrations above the detection limit. After placebo intervention, $12 \%$ of urine samples had urinary quercetin concentrations slightly above the detection limit. Based on returned capsules and diary entries, more than $98 \%$ of capsules distributed were ingested, and all subjects (excluding dropouts) ingested at least $80 \%$ during each intervention.

\section{Flavonoid Supplementation}

Epicatechin supplementation did not change FMD significantly $(1.1 \%$ absolute; $95 \% \mathrm{Cl}$ : -0.1, 2.3; $p=0.07$ ) over the 4-week period, and no acute-on-chronic effects were seen (Table

2). Endothelium-independent vasodilation did not change following acute or chronic 
TABLE 2. Effects of (-)-epicatechin (100 mg, $345 \mu \mathrm{mol}$ ) and quercetin-3-glucoside (160 mg, $345 \mu \mathrm{mol})$ supplementation daily for 4 weeks on vascular function, BP and body weight in healthy subjects1.

\begin{tabular}{|c|c|c|c|c|c|c|}
\hline & \multicolumn{3}{|c|}{ (-)-Epicatechin $(n=35)$} & \multicolumn{3}{|c|}{ Quercetin-3-glucoside $(n=35)$} \\
\hline & Treatment & & & Treatment & & \\
\hline & effect & $(95 \% \mathrm{Cl})$ & $P$-value & effect & $(95 \% \mathrm{Cl})$ & $P$-value \\
\hline FMD chronic $(\%)^{2}$ & 1.08 & $(-0.09,2.26)$ & 0.07 & 0.33 & $(-0.79,1.44)$ & 0.56 \\
\hline FMD acute $(\%)^{2}$ & -0.19 & $(-1.47,1.10)$ & 0.77 & 0.20 & $(-1.05,1.45)$ & 0.75 \\
\hline EID chronic $(\%)^{2}$ & 0.99 & $(-2.15,4.13)$ & 0.53 & 0.16 & $(-2.89,3.22)$ & 0.91 \\
\hline EID acute $(\%)^{2}$ & -1.08 & $(-3.27,1.11)$ & 0.32 & -1.53 & $(-3.63,0.56)$ & 0.15 \\
\hline \multicolumn{7}{|l|}{ Office BP (mmHg) } \\
\hline SBP & -0.51 & $(-5.38,4.36)$ & 0.84 & 1.77 & $(-3.12,6.65)$ & 0.47 \\
\hline DBP & -0.06 & $(-2.32,2.20)$ & 0.96 & 0.78 & $(-1.48,3.05)$ & 0.49 \\
\hline Office HR (bpm) & 0.05 & $(-3.18,3.30)$ & 0.97 & 0.14 & $(-3.10,3.38)$ & 0.93 \\
\hline \multicolumn{7}{|l|}{ 24-hour BP (mmHg) } \\
\hline SBP & -2.37 & $(-5.95,1.21)$ & 0.19 & 0.67 & $(-2.91,4.25)$ & 0.71 \\
\hline DBP & -1.49 & $(-3.50,0.38)$ & 0.12 & 0.32 & $(-1.54,2.19)$ & 0.73 \\
\hline \multicolumn{7}{|l|}{ Daytime BP (mmHg) } \\
\hline SBP & -1.90 & $(-5.72,1.92)$ & 0.32 & 1.05 & $(-2.77,4.87)$ & 0.58 \\
\hline DBP & -1.31 & $(-3.56,0.93)$ & 0.25 & 0.68 & $(-1.57,2.93)$ & 0.55 \\
\hline \multicolumn{7}{|l|}{ Night-time BP (mmHg) } \\
\hline SBP & -3.77 & $(-8.87,1.33)$ & 0.14 & -0.61 & $(-5.70,4.49)$ & 0.81 \\
\hline DBP & -1.90 & $(-4.74,0.94)$ & 0.19 & -0.34 & $(-3.18,2.49)$ & 0.81 \\
\hline $\begin{array}{l}\text { Pulse Wave Velocity } \\
(\mathrm{m} / \mathrm{s})\end{array}$ & 0.32 & $(-0.33,0.96)$ & 0.33 & 0.18 & $(-0.45,0.82)$ & 0.58 \\
\hline \multicolumn{7}{|l|}{ Pulse Wave Analysis } \\
\hline Central SBP (mmHg) & 1.23 & $(-3.22,5.67)$ & 0.58 & 2.10 & $(-2.33,6.54)$ & 0.35 \\
\hline Central DBP (mmHg) & -1.14 & $(-3.61,1.34)$ & 0.36 & 0.16 & $(-2.31,2.63)$ & 0.90 \\
\hline Alx (\%) & -1.37 & $(-3.10,0.37)$ & 0.12 & -0.70 & $(-2.43,1.04)$ & 0.43 \\
\hline SEVR (\%) & 3.83 & $(-3.80,11.50)$ & 0.32 & 3.01 & $(-4.60,10.60)$ & 0.43 \\
\hline Body weight (kg) & -0.21 & $(-0.90,0.47)$ & 0.54 & -0.35 & $(-1.03,0.33)$ & 0.31 \\
\hline
\end{tabular}

${ }^{1}$ All values are least square means $(95 \% \mathrm{Cl})$ from linear mixed model for repeated measures with compound symmetry as covariant structure. 'Treatment' and 'period' were set as fixed effects and 'subject' as random effect. $P$ values were derived from this model.

${ }^{2}$ Absolute difference.

Abbreviations: Alx, augmentation index corrected for heart rate of 75 bpm; DBP, diastolic blood pressure; EID, endothelium-independent dilation; FMD, flow-mediated dilation; HR, heart rate; SBP, systolic blood pressure; SEVR, subendocardial viability ratio. 


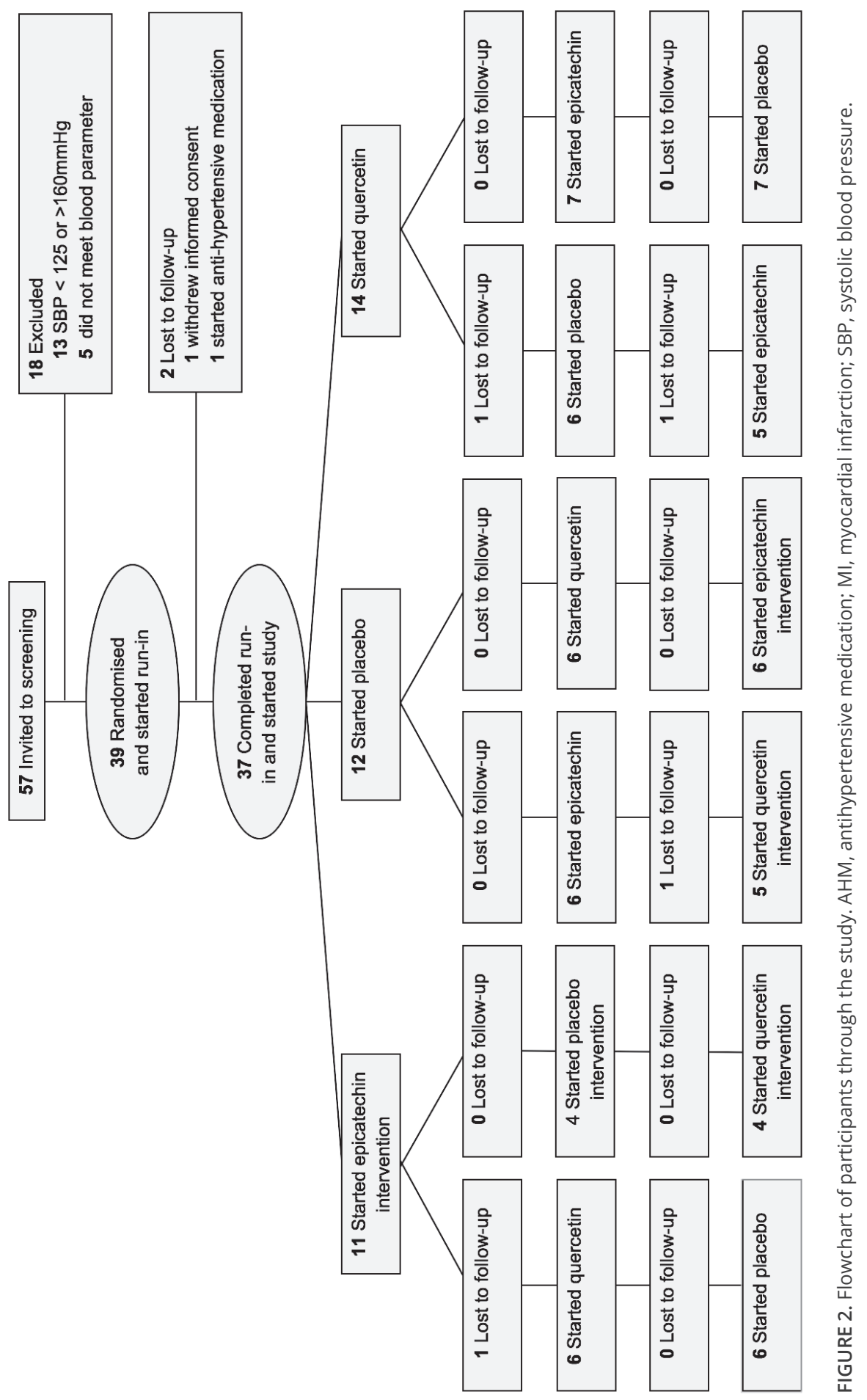


epicatechin supplementation. No changes were seen for plasma glucose concentrations. Mean plasma fasting insulin changed by $-1.46 \mathrm{mU} / \mathrm{L}(95 \% \mathrm{Cl}:-2.74,-0.18 ; \mathrm{p}=0.03)$, resulting in a change in HOMA-IR of $-0.38(95 \% \mathrm{Cl}:-0.74,-0.01 ; \mathrm{p}=0.04)$ (Table 3). Epicatechin supplementation had no effect on office BP or HR. Mean 24-h SBP $(\Delta:-2.4 \mathrm{~mm} \mathrm{Hg}$; $95 \%$ $\mathrm{Cl}:-5.95,1.21 ; \mathrm{p}=0.19)$ and DBP $(\Delta:-1.5 \mathrm{~mm} \mathrm{Hg}$; 95\% Cl: $-3.50,0.38 ; \mathrm{p}=0.12)$ did not change significantly after epicatechin supplementation (Table 2). No changes were seen for other markers of cardiometabolic health (Table 3).

Quercetin supplementation did not affect FMD, insulin resistance, or any other marker of cardiometabolic health (Tables 2 and 3).

TABLE 3. Effects of (-)-epicatechin (100 mg, $345 \mu \mathrm{mol}$ ) and quercetin-3-glucoside (160 mg, $345 \mu \mathrm{mol})$ supplementation daily for 4 weeks on biomarkers of cardiometabolic health in healthy subjects'.

\begin{tabular}{|c|c|c|c|c|c|c|}
\hline & \multicolumn{3}{|c|}{$(-)$-Epicatechin $(n=35)$} & \multicolumn{3}{|c|}{ Quercetin-3-glucoside ( $n=35)$} \\
\hline & $\begin{array}{c}\text { Treatment } \\
\text { effect }\end{array}$ & $(95 \% \mathrm{Cl})$ & $P$-value & $\begin{array}{c}\text { Treatment } \\
\text { effect }\end{array}$ & $(95 \% \mathrm{Cl})$ & $P$-value \\
\hline Glucose (mmol/L) & -0.02 & $(-0.21,0.18)$ & 0.88 & 0.01 & $(-0.19,0.21)$ & 0.94 \\
\hline Insulin (mU/L) & -1.46 & $(-2.74,-0.18)$ & 0.03 & -0.34 & $(-1.62,0.94)$ & 0.60 \\
\hline HOMA-IR & -0.38 & $(-0.74,-0.01)$ & 0.04 & -0.07 & $(-0.44,0.29)$ & 0.68 \\
\hline $\begin{array}{l}\text { Nitric oxide chronic } \\
\text { (nmol/L) }\end{array}$ & -6.99 & $(-32.5,18.5)$ & 0.59 & 6.68 & $(-19.1,32.4)$ & 0.61 \\
\hline $\begin{array}{l}\text { Nitric oxide acute } \\
(\mathrm{nmol} / \mathrm{L})\end{array}$ & -5.64 & $(-27.2,15.9)$ & 0.60 & -13.1 & $(-34.7,8.5)$ & 0.23 \\
\hline Endothelin-1 (pg/ml) & -0.03 & $(-0.20,0.13)$ & 0.68 & 0.04 & $(-0.13,0.21)$ & 0.65 \\
\hline \multicolumn{7}{|l|}{$\begin{array}{l}\text { Fasting serum lipids } \\
\text { (mmol/L) }\end{array}$} \\
\hline Total cholesterol & -0.08 & $(-0.36,0.19)$ & 0.54 & -0.001 & $(-0.28,0.28)$ & 0.99 \\
\hline HDL cholesterol & -0.01 & $(-0.09,0.07)$ & 0.79 & 0.03 & $(-0.05,0.11)$ & 0.43 \\
\hline LDL cholesterol & -0.02 & $(-0.25,0.22)$ & 0.90 & -0.01 & $(-0.25,0.23)$ & 0.92 \\
\hline Triglycerides & -0.13 & $(-0.35,0.08)$ & 0.22 & -0.04 & $(-0.26,0.17)$ & 0.69 \\
\hline
\end{tabular}

1 All values are least square means $(95 \% \mathrm{CI}$ ) from linear mixed model for repeated measures with compound symmetry as covariant structure. Treatment' and 'period' were set as fixed effects and 'subject' as random effect. $P$ values were derived from this model.

HDL, high-density lipoprotein; HOMA-IR, homeostasis model assessment of insulin resistance; LDL, low-density lipoprotein. 


\section{DISCUSSION}

In this study of 37 healthy older adults, supplementation of pure epicatechin did not improve FMD but reduced insulin resistance. Epicatechin had no effect on any other marker of cardiometabolic health. Quercetin supplementation did not affect FMD, insulin resistance, or any other marker of cardiometabolic health.

Increases in plasma flavonoid concentrations after active treatment but not after placebo showed that epicatechin and quercetin were absorbed. Because of the short elimination half-life of epicatechin (2 h) [37], plasma epicatechin concentrations remained below the detection limit in fasting blood after chronic supplementation. Plasma epicatechin concentrations did increase after acute supplementation (to $1950 \mathrm{nmol} / \mathrm{L}$ ). This increase was considerably higher than in previous studies on acute cocoa consumption $( \pm 400$ $\mathrm{nmol} / \mathrm{L}$ after $100 \mathrm{mg}$ epicatechin) $[25,38]$. Because of the longer plasma elimination halflife of quercetin (17 h) [29], plasma quercetin concentrations increased both chronically $(p<0.001)$ and acutely $(p<0.001)$.

\section{Flow-Mediated Dilation}

On the basis of a meta-analysis of cocoa studies, we expected a mean absolute increase in FMD of $1.3 \%$. However, we did not observe a significant effect of epicatechin on FMD (absolute $\Delta:+1.1 \%$; $95 \% \mathrm{Cl}:-0.1,2.3 ; \mathrm{p}=0.07$ ). Our intervention was sufficiently powered to detect an absolute change in FMD of $1.3 \%$, indicating that the effect, if any, is expected to be smaller than $1.3 \%$. A $1 \%$ increase in FMD would be clinically relevant, because at a population level, a $1 \%$ increase in FMD is associated with a $13 \%$ lower risk of a cardiovascular event [39].

We did not observe an acute-on-chronic effect of epicatechin supplementation on FMD. This is contrary to earlier data that showed the acute effect of cocoa to be larger than the chronic effect [4]. Previous studies, however, investigated the acute effects of cocoa consumption not in combination with chronic effects. Possibly in our study, a plateau in endothelial function was reached after 4 weeks, and an additional acute dose could not elicit more effect on FMD.

Quercetin supplementation did not affect FMD, suggesting that quercetin alone is not responsible for the changes in endothelial function observed after tea consumption [12]. The median daily dose of tea used in the tea interventions $(500 \mathrm{~mL})$ would provide just 8 mg of quercetin [20], much lower than the dose of $100 \mathrm{mg}$ used in the current study.

\section{Insulin Resistance}

Epidemiological studies have shown an association between HOMA-IR and CVD risk $[42,43]$. In our study, the reduction in mean HOMA-IR of -0.38 following epicatechin 
supplementation was smaller than that of the cocoa meta-analysis (-0.67), although it did fall within the $95 \% \mathrm{Cl}(-0.98,-0.36)$ of this meta-analysis [4]. Our study population had a mean HOMA-IR of 1.57, which is below the threshold of insulin resistance $(<2.77)[44]$. The response to epicatechin may be stronger in subjects with impaired fasting glucose concentrations and higher levels of insulin resistance [45]. The results of the present study suggest that epicatechin contributes to the favourable effects seen in cocoa trials $[46,47]$. Insulin and HOMA-IR may influence vascular function through stimulation of the production of NO $[40,41]$. Epicatechin did not affect plasma NO concentrations, which suggests no involvement of $\mathrm{NO}$ in this favourable response. Besides NO, improvements in pancreatic $\beta$-cell function as well as induction of the AKT/PI-3-kinase and ERK1/2 pathways have been suggested to play a role in effects on insulin resistance of cocoa flavan-3-ols [28, 48]. Future studies should explore these mechanisms.

In our study, quercetin supplementation did not affect HOMA-IR. Green tea contains almost 3 times more epicatechin than does quercetin [49], suggesting that epicatechin rather than quercetin is responsible for the beneficial effects of green tea on insulin resistance [13].

\section{Blood Pressure}

The measurement of 24-h ABPM is a strength of our study because it is considered superior to office BP in predicting cardiovascular mortality [50]. In contrast to cocoa RCTs, epicatechin did not change office BP. Hooper et al. [4] deduced that improvements in BP occurred with cocoa/chocolate containing 50-100 mg epicatechin, with no further reductions above $100 \mathrm{mg}$. As we supplemented $100 \mathrm{mg}$ epicatechin/d in our study, an effect on BP was expected. However, we did not observe a statistically significant effect.

Quercetin had no effect on office BP or 24-h ABPM. This is in contrast to studies using pure quercetin aglycone. Egert et al. [22] noted a $2.6 \mathrm{~mm}$ Hg reduction of SBP compared with placebo in overweight weight-stable subjects following 6 weeks of quercetin supplementation (150 mg/d). Similarly, Edwards et al. [21] reported a reduction in SBP/ DBP of $7 / 5 \mathrm{~mm} \mathrm{Hg}$ compared with placebo in untreated stage I weight-stable subjects with hypertension following 4 weeks of quercetin consumption $(730 \mathrm{mg} / \mathrm{d})$. Possibly, a higher quercetin intake is required, and/or the health state plays a role.

\section{Other Vascular Function Markers}

Endothelin-1 and NO - important mediators of vasoconstriction/vasodilation - were not affected by epicatechin or quercetin supplementation, consistent with the unchanged FMD. The beneficial effects of cocoa flavan-3-ols on FMD, BP, and insulin resistance are thought to be partly mediated through the release of NO [51]. Both epicatechin and quercetin in pure forms have been shown to increase NO products acutely at high doses of $200 \mathrm{mg}$ [23]. The dose used in our study (100 mg) was possibly too small to elicit an effect on NO metabolism. 
Arterial stiffness was not affected by epicatechin or quercetin. Most RCTs that reported improvements in arterial stiffness following dietary interventions had durations between 1.5 and 25 months [52]. The current study may have been too short to elicit structural vascular changes.

Results from cocoa studies show that cocoa reduced LDL and total cholesterol [11]. In our study, epicatechin supplementation had no effect on cholesterol, suggesting that epicatechin is not responsible for the observed effects of cocoa. Quercetin supplementation also did not affect cholesterol. This is in line with Conquer et al. [53], who did not find an effect of even a much higher dosage of quercetin (1000 mg) on serum cholesterol and triglyceride concentrations.

\section{Study Limitations}

In the present study, a number of markers of cardiometabolic health were assessed. We cannot, therefore, exclude the possibility of a false-positive finding. Nevertheless, we chose not to correct for multiple testing, based on the arguments of Rothman [54]. That said, for readers who wish to know which results would and would not be statistically significant if we did adjust for multiple testing, we note that we conducted 29 tests. Therefore, to maintain a family-wise type I error rate of 0.05 , were one to use a Bonferroni correction, $p$-values would need to be $<0.05 / 29=0.002$. Readers may view our reported $p$-values in that context. To exclude the possibility of false positives, more studies are needed to confirm our results.

By studying pure flavonoids, we excluded potential interactions with other flavonoids and compounds in cocoa/tea. It is possible that such interactions play a role in the effects of cocoa and tea; however, to our knowledge, studies on such interactions have not been published.

The analytic method for plasma and urinary flavonoids was not sensitive enough to reliably determine concentrations smaller than $300 \mathrm{nmol} / \mathrm{L}$. Although we were able to demonstrate differences between placebo and interventions and sufficient washout between interventions, comparison with cocoa/tea studies should be made cautiously.

\section{CONCLUSIONS}

Our findings suggest that epicatechin plays a role in the beneficial effects of cocoa and tea on insulin resistance. No effects of epicatechin were seen on endothelial function or other markers of cardiometabolic health. Quercetin, a major flavonol in tea, did not influence any of the markers of cardiometabolic health. It is unlikely, therefore, that quercetin plays a role in the cardioprotective effects of tea. 


\section{ACKNOWLEDGMENTS}

We thank Harrie Robins for his practical assistance in carrying out the study and Dini Venema for carrying out biochemical analyses. We also thank Hendriek Boshuizen for statistical advice.

\section{FUNDING SOURCES}

Supported by Top Institute Food and Nutrition, a public-private partnership on precompetitive research in food and nutrition. The sponsors provided funding but had no role in the study concept and design, data acquisition and analysis, drafting of the manuscript, or decision to publish.

\section{DISCLOSURES}

PLZ is employed by Unilever R\&D Vlaardingen. No other authors declared a conflict of interest. 


\section{REFERENCES}

1. Buitrago-Lopez A, Sanderson J, Johnson L, et al.. Chocolate consumption and cardiometabolic disorders: systematic review and meta-analysis. BMJ (Online). 2011;343.

2. Arab L, Liu W, Elashoff D. Green and black tea consumption and risk of stroke: a meta-analysis. Stroke. 2009;40:1786-1792.

3. Yang WS, Wang WY, Fan WY, Deng Q, Wang X. Tea consumption and risk of type 2 diabetes: a doseresponse meta-analysis of cohort studies. BrJ Nutr. 2014;111:1329-1339.

4. Hooper L, Kay C, Abdelhamid A, et al. Effects of chocolate, cocoa, and flavan-3-ols on cardiovascular health: a systematic review and meta-analysis of randomized trials. Am J Clin Nutr. 2012;95:740751.

5. Ried K, Sullivan T, Fakler P, Frank OR, Stocks NP. Does chocolate reduce blood pressure? A metaanalysis. BMC Med. 2010;8:39.

6. Blacher J, Asmar R, Djane S, London GM, Safar ME. Aortic pulse wave velocity as a marker of cardiovascular risk in hypertensive patients. Hypertension. 1999;33:1111-1117.

7. Blacher J, Guerin AP, Pannier B, Marchais SJ, Safar ME, London GM. Impact of aortic stiffness on survival in end-stage renal disease. Circulation. 1999;99:2434-2439.

8. Vlachopoulos C, Aznaouridis K, O'Rourke MF, Safar ME, Baou K, Stefanadis C. Prediction of cardiovascular events and all-cause mortality with central haemodynamics: a systematic review and meta-analysis. Eur Heart J. 2010;31:1865-1871.

9. Esser D, Mars M, Oosterink E, Stalmach A, Muller M, Afman LA. Dark chocolate consumption improves leukocyte adhesion factors and vascular function in overweight men. FASEB J. 2014;28:1464-1473.

10. Vlachopoulos C, Aznaouridis K, Alexopoulos N, Economou E, Andreadou I, Stefanadis C. Effect of dark chocolate on arterial function in healthy individuals. Am J Hypertens. 2005;18:785-791.

11. Tokede OA, Gaziano JM, Djoussé L. Effects of cocoa products/dark chocolate on serum lipids: a meta-analysis. EurJ Clin Nutr. 2011;65:879-886.

12. Ras RT, Zock PL, Draijer R. Tea consumption enhances endothelial-dependent vasodilation; a meta-analysis. PLOS ONE. 2011;6.

13. Hsu CH, Liao YL, Lin SC, Tsai TH, Huang CJ, Chou P. Does supplementation with green tea extract improve insulin resistance in obese type 2 diabetics? A randomized, double-blind, and placebocontrolled clinical trial. Altern Med Rev. 2011;16:157-163.

14. Khalesi S, Sun J, Buys N, Jamshidi A, Nikbakht-Nasrabadi E, Khosravi-Boroujeni H. Green tea catechins and blood pressure: a systematic review and meta-analysis of randomised controlled trials. EurJ Nutr. 2014;53:1299-1311.

15. Onakpoya I, Spencer E, Heneghan C, Thompson M. The effect of green tea on blood pressure and lipid profile: a systematic review and meta-analysis of randomized clinical trials. Nutr Metab Cardiovasc Dis. 2014;24:823-836.

16. Arts ICW, Hollman PCH, Feskens EJM, Bueno De Mesquita HB, Kromhout D. Catechin intake and associated dietary and lifestyle factors in a representative sample of Dutch men and women. Eur J Clin Nutr. 2001;55:76-81. 
17. Arts ICW, Van De Putte B, Hollman PCH. Catechin contents of foods commonly consumed in The Netherlands: 1. Fruits, vegetables, staple foods, and processed foods. J Agric Food Chem. 2000;48:1746-1751.

18. Hertog MGL, Feskens EJM, Hollman PCH, Katan MB, Kromhout D. Dietary antioxidant flavonoids and risk of coronary heart disease: the Zutphen Elderly Study. Lancet. 1993;342:1007-1011.

19. Arts ICW, Van De Putte B, Hollman PCH. Catechin contents of foods commonly consumed in The Netherlands: 2. Tea, wine, fruit juices, and chocolate milk. J Agric Food Chem. 2000;48:1752-1757.

20. Hertog MGL, Hollman PCH, Katan M. Content of potentially anticarcinogenic flavonoids of 28 vegetables and 9 fruits commonly consumed in the Netherlands. J Agric Food Chem. 1992;40:23792383.

21. Edwards RL, Lyon T, Litwin SE, Rabovsky A, Symons JD, Jalili T. Quercetin reduces blood pressure in hypertensive subjects. J Nutr. 2007; 137:2405-2411.

22. Egert S, Bosy-Westphal A, Seiberl J, et al. Quercetin reduces systolic blood pressure and plasma oxidised low-density lipoprotein concentrations in overweight subjects with a high-cardiovascular disease risk phenotype: a double-blinded, placebo-controlled cross-over study. Br J Nutr. 2009;102:1065-1074.

23. Loke WM, Hodgson JM, Proudfoot JM, McKinley AJ, Puddey IB, Croft KD. Pure dietary flavonoids quercetin and (-)-epicatechin augment nitric oxide products and reduce endothelin-1 acutely in healthy men. Am J Clin Nutr. 2008;88:1018-1025.

24. Schroeter $\mathrm{H}$, Heiss C, Balzer J, et al. (-)-Epicatechin mediates beneficial effects of flavanol-rich cocoa on vascular function in humans. Proc Natl Acad Sci USA. 2006;103:1024-1029.

25. Engler MB, Engler MM, Chen CY, et al. Flavonoid-rich dark chocolate improves endothelial function and increases plasma epicatechin concentrations in healthy adults. J Am Coll Nutr. 2004;23:197204.

26. Faridi Z, Njike VY, Dutta S, Ali A, Katz DL. Acute dark chocolate and cocoa ingestion and endothelial function: a randomized controlled crossover trial. Am J Clin Nutr. 2008;88:58-63.

27. Farouque HMO, Leung M, Hope SA, et al. Acute and chronic effects of flavanol-rich cocoa on vascular function in subjects with coronary artery disease: a randomized double-blind placebocontrolled study. Clin Sci. 2006;111:71-80.

28. Grassi D, Desideri G, Necozione S, et al. Blood pressure is reduced and insulin sensitivity increased in glucose-intolerant, hypertensive subjects after 15 days of consuming high-polyphenol dark chocolate. J Nutr. 2008;138:1671-1676.

29. Hollman PCH, Bijsman MNCP, Van Gameren Y, Cnossen EPJ, De Vries JHM, Katan MB. The sugar moiety is a major determinant of the absorption of dietary flavonoid glycosides in man. Free Radic Re.s 1999;31:569-573.

30. Karamanoglu M, O'Rourke MF, Avolio AP, Kelly RP. An analysis of the relationship between central aortic and peripheral upper limb pressure waves in man. Eur Heart J. 1993;14:160-167.

31. Pauca AL, O'Rourke MF, Kon ND. Prospective evaluation of a method for estimating ascending aortic pressure from the radial artery pressure waveform. Hypertension. 2001;38:932-937. 
32. Matthews DR, Hosker JP, Rudenski AS, Naylor BA, Treacher DF, Turner RC. Homeostasis model assessment: insulin resistance and b-cell function from fasting plasma glucose and insulin concentrations in man. Diabetologia.1985;28:412-419.

33. Friedewald WT, Levy RI, Fredrickson DS. Estimation of the concentration of low-density lipoprotein cholesterol in plasma, without use of the preparative ultracentrifuge. Clin Chem. 1972;18:499-502.

34. Appeldoorn MM, Venema DP, Peters THF, et al. Some phenolic compounds increase the nitric oxide level in endothelial cells in vitro. J Agric Food Chem. 2009;57:7693-7699.

35. Arts ICW, Venema DP, Hollman PCH. Quantitative determination of flavonols in plant foods and biological fluids. In: Santos-Buelga C, Williamson G, editors. Methods in polyphenol analysis. Cambridge (UK): Royal Society of Chemistry; 2003. p. 214-228.

36. Geleijnse JM, Giltay EJ, Schouten EG, et al. Effect of low doses of n-3 fatty acids on cardiovascular diseases in 4,837 post-myocardial infarction patients: design and baseline characteristics of the Alpha Omega Trial. Am Heart J 2010;159:539-546.

37. Manach C, Williamson G, Morand C, Scalbert A, Rémésy C. Bioavailability and bioefficacy of polyphenols in humans: I. Review of 97 bioavailability studies. Am J Clin Nutr. 2005;81:230S-242S.

38. Wang JF, Schramm DD, Holt RR, et al. A dose-response effect from chocolate consumption on plasma epicatechin and oxidative damage. J Nutr. 2000;130:2115S-2119S.

39. Inaba Y, Chen JA, Bergmann SR. Prediction of future cardiovascular outcomes by flow-mediated vasodilatation of brachial artery: a meta-analysis. Int J Cardiovasc Imaging. 2010;26:631-640.

40. Kim JA, Montagnani M, Kwang KK, Quon MJ. Reciprocal relationships between insulin resistance and endothelial dysfunction: molecular and pathophysiological mechanisms. Circulation. 2006;113:1888-1904.

41. Vincent MA, Montagnani M, Quon MJ. Molecular and physiologic actions of insulin related to production of nitric oxide in vascular endothelium. Curr Diab Rep. 2003;3:279-288.

42. Bonora E, Kiechl S, Willeit J, et al. Insulin resistance as estimated by homeostasis model assessment predicts incident symptomatic cardiovascular disease in Caucasian subjects from the general population: the Bruneck Study. Diabetes Care. 2007;30:318-324.

43. Hanley AJG, Williams K, Stern MP, Haffner SM. Homeostasis model assessment of insulin resistance in relation to the incidence of cardiovascular disease: the San Antonio Heart Study. Diabetes Care. 2002; 25:1177-1184.

44. Bonora E, Kiechl S, Willeit J, et al. Prevalence of insulin resistance in metabolic disorders: the Bruneck Study. Diabetes. 1998;47:1643-1649.

45. Pittas AG, Harris SS, Stark PC, Dawson-Hughes B. The effects of calcium and vitamin D supplementation on blood glucose and markers of inflammation in nondiabetic adults. Diabetes Care. 2007;30:980-986.

46. Grassi D, Lippi C, Necozione S, Desideri G, Ferri C. Short-term administration of dark chocolate is followed by a significant increase in insulin sensitivity and a decrease in blood pressure in healthy persons. Am J Clin Nutr. 2005;81:611-614.

47. Grassi D, Necozione S, Lippi C, et al. Cocoa reduces blood pressure and insulin resistance and improves endothelium-dependent vasodilation in hypertensives. Hypertension. 2005;46:398-405. 
48. Granado-Serrano AB, Martín MA, Haegeman G, Goya L, Bravo L, Ramos S. Epicatechin induces NFkB activator protein-1 (AP-1) and nuclear transcription factor erythroid 2p45-related factor 2 (Nrf2) via phosphatidylinositol-3-kinase/protein kinase B (PI3K/AKT) and extracellular regulated kinase (ERK) signalling in HepG2 cells. Br J Nutr. 2010;103:168-179.

49. Bhagwat S, Haytowitz D, Holden J. USDA database for the flavonoid content of selected foods (3). Beltsville (MD): USDA; 2011.

50. Dolan E, Stanton A, Thijs L, et al. Superiority of ambulatory over clinic blood pressure measurement in predicting mortality: the Dublin Outcome Study. Hypertension. 2005;46:156-161.

51. Ellam S, Williamson G. Cocoa and human health. Annu Rev Nutr. 2013;33:105-128.

52. Pase MP, Grima NA, Sarris J. The effects of dietary and nutrient interventions on arterial stiffness: a systematic review. Am J Clin Nutr. 2011;93:446-454.

53. Conquer JA, Maiani G, Azzini E, Raguzzini A, Holub BJ. Supplementation with quercetin markedly increases plasma quercetin concentration without effect on selected risk factors for heart disease in healthy subjects. J Nutr. 1998;128:593-597.

54. Rothman KJ. No adjustments are needed for multiple comparisons. Epidemiology. 1990;1:43-46. 


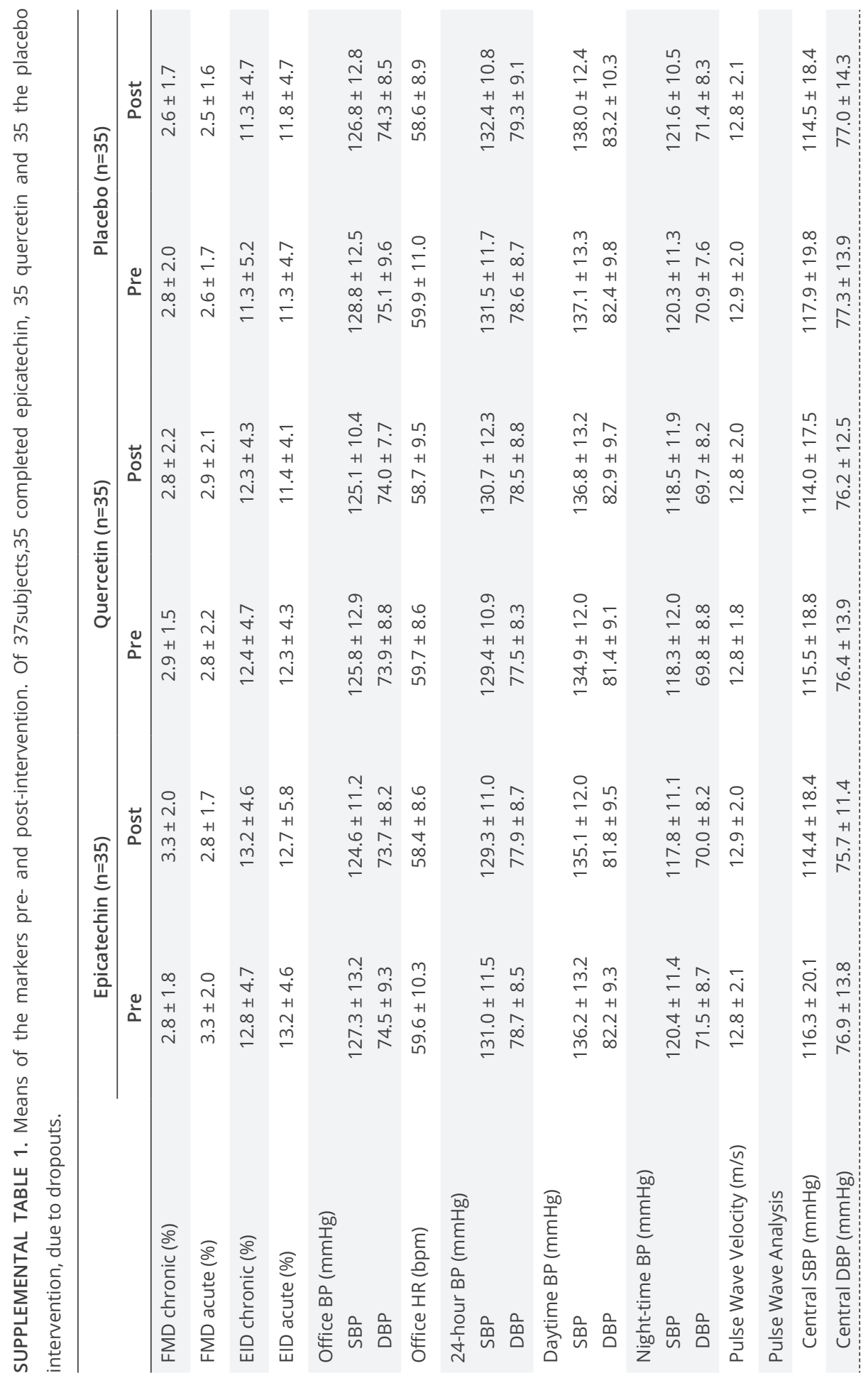




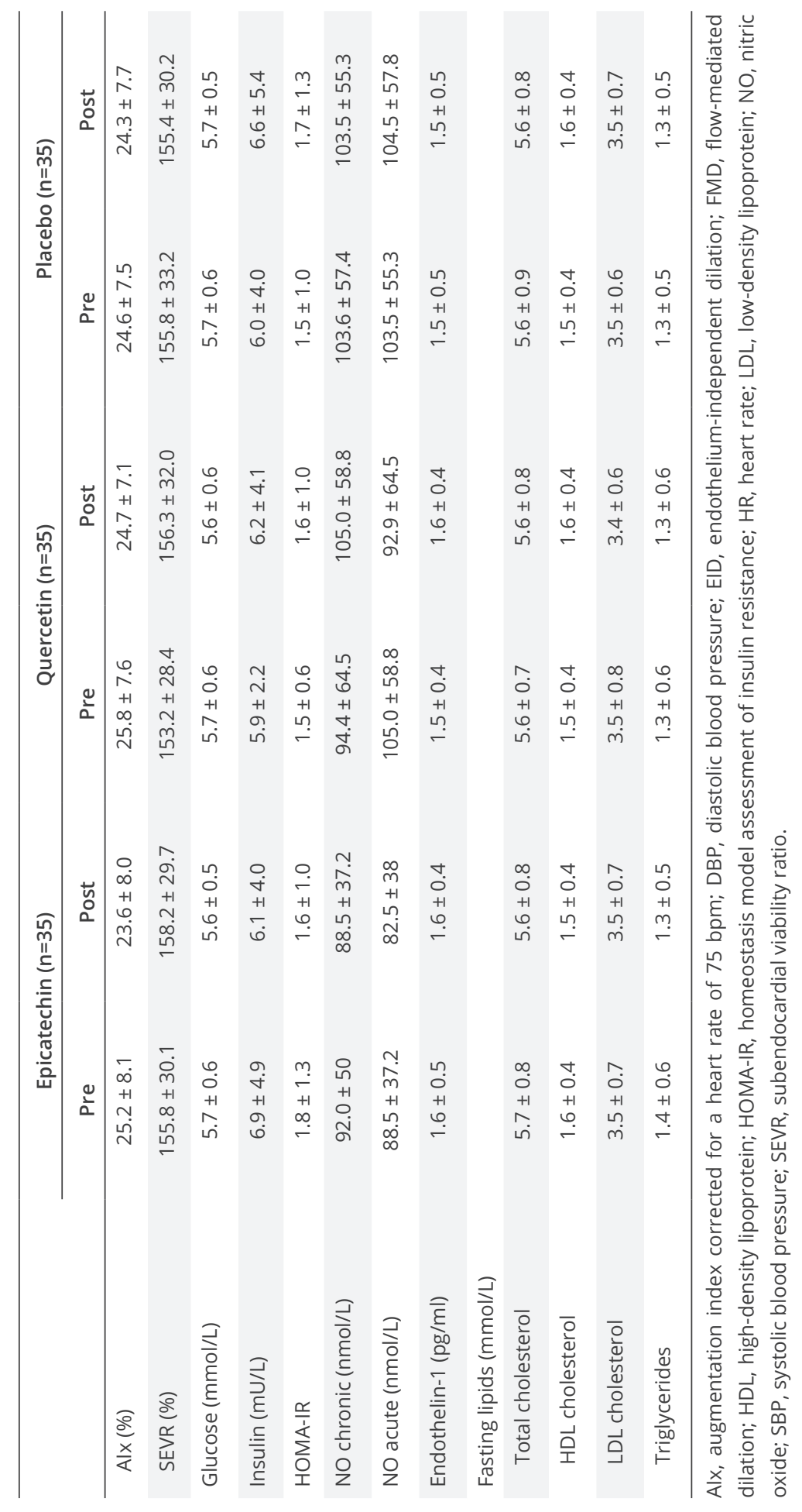


SUPPLEMENTAL TABLE 2. Baseline characteristics of study population by treatment group. Of the 37 subjects, 35 completed the epicatechin, 35 the quercetin and 35 the placebo intervention, due to dropouts.

\begin{tabular}{lcc}
\hline & $\begin{array}{c}\text { Subjects in epicatechin } \\
\text { group }(\mathrm{n}=35)\end{array}$ & $\begin{array}{c}\text { Subjects in quercetin group } \\
(\mathrm{n}=35)\end{array}$ \\
\hline Men/women & $23 / 12$ & $23 / 12$ \\
Age (yrs) & $65.9 \pm 7.9$ & $66.0 \pm 7.9$ \\
BMI (kg/m²) & $26.6 \pm 3.4$ & $26.6 \pm 3.3$ \\
Systolic BP (mmHg) & $129.4 \pm 14.5$ & $129.2 \pm 14.2$ \\
Diastolic BP (mmHg) & $75.0 \pm 9.8$ & $74.7 \pm 10.04$ \\
Pulse Wave Velocity (m/s) & $12.8 \pm 1.9$ & $12.9 \pm 1.9$ \\
Augmentation Index (\%) & $25.8 \pm 7.9$ & $26.0 \pm 7.9$ \\
Plasma glucose (mmol/L) & $5.70 \pm 0.67$ & $5.69 \pm 0.66$ \\
Serum insulin (mU/L) & $6.14 \pm 3.85$ & $6.09 \pm 3.87$ \\
HOMA-IR & $1.58 \pm 0.99$ & $1.56 \pm 1.00$ \\
Fasting serum lipids (mmol/L) & & \\
Total cholesterol & $1.30 \pm 0.57$ & $5.57 \pm 0.85$ \\
LDL cholesterol & & $3.43 \pm 0.75$ \\
HDL cholesterol & $5.65 \pm 0.89$ & $1.55 \pm 0.42$ \\
Triglycerides & $3.49 \pm 0.79$ & $1.29 \pm 0.57$ \\
\hline
\end{tabular}

Data are given as mean \pm SD.

Abbreviations: $\mathrm{BMI}=$ body mass index; $\mathrm{BP}=$ blood pressure; $\mathrm{HOMA}-\mathrm{IR}=$ homeostasis model assessment of insulin resistance; $\mathrm{HDL}$ = high-density lipoprotein; $L D L=$ low-density lipoprotein. 


\section{SUPPLEMENTAL MATERIAL 1.}

Flavonoid isolation and purification process

ChromaDex (Irvine, CA, USA) developed procedures to isolate and purify (-)-epicatechin and quercetin-3-glucoside. (-)-Epicatechin was extracted from Acacia heart wood with aqueous alcohol. The crude extract was purified by preparative chromatography, followed by repeated fractional crystallisation from water. Rutin was extracted from Uncaria elliptica leaves with aqueous alcohol, followed by partial acid hydrolysis to give quercetin-3-O- $\beta$ D-glucoside, which was purified on activated charcoal. All solvents and equipment used were food grade. Identity was confirmed using NMR and MS. Purity was checked by HPLC, and was $96.2 \%$ for (-)-epicatechin (water $0.3 \%$ ) and $93.2 \%$ for quercetin-3-O- $\beta$-D-glucoside (water 4.0\%). Supplements were encapsulated in non-transparent capsules which were matched for size and colour, using microcrystalline cellulose as an excipient and 1\% colloidal siliciumdioxide. Variation in contents was within 3.7\% (SD/mean*100\%) for epicatechin and $5.7 \%$ for quercetin. Placebo capsules contained microcrystalline cellulose. 


\section{SUPPLEMENTAL MATERIAL 2.}

Letter to the editor from Schroeter et al. and reply

\section{Is this the end of (-)-epicatechin, or not? New study highlights the complex challen- ges associated with research into the cardiovascular health benefits of bioactive food constituents}

Hagen Schroeter; Carl L Keen; Howard D Sesso; Joann E Manson; Joanne R Lupton

\section{Dear Editor:}

A considerable body of evidence supports the beneficial effects of dietary flavanols in relation to cardiovascular health, and the data for cocoa flavanols are particularly extensive and consistent. In addition to the reported results of individual studies, cocoa flavanolrelated health benefits also have been substantiated by a Cochrane Review [1], as well as by a scientific consensus statement resulting in a European Food Safety Authority health claim [2]. However, it is important to consider that the compound classes of flavanols and procyanidins include a variety of chemically distinct bioactives, one of which, (-)-epicatechin, has been identified as one of the bioactive flavonoid constituents of cocoa [3]. Although food matrix properties and other constituents present in flavanol-containing foods are likely to contribute to, or modulate, the effects of (-)-epicatechin by affecting its bioactivity and/or bioavailability, we agree with Dower et al. [4] in a recent article in the Journal that it is important to investigate individual bioactives and to rigorously test on a larger scale the validity of previous findings. In their article, Dower et al. [4] investigated the effects of "pure epicatechin" in a controlled, double-masked, crossover study in humans and concluded that although (-)-epicatechin intake did not significantly increase flow-mediated arterial dilation (FMD; primary endpoint) or decrease blood pressure, it did have a significant beneficial effect on insulin resistance (secondary endpoint).

In an Editorial in the Journal that accompanied the Dower et al. article, Scalbert and Zamoras-Ros [5] emphasized that, "In contrast to the negative results observed on CVD [cardiovascular disease] markers, Dower et al. also observed a decrease in fasting plasma insulin...." We are concerned that the authors represent effects that are not statistically significant as "negative results" and that their interpretation does not distinguish between the primary endpoint the study was prospectively powered for, from outcomes representing secondary endpoints. So should the data by Dower et al. put to rest the idea that (-)-epicatechin represents a bioactive food constituent with cardiovascular health benefits? In other words, how rigorous are the data, what are the limitations of their interpretation, and how high is the risk of a false negative result? According to Dower et al. [4], "A 1\% increase in FMD would be clinically relevant, because at a population level, a $1 \%$ increase in FMD is associated with a $13 \%$ lower risk of a cardiovascular event." We 
fully agree with the statement and the reference provided in its support. Dower et al. reported that they observed an (-)-epicatechin intake-related increase in FMD of 1.1\%, an outcome that did not reach statistical significance ( $p=0.07$; Table 2 in their article), because a hypothesized $1.3 \%$ change in FMD was the basis for their power calculation. Although we agree with the conclusion by Dower et al. that the statistical evaluation of their data disproves their hypothesis, we submit that drawing general conclusions from this work requires a careful consideration of all study limitations, including the question of sufficient statistical power in the context of a diverse study population. We appreciate the technical challenges of detecting a comparatively small change in FMD in healthy individuals in the context of a dietary intervention study of this scale. Although technical considerations are often overlooked and unappreciated, they can have a considerable impact on outcomes and final interpretations. One of the challenges encountered by Dower et al. [4] was the relatively large heterogeneity of their study population, especially considering the small total number of participants. The study population ranged in age from 48 to $79 \mathrm{y}$ and in BMI (in kg/m2) from 20 to 35, and although the average systolic/diastolic blood pressure was $129 / 75 \mathrm{~mm} \mathrm{Hg}$, 22\% of participants would be considered as hypertensive. These characteristics, which will very likely also result in a high inter-individual variability in the primary endpoint of FMD, can represent a considerable challenge with regard to detecting small effect sizes. Moreover, the overall health status of the study population is an important consideration, especially when investigating the effects of a bioactive such as (-)-epicatechin in the context of health and nutrition. Although Dower et al. aimed at recruiting healthy individuals, the reported intervention-independent occurrence of 1 myocardial infarction and 1 fatal stroke, as well as the $22 \%$ prevalence of hypertension in the overall study population, indicates significant heterogeneity in vascular disease risk factor status. Further complicating the interpretation of the study, the primary endpoint of FMD was assessed with the use of a less-than-ideal methodology. Harris et al. [6], among others, demonstrated that an ultrasound transducer of $10-14 \mathrm{MHz}$ is needed to optimally image superficial vessels. Dower et al. [4] used a 7.5 MHz transducer, which can result in significant interassay variations that may have contributed to the $2.7 \%$ SD of FMD measurements observed in their study. This may also explain why $11 \%$ of FMD recordings were removed from the analysis. We also have some concerns regarding the level of compliance in the study by Dower et al. Assuming that 5-20\% of dietary (-)-epicatechin is thought to be excreted in urine over $24 \mathrm{~h} \mathrm{[7],5-20} \mathrm{mg} \mathrm{of} \mathrm{(-)-epicatechin} \mathrm{equivalents} \mathrm{should}$ have been detected in urine. Conservatively assuming a diuresis of $3 \mathrm{~L} / \mathrm{d}$, the concentration of (-)-epicatechin equivalents detected in urine should have been between 5 and $20 \mathrm{M}$, i.e., between 20 and 80 times higher than the limit of detection reported by Dower et al. Because $49 \%$ of urine samples were reported below the limit of detection, these results would suggest an analytic problem, or a problem with compliance, which would greatly affect any outcomes assessment. 
Taken together, the low statistical power, heterogeneity of the study populationparticularly with respect to cardiovascular disease risk factor status-questions regarding compliance, and the proficiency in assessing the primary endpoint of FMD each represent limitations that need to be taken into account when interpreting the final outcomes presented by Dower et al., and, more generally, when investigating clinically meaningful effect sizes in small study populations. Consequently, although important and timely, we submit that the data by Dower et al. do not represent strong evidence for or against the bioactivity of (-)-epicatechin in the context of cardiovascular health. Further research in this area, including large-scale randomized trials with clinical event outcomes, is needed to better define the potential health benefits of (-)-epicatechin. 


\section{REFERENCES}

1. Ried K, Sullivan TR, Fakler P, Frank OR, Stocks NP. Effect of cocoa on blood pressure. Cochrane Database Syst Rev 2012;8:CD008893.

2. EFSA Panel on Dietetic Products. Nutrition and allergies. Scientific opinion on the substantiation of a health claim related to cocoa flavanols and maintenance of normal endothelium-dependent vasodilation pursuant to Article 13(5) of Regulation (EC) No 1924/2006. EFSA J 2012;10:2809.

3. Schroeter H, Heiss C, Balzer J, Kleinbongard P, Keen CL, Hollenberg NK, Sies H, Kwik-Uribe C, Schmitz HH, Kelm M. (-)-Epicatechin mediates beneficial effects of flavanol-rich cocoa on vascular function in humans. Proc Natl Acad Sci USA 2006;103:1024-9.

4. Dower JI, Geleijnse JM, Gijsbers L, Zock PL, Kromhout D, Hollman P. Effects of the pure flavonoids epicatechin and quercetin on vascular function and cardiometabolic health: a randomized, double-blind, placebo-controlled, crossover trial. Am J Clin Nutr 2015;101:914-21.

5. Scalbert A, Zamora-Ros R. Bridging evidence from observational and intervention studies to identify flavonoids most protective for human health. Am J Clin Nutr 2015;101:897-8.

6. Harris RA, Nishiyama SK, Wray DW, Richardson RS. Ultrasound assessment of flow-mediated dilation. Hypertension 2010;55:1075-85.

7. Clifford MN, van der HooftJJ, Crozier A. Human studies on the absorption, distribution, metabolism, and excretion of tea polyphenols. Am J Clin Nutr 2013;98(6 Suppl):1619S-30S. 


\section{REPLY TO H SCHROETER ET AL.}

James I Dower; Johanna M Geleijnse; Daan Kromhout and Peter CH Hollman

Dear Editor:

In their letter, Schroeter et al. raise a number of interesting issues on which we would like to comment. In our study, we found that daily supplementation with $100 \mathrm{mg}$ of "pure epicatechin" (quotes by Schroeter et al., but purity was $>96 \%$ !) increased flow-mediated dilation (FMD) by $1.1 \%$. Although this effect was not statistically significant, we agree with Schroeter et al. that this effect, judged in the context of the total evidence, is of clinical interest.

Schroeter et al. suggest that the variation in age, BMI, and blood pressure in our study population contributes to a large inter-individual variability in FMD, thereby reducing statistical power. However, the effects of cocoa consumption on FMD have been reported in studies with similar populations, often with smaller sample sizes. For example, Grassi et al. [1] showed that cocoa dose-dependently improved FMD in 20 participants (crossover design) aged 18-70 y with a BMI (in $\mathrm{kg} / \mathrm{m}^{2}$ ) between 19 and 30 and blood pressure,140/90 $\mathrm{mm} \mathrm{Hg}$. Similar results were obtained by Davison et al. [2] with 25 overweight/obese participants (parallel design) with a blood pressure ,160/100 $\mathrm{mm} \mathrm{Hg}$. In addition, the effects of high flavan-3-ol cocoa extracts on FMD were similar in young ( $<35 \mathrm{y})$ and elderly (50-80 y) men [3]. Furthermore, we are not aware of published data reporting that health status modifies the vascular effects of cocoa. We therefore do not consider the heterogeneity of our study population to be a major problem.

Schroeter et al. also pointed out that an ultrasound transducer of $10-14 \mathrm{MHz}$ is required to adequately measure FMD, whereas we used an ultrasound transducer of $7.5 \mathrm{MHz}$. Two commonly used guidelines state that a linear array transducer with a minimum frequency of 7-7.5 MHz is required for FMD measurement $[4,5]$. Furthermore, previous studies with the use of a 7.0-MHz transducer have shown improvements in FMD after cocoa consumption $[6,7]$.

In their letter, Schroeter et al. also raised concerns about compliance. We checked compliance based on diary entries and returned capsules, as well as biomarkers. More than $98 \%$ of capsules distributed were ingested, and all subjects (excluding dropouts) ingested at least $80 \%$ during each intervention, which proves adequate compliance. Urine samples were collected as an additional objective measure of compliance. The low urinary epicatechin excretion is very likely caused by poor deconjugation of the aryl-sulfatases used in the analysis [8], which will have a high impact because epicatechin sulfates account for $>90 \%$ of urinary metabolites [9]. Nevertheless, differences between epicatechin and 
placebo support compliance. Taken as a whole, based on returned capsules, diary entries, and an increase in urinary epicatechin, we are confident that we achieved a high level of compliance.

In conclusion, we thank Schroeter et al. for their comments and agree that evidence of the effects of epicatechin on vascular function is still limited. More and larger trials with pure epicatechin are needed to unravel the potential role of epicatechin on the cardiometabolic effects of cocoa. None of the authors had a conflict of interest with the content of this letter. 


\section{REFERENCES}

1. Grassi $D$, Desideri G, Necozione S, et al. Cocoa consumption dose-dependently improves flowmediated dilation and arterial stiffness decreasing blood pressure in healthy individuals. J Hypertens. 2015;33:294-303.

2. Davison K, Coates AM, Buckley JD, Howe PRC. Effect of cocoa flavanols and exercise on cardiometabolic risk factors in overweight and obese subjects. Int J Obes (Lond). 2008;32: 1289-1296.

3. Heiss $\mathrm{C}$, Sansone R, Karimi $\mathrm{H}$, et al. Impact of cocoa flavanol intake on age-dependent vascular stiffness in healthy men: a randomized, controlled, double- masked trial. Age (Dordr). 2015;37:9794.

4. Corretti MC, Anderson TJ, Benjamin EJ, et al. Guidelines for the ultrasound assessment of endothelial-dependent flowmediated vasodilation of the brachial artery: A report of the international brachial artery reactivity task force. J Am Coll Cardiol. 2002;39:257-265.

5. Thijssen DHJ, Black MA, Pyke KE, et al. Assessment of flow-mediated dilation in humans: A methodological and physiological guideline. Am J Physiol Heart Circ Physiol. 2011;300:H2-12.

6. Grassi D, Desideri G, Necozione S, et al. Blood pressure is reduced and insulin sensitivity increased in glucose-intolerant, hypertensive subjects after 15 days of consuming high-polyphenol dark chocolate. J Nutr. 2008;138:1671-1676.

7. Grassi D, Necozione S, Lippi C, et al. Cocoa reduces blood pressure and insulin resistance and improves endothelium-dependent vasodilation in hypertensives. Hypertension. 2005;46:398-405.

8. Saha S, Hollands W, Needs PW, et al. Human O-sulfated metabolites of (-)-epicatechin and methyl(-)-epicatechin are poor substrates for commercial aryl-sulfatases: Implications for studies concerned with quantifying epicatechin bioavailability. Pharmacol Res. 2012;65:592-602.

9. Stalmach A, Mullen W, Steiling H, Williamson G, Lean MEJ, Crozier A. Absorption, metabolism, and excretion of green tea flavan-3-ols in humans with an ileostomy. Mol Nutr Food Res. 2010;54:323334. 


Supplementation of the Pure Flavonoids Epicatechin and Quercetin Affects Some Biomarkers of Endothelial Dysfunction and Inflammation in (Pre)Hypertensive Adults: A Randomised Double-Blind, Placebo-Controlled, Crossover Trial

James I Dower

Johanna M Geleijnse

Lieke Gijsbers

Casper Schalkwijk

Daan Kromhout

Peter C Hollman 


\section{ABSTRACT}

\section{Background}

Consumption of flavonoid-rich foods such as cocoa and tea may reduce cardiovascular disease risk. The flavonoids epicatechin (in cocoa and tea) and quercetin (in tea) probably play a role by reducing endothelial dysfunction and inflammation, two main determinants of atherosclerosis. We aimed to study the effects of supplementation of pure epicatechin and quercetin on biomarkers of endothelial dysfunction and inflammation.

\section{Methods}

Thirty-seven apparently healthy (pre)hypertensive men and women (40-80 years) participated in a randomised, double-blind, placebo-controlled crossover trial. Participants ingested (-)-epicatechin (100 mg/d), quercetin-3-glucoside (160 mg/d), or placebo capsules for a period of four weeks, in random order. Plasma biomarkers of endothelial dysfunction and inflammation were measured at the start and end of each four-week intervention period. The differences in changes over time between the intervention and placebo periods ( $\Delta$ intervention - $\Delta$ placebo) were calculated and tested with a linear mixed model for repeated measures.

\section{Results}

Epicatechin supplementation decreased soluble endothelial selectin (sE-selectin) by 7.7 ng/mL (95\% Cl: 14.5, 0.83; P=0.03), when compared to placebo ( $\Delta$ epicatechin - $\Delta$ placebo). Epicatechin did not significantly change the $z$-score for endothelial dysfunction $(-0.30$; 95\% Cl: $-0.61,0.01 ; P=0.06)$. Quercetin lowered sE-selectin by $-7.4 \mathrm{ng} / \mathrm{mL}$ (95\% Cl: -14.3 , $-0.56 ; \mathrm{P}=0.03), \mathrm{IL}-1 \beta$ by $-0.23 \mathrm{pg} / \mathrm{mL}(95 \% \mathrm{Cl}:-0.40,-0.06 ; \mathrm{P}=0.009)$, and the $z$-score for inflammation by $-0.33(95 \% \mathrm{Cl}:-0.60,-0.05 ; \mathrm{P}=0.02)$, when compared to placebo.

\section{Conclusions}

In (pre)hypertensive men and women, epicatechin may contribute to the cardioprotective effects of cocoa and tea through improvements in endothelial function. Quercetin may contribute to the cardioprotective effects of tea by improving endothelial function and reducing inflammation. This trial was registered at clinicaltrials.gov as NCT01691404. 


\section{INTRODUCTION}

Flavonoids (a subclass of polyphenols) are structurally related secondary metabolites that are ubiquitous in plant foods. Consumption of flavonoid-rich foods such as cocoa and tea are associated with a lower risk of cardiovascular disease (CVD). Data from 7 studies ( $n=$ $114,009)$ showed that the risk of CVD was $37 \%$ lower in subjects with the highest amount of chocolate consumption [1]. Likewise, data from 9 studies ( $n=194,965)$ showed a $21 \%$ lower risk of stroke for subjects who consumed $3 \mathrm{cups} / \mathrm{d}$ of tea than for subjects who consumed $<1$ cup/d [2]. It is suggested that the beneficial effects of flavonoid-rich foods are mediated through reduction of endothelial dysfunction and inflammation which are important early steps in the pathogenesis of atherosclerosis [3-5].

Atherosclerosis is characterised by the accumulation of lipids and fibrous elements in large arteries and is one of the main contributors to CVD [6]. At sites of inflammation, activated endothelial cells release cytokines such as TNF-a, C-reactive protein (CRP), and IL-1 $\beta$, IL-6, and IL-8. In response to these cytokines, adhesion molecules such as soluble endothelial selectin (sE-selectin), soluble vascular cell adhesion molecule-1 (sVCAM-1), soluble intercellular adhesion molecule-1 (sICAM-1), and von Willebrand factor (vWf) are synthesized by endothelial cells and induce adhesion of leukocytes to the endothelium. After adhesion, monocyte chemoattractant protein-1 (MCP-1) induces the transendothelial migration of monocytes into the intima [7]. Once in the intima, monocytes take on the role and properties of macrophages as they scavenge oxidized LDL, form foam cells, and cause fatty streaks and fibrous plaques, leading to atherosclerosis. Indeed, studies have shown that biomarkers of inflammation (e.g. CRP, TNF-a, and IL-6) and endothelial dysfunction (e.g. sVCAM-1, sICAM-1, and sE-selectin) are predictors of CVD risk [8-10].

A limited number of human intervention studies with a duration of 2-6 weeks investigated the effects of flavonoid-rich foods, such as cocoa and tea, on biomarkers of endothelial dysfunction and inflammation. Consuming a high flavan-3-ol (the flavonoid subclass of epicatechin) cocoa beverage decreased plasma concentrations of sVCAM-1 by $11 \%$ [11] but did not change sICAM-1. In contrast, consuming $40 \mathrm{~g}$ of cocoa decreased serum concentrations of sICAM-1 by $10 \%$ but did not change SVCAM-1 or markers of inflammation, including IL-6 and high-sensitivity CRP [12]. Similarly, consumption of dark chocolate and a cocoa drink had no effect on IL-1 $\beta$, IL-6, high-sensitivity CRP, and TNF- $\alpha$ [13]. For black tea, Hodgson et al. [14] found that consumption of 5 cups/d (1 cup $=250$ $\mathrm{mL}$ ) had no effect on the adhesion molecules E-selectin, P-selectin, SICAM-1, and SVCAM-1, which was confirmed by Steptoe et al. [15] for P-selectin. Only one tea intervention studied the effect on MCP-1 and found a decrease of 19\% [16]. A reduction in CRP of $27 \%-47 \%$ was found in two tea interventions $[15,16]$, whereas another did not find an effect on CRP, IL$1 \beta$, IL-6, or TNF-a [17]. 
Until now, human intervention studies have only investigated the effects of flavonoidrich foods such as cocoa and tea on a limited number of biomarkers of inflammation and endothelial dysfunction. These foods are complex mixtures of flavonoids and other substances. To unravel the role of individual flavonoids, pure flavonoids should be studied. Cocoa and tea are rich dietary sources of epicatechin, whereas tea is the main dietary source of quercetin $[18,19]$. For this reason, we hypothesised that epicatechin and quercetin are responsible for the cardioprotective effects of cocoa and tea. The aim of the present study was to investigate whether pure (-)-epicatechin and quercetin could account for the beneficial effects of cocoa/chocolate and tea on inflammation and endothelial function. This was done for the first time, by measuring a comprehensive set of biomarkers of these two functions in a double-blind, placebo-controlled, crossover study in 37 healthy (pre)hypertensive adults who ingested supplements with pure isolated (-)-epicatechin, quercetin-3-glucoside, or placebo daily for periods of 4 weeks.

\section{METHODS}

\section{Study Design}

The study was conducted as a 3-armed, randomised, double-blind, placebo-controlled, crossover study as described previously [20]. In brief, 37 apparently healthy non-smoking men and women between the ages of 40 and 80 years with a BMI (in $\mathrm{kg} / \mathrm{m}^{2}$ ) between 20 and 40 and systolic blood pressure between 125 and $160 \mathrm{~mm} \mathrm{Hg}$ took part in the study. Excluded from participation were subjects with chronic diseases, users of medication, users of prescribed diet, and pregnant or lactating women [20].

Participants ingested equimolecular amounts of (-)-epicatechin $(100 \mathrm{mg} / \mathrm{d}=345 \mu \mathrm{mol} / \mathrm{d})$ and quercetin-3-glucoside (160 mg/d = $345 \mu \mathrm{mol} / \mathrm{d}$ ) and placebo capsules for periods of 4 weeks, in random order, separated by 4-week washout periods. The dosage of epicatechin chosen was in line with the amount of epicatechin present in previous cocoa/chocolate intervention studies (46-107 mg/d) [21-24]. For quercetin an equimolecular dose was chosen. In The Netherlands, the habitual intake of epicatechin is $11 \mathrm{mg} / \mathrm{d}$ and of quercetin is $16 \mathrm{mg} / \mathrm{d}$ [20]. Subjects were asked to avoid consumption of flavonoid-rich foods (cocoa, tea, apples, onion, and red wine) during the study. They consumed a standardised lowflavonoid meal (boiled potato with a meatball and spinach) the evening before each measurement day. Fasted blood samples were collected at the research centre at the start and end of each intervention period. All participants provided written consent before the start of the study. The study was approved by the Medical Ethics Committee of Wageningen University (NL 40772.081.12), and informed consent of all participants was obtained. The trial was registered at clinicaltrials.gov as NCT01691404. 


\section{Biomarkers of Endothelial Dysfunction and Inflammation}

Serum biomarkers of endothelial dysfunction (SICAM-1, sVCAM-1, sE-selectin, and MCP-1) and inflammation [CRP, serum amyloid A (SAA), TNF- $\alpha$, IL-1 $\beta$, IL-6, IL-8, and sICAM-1] were assessed by an electrochemiluminescence detection system and $\mathrm{VWf}$ by ELISA, as described previously [25]. The interassay CVs ranged from $1.8 \%$ to $11.1 \%$ for all biomarkers.

Individual z-scores were calculated for each biomarker using the following formula: (individual value - population mean)/population SD. Overall z-scores were calculated by averaging the individual z-scores according to clusters of biomarkers for endothelial dysfunction and inflammation [26, 27]. The endothelial dysfunction cluster consisted of sICAM-1, SVCAM-1, sE-selectin, vWf, and MCP-1. The inflammation cluster consisted of TNF-a, CRP, SAA, IL-1 $\beta$, IL-6, IL-8, and SICAM-1.

\section{Statistical Analysis}

Statistical analyses were performed according to a pre-defined analysis plan using SAS 9.2 (SAS Institute). Baseline variables were checked for normality of distribution and were expressed as mean \pm SD for normally distributed variables and median with IQRS for skewed variables. The difference between the change during each 4-week treatment period and the change during the 4-week placebo period was calculated. This difference ( $\Delta$ treatment - $\Delta$ placebo) was defined as the treatment effect of epicatechin and quercetin, and was statistically tested. Treatment effects were checked for normality of distribution, and all variables were considered to be normally distributed. A linear mixed model for repeated measures (SAS, PROC MIXED) was used to test the treatment effects. Treatment and period were set as fixed effects and subject was set as random effect. Compound symmetry was used as covariant structure because this resulted in the best fit according to a likelihood ratio test. No clear carryover effect was apparent; therefore, previous treatment was not included in the model. Treatment effects are expressed as least squares mean with $95 \% \mathrm{Cls}$. Statistical significance was set at a 2-sided a-level of 0.05 . Effects of outliers were checked by performing additional analyses after removal of outliers $>5$ times the SD from the mean. This resulted in the removal of one outlier for MCP-1, VWf, IL-1 $\beta$, IL-6, IL-8, TNF-a, and CRP and two outliers for SAA, distributed over 7 subjects. 


\section{RESULTS}

Of the 37 subjects who participated in the study, 4 subjects did not complete all 3 interventions [20]. These dropouts occurred at different points in the study, meaning that 35 completed the epicatechin intervention, 35 the quercetin intervention, and 35 the placebo intervention. At the start of the study, the mean age of the study population was $66.4 \pm$ 7.9 years. The average blood pressure (systolic blood pressure/diastolic blood pressure) was 129/75 mm Hg, and 23 subjects (62\%) had a BMI > $25 \mathrm{~kg} / \mathrm{m}^{2}$ (Table 1). Body weight remained stable throughout the study period (mean change body weight: $0.2 \pm 1.3 \mathrm{~kg}$ ).

The treatment effect of epicatechin supplementation ( $\Delta$ epicatechin - $\Delta$ placebo) was a significant decrease of plasma sE-selectin by $7.7 \mathrm{ng} / \mathrm{mL}(95 \% \mathrm{Cl}: 14.5,0.83 ; \mathrm{p}=0.03$ ) (Table 2). The magnitude of this effect equalled $10 \%$ of the baseline value (Table 1 ). All other markers of endothelial dysfunction did not change significantly. Epicatechin supplementation did not significantly change the z-score for endothelial dysfunction biomarkers $(\Delta=-0.30 ; 95 \%$ $\mathrm{Cl}$ : $-0.61,0.01 ; \mathrm{p}=0.06$ ). Epicatechin had no significant effect on markers of inflammation or the z-score for inflammation.

The treatment effect of quercetin supplementation ( $\Delta$ quercetin - $\Delta$ placebo) was a significant decrease of plasma sE-selectin by $7.4 \mathrm{ng} / \mathrm{mL}(95 \% \mathrm{Cl}$ : 14.3, 0.56; $\mathrm{p}=0.03$ ) (Table 2). The magnitude of this effect equalled $10 \%$ of the baseline value (Table 1). No other changes in markers of endothelial dysfunction or the z-score for endothelial dysfunction were seen. Quercetin significantly decreased ( $\Delta$ quercetin - $\Delta$ placebo) IL-1 $\beta$ by $0.23 \mathrm{pg} / \mathrm{mL}$ (95\% Cl: 0.40, 0.06; $p=0.009$ ) (Table 2). The magnitude of this effect equalled $29 \%$ of the baseline value (Table 1). All other markers of inflammation did not change significantly. However, quercetin supplementation significantly lowered the z-score for biomarkers of inflammation ( $\Delta=0.33 ; 95 \% \mathrm{Cl}: 0.60,0.05 ; \mathrm{p}=0.02$ ), when compared to placebo. Removal of outliers did not change these effects, with the exception of vWf that decreased by $22.6 \%$ absolute (95\% Cl: 40.1, 5.0; $\mathrm{p}=0.01)$ after epicatechin supplementation once the outlier was removed. 
TABLE 1. Baseline characteristics of study population ${ }^{1}$

\begin{tabular}{lc}
\hline Characteristic & Value \\
\hline $\mathrm{n}$, male/female & $37,25 / 12$ \\
Age, yrs & $66.4 \pm 7.9$ \\
Body mass index, kg/m² & $26.7 \pm 3.3$ \\
Systolic blood pressure, mmHg & $129.3 \pm 14.1$ \\
Diastolic blood pressure, mmHg & $74.8 \pm 9.8$ \\
IL-1ß, pg/mL & $0.78(0.50-1.26)$ \\
IL-6, pg/mL & $2.5(1.8-4.7)$ \\
IL-8, pg/mL & $5.3(4.7-6.8)$ \\
TNF-a, pg/mL & $7.1(6.5-9.1)$ \\
CRP, $\mu$ g/mL & $0.97(0.52-2.32)$ \\
SAA, $\mu$ g/mL & $2.4(1.6-5.4)$ \\
sVCAM-1, ng/mL & $427(359-477)$ \\
sICAM-1, ng/mL & $264(242-291)$ \\
sE-selectin, ng/mL & $73.6(60.3-119)$ \\
vWf, \% & $144(105-181)$ \\
MCP-1, pg/mL & $284(247-327)$ \\
\hline
\end{tabular}

${ }^{1}$ Data are given as mean \pm SD and median (IQR).

Biomarkers of endothelial dysfunction and inflammation were determined in fasting plasma samples. Abbreviations: $\mathrm{CRP}=\mathrm{C}$-reactive protein; IL = interleukin; $\mathrm{MCP}-1$ = monocyte chemotactic protein-1; $\mathrm{SAA}=$ serum amyloid $\mathrm{A}$; sICAM-1 =soluble intercellular adhesion molecule- 1 ; sE-selectin = soluble endothelial selectin; sVCAM-1 = soluble vascular cell adhesion molecule-1; TNF- $a=$ tumor necrosis factor-a; $v W f=$ von Willebrand factor. 


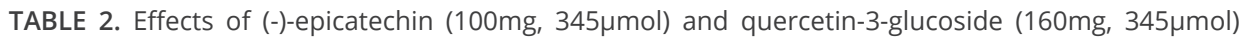
supplementation on markers of endothelial dysfunction and inflammation in (pre)hypertensive subjects $(n=35) .1$

\begin{tabular}{|c|c|c|c|c|}
\hline & \multicolumn{2}{|c|}{ (-)-Epicatechin } & \multicolumn{2}{|c|}{ Quercetin-3-glucoside } \\
\hline & $\begin{array}{l}\text { Treatment effect } \\
\qquad(95 \% \mathrm{CI})^{2}\end{array}$ & $P$-value ${ }^{3}$ & $\begin{array}{l}\text { Treatment effect } \\
(95 \% \mathrm{Cl})^{2}\end{array}$ & $P$-value ${ }^{3}$ \\
\hline \multicolumn{5}{|c|}{$\begin{array}{l}\text { Markers of endothelial } \\
\text { dysfunction }\end{array}$} \\
\hline sVCAM-1, ng/mL & $-10(-58,37)$ & 0.66 & $5(-42,52)$ & 0.84 \\
\hline sICAM-1, ng/mL & $-11(-28,4.7)$ & 0.16 & $-6(-22,10)$ & 0.47 \\
\hline sE-selectin, ng/mL & $-7.7(-14.5,-0.83)$ & 0.03 & $-7.4(-14.3,-0.56)$ & 0.03 \\
\hline vWf, \% & $-15(-37,8)$ & 0.19 & $-2(-25,20)$ & 0.84 \\
\hline MCP-1, pg/mL & $-28(-77,22)$ & 0.27 & $-39(-88,11)$ & 0.12 \\
\hline Z-score & $-0.30(-0.61,0.01)$ & 0.06 & $-0.20(-0.52,0.11)$ & 0.20 \\
\hline \multicolumn{5}{|c|}{ Markers of inflammation } \\
\hline $\mathrm{IL}-1 \beta, \mathrm{pg} / \mathrm{mL}$ & $-0.07(-0.24,0.10)$ & 0.42 & $-0.23(-0.40,-0.06)$ & 0.009 \\
\hline $\mathrm{IL}-6, \mathrm{pg} / \mathrm{mL}$ & $0.13(-0.92,1.17)$ & 0.81 & $-0.31(-1.35,0.74)$ & 0.56 \\
\hline IL-8, pg/mL & $-1.1(-3.4,1.2)$ & 0.35 & $-1.5(-3.8,0.8)$ & 0.19 \\
\hline TNF-a, pg/mL & $-0.09(-0.84,0.66)$ & 0.81 & $-0.48(-1.23,0.27)$ & 0.20 \\
\hline $\mathrm{CRP}, \mu \mathrm{g} / \mathrm{mL}$ & $-1.3(-6.0,3.3)$ & 0.57 & $-0.90(-5.5,3.7)$ & 0.70 \\
\hline $\mathrm{SAA}, \mu \mathrm{g} / \mathrm{mL}$ & $-6.4(-21.1,8.2)$ & 0.38 & $-8.7(-23.4,6.0)$ & 0.24 \\
\hline Z-score & $-0.12(-0.39,0.16)$ & 0.40 & $-0.33(-0.60,-0.05)$ & 0.02 \\
\hline
\end{tabular}

${ }^{1}$ All biomarkers were determined in fasting plasma samples.

${ }^{2}$ Data are least square means $(95 \% \mathrm{Cl})$ from linear mixed model for repeated measures with compound symmetry as covariant structure. Treatment effect $=(\Delta$ treatment $)-(\Delta$ placebo $)$.

${ }^{3} \mathrm{P}$-value for treatment effect.

Abbreviations: $C R P=$ C-reactive protein; IL = interleukin; MCP-1 = monocyte chemotactic protein-1; $\mathrm{SAA}=$ serum amyloid $\mathrm{A} ;$ sICAM-1 =soluble intercellular adhesion molecule-1; $\mathrm{sE}$-selectin = soluble endothelial selectin; sVCAM-1 = soluble vascular cell adhesion molecule-1; TNF- $a=$ tumor necrosis factor-a; vWf = von Willebrand factor. 


\section{DISCUSSION}

In this randomised crossover study of 37 healthy (pre)hypertensive adults, supplementation of pure epicatechin decreased sE-selectin. All other markers for endothelial dysfunction, including the z-score, did not change significantly. Supplementation of pure quercetin significantly decreased sE-selectin and IL-1 $\beta$ and the z-score for inflammation. These data suggest that the cardiometabolic effects of quercetin and epicatechin only partly overlap, which may distinguish the effects of cocoa and tea.

When assessing markers of inflammation and endothelial dysfunction, it is important to consider within-subject biological variation [28]. To minimize within-subject variation, we designed a crossover study that used a rather strict study protocol. Subjects avoided consumption of flavonoid-rich foods throughout the study and also consumed a standardised low-flavonoid meal the evening before each measurement day. To reduce diurnal variation [29], blood samples were taken at the same time of day. Despite these precautions, a large biological variation in markers of inflammation and endothelial dysfunction is evident from wide confidence intervals. Baseline values and variation of markers of inflammation and endothelial dysfunction were, however, similar to values reported in a study with younger Dutch adults $(n=293)$ that used the same analytical methods [30]. Another strength of our study was the high compliance, because $>98 \%$ of capsules distributed were consumed. In addition, increases in plasma epicatechin and quercetin concentrations due to supplementation also showed that the flavonoids in the capsules were absorbed [20].

Because of the number of biomarkers $(n=11)$ measured, we cannot exclude the possibility of a false-positive finding. Nevertheless, we did not correct for multiple testing because these markers are mutually dependent, and correction may hide a true effect. With the use of a Bonferroni correction for multiple testing, p-values would need to be $<0.005(0.05 / 11)$ to be considered statistically significant. After this correction, the changes found would no longer be statistically significant. The z-scores for biomarkers of endothelial dysfunction and inflammation were calculated because the pathogenesis of atherosclerosis is a complex process, involving numerous cytokines and adhesion molecules. As mentioned by van Bussel et al. [31], the calculation of a z-score does hold some limitations because its calculation is based on the assumption that each biomarker carries a similar weight. This may not be the case because some biomarkers may outweigh others. As such, the z-scores calculated here do provide pooled measures of endothelial dysfunction and inflammation biomarkers, but may not optimally reflect the pathophysiology of endothelial dysfunction and inflammation.

To our knowledge, the present study is the first to assess the effects of pure flavonoids on a comprehensive set $(n=11)$ of biomarkers of endothelial dysfunction and inflammation. 
Only a limited number of interventions with cocoa and tea were published, which all addressed only a few of these biomarkers at the same time. Interventions with cocoa and tea did not find effects on E-selectin $[11,12,14]$. The magnitude of the effect on E-selectin of $\sim 7 \%$ found in the present study is similar to the effect of $\sim 10 \%$ found for other adhesion molecules in some of the cocoa and tea interventions [11, 12]. E-selectin is involved in the adhesion of leukocytes to the endothelium [32]. A previous study showed that E-selectin concentrations in patients with carotid artery atherosclerosis were $15 \%$ higher than in control subjects [33]. Furthermore, E-selectin was inversely associated to flow-mediated dilation (FMD), a functional marker of endothelial function [28]. This suggests that the reductions in sE-selectin of $7 \%$ found after both epicatechin and quercetin supplementation could beneficially affect endothelial function and the development of atherosclerosis. However, we previously published that in this study FMD did not change significantly after epicatechin or quercetin supplementation [20]. Endothelial function is a complex process that involves numerous molecules and pathways and also pathologic conditions. The lack of an effect on FMD of our supplementations, despite a decrease in sE-selectin, suggests that other molecules besides sE-selectin and other factors may play a role.

The lack of an effect of epicatechin on markers of inflammation is in line with previous chocolate and cocoa intervention studies that showed no effects on markers of inflammation $[12,13]$. In contrast to epicatechin, we found that quercetin supplementation decreased IL-1 $\beta$ and the z-score for inflammation. To our knowledge, no studies have investigated the effects of pure quercetin on inflammation. Only a limited number of studies with tea, the main dietary source of quercetin, were reported. Two of 3 of these tea interventions found that tea suppressed CRP $[15,16]$. However, only one tea intervention measured IL-1 $\beta$, IL-6, and TNF- $\alpha$, which did not change [17]. These results should be compared cautiously, because the dosage of pure quercetin used in the present study $(100 \mathrm{mg} / \mathrm{d}$ ) is notably higher than the amount of quercetin present in 4 cups ( 1 cup $=250$ $\mathrm{mL}$ ) of black tea (19 mg) [34].

In this intervention study, we previously reported improvements in insulin resistance after epicatechin supplementation only [20]. It was suggested that endothelial dysfunction is closely related to the pathogenesis of insulin resistance and impaired glucose metabolism [5]. Higher concentrations of sE-selectin and, to a lesser extent, sICAM-1 were associated with an increased risk of developing diabetes [35]. Similarly, studies have shown higher concentrations of sE-selectin and SICAM-1 in subjects with insulin resistance [36-38]. In the present study, the decrease in sE-selectin after epicatechin supplementation may have contributed to the improvements in insulin resistance reported previously. However, quercetin also decreased sE-selectin but did not affect insulin resistance, suggesting that other markers are also involved. 
In conclusion, in (pre)hypertensive men and women, epicatechin supplementation reduced sE-selectin, a marker of endothelial dysfunction, but did not significantly change other markers of endothelial dysfunction when compared to placebo. This suggests that epicatechin may contribute to the cardioprotective effects of epicatechin-rich foods such as cocoa and tea. Similarly, quercetin supplementation reduced sE-selectin but also reduced $\mathrm{IL}-1 \beta$ and the $z$-score for inflammation. This suggests that quercetin may contribute to the cardioprotective effects of quercetin-rich foods such as tea by improving endothelial function and reducing inflammation. Further long-term studies are needed to confirm these results and to gain more insight into the potential mechanisms behind the proposed effects of both epicatechin and quercetin.

\section{ACKNOWLEDGEMENTS}

We thank Harrie Robins for practical assistance in performing the study, Marjo van de Waarenburg for performing biochemical analyses, and Prof. dr. Hendriek Boshuizen for statistical advice.

\section{SOURCES OF FUNDING}

Supported by Top Institute Food and Nutrition (TIFN) (IID, JMG, and PCH), a public-private partnership on pre-competitive research in food and nutrition. TIFN had no role in the study design, data acquisition and analysis or drafting of the manuscript, or decision to publish.

\section{AUTHOR DISCLOSURES}

The authors report no conflicts of interest. 


\section{REFERENCES}

1. Buitrago-Lopez A, Sanderson J, Johnson L, et al. Chocolate consumption and cardiometabolic disorders: systematic review and meta-analysis. BMJ. 2011;343.

2. Arab L, Liu W, Elashoff D. Green and black tea consumption and risk of stroke: a meta-analysis. Stroke. 2009;40:1786-1792.

3. González R, Ballester I, López-Posadas R, et al. Effects of flavonoids and other polyphenols on inflammation. Crit Rev Food Sci Nutr. 2011;51:331-362.

4. Calder PC, Ahluwalia N, Brouns F, et al. Dietary factors and low-grade inflammation in relation to overweight and obesity. Br J Nutr. 2011;106:S5-78.

5. Esper RJ, Nordaby RA, Vilarino JO, Paragano A, Cacharrón JL, Machado RA. Endothelial dysfunction: a comprehensive appraisal. Cardiovasc Diabetol. 2006;5:4.

6. Libby P. Inflammation in atherosclerosis. Nature. 2002;420:868-874.

7. Libby P. Vascular biology of atherosclerosis: overview and state of the art. Am J Cardiol. 2003;91:3A$6 \mathrm{~A}$.

8. Mulvihill NT, Foley JB, Murphy RT, Curtin R, Crean PA, Walsh M. Risk stratification in unstable angina and non-Q wave myocardial infarction using soluble cell adhesion molecules. Heart. 2001;85:623627.

9. Tuomisto K, Jousilahti P, Sundvall J, Pajunen P, Salomaa V. C-reactive protein, interleukin-6 and tumor necrosis factor alpha as predictors of incident coronary and cardiovascular events and total mortality. A population-based, prospective study. Thromb Haemost. 2006;95:511-518.

10. Tzoulaki I, Murray GD, Lee AJ, Rumley A, Lowe GDO, Fowkes FGR. Relative value of inflammatory, hemostatic, and rheological factors for incident myocardial infarction and stroke: the Edinburgh artery study. Circulation. 2007;115:2119-2127.

11. Wang-Polagruto JF, Villablanca AC, Polagruto JA, et al. Chronic consumption of flavanolrich cocoa improves endothelial function and decreases vascular cell adhesion molecule in hypercholesterolemic postmenopausal women. J Cardiovasc Pharmacol. 2006;47:S177-S186.

12. Monagas M, Khan N, Andres-Lacueva C, et al. Effect of cocoa powder on the modulation of inflammatory biomarkers in patients at high risk of cardiovascular disease. Am J Clin Nutr. 2009;90:1144-1150.

13. Mathur S, Devaraj S, Grundy SM, Jialal I. Cocoa products decrease low density lipoprotein oxidative susceptibility but do not affect biomarkers of inflammation in humans. J Nutr. 2002;132:36633667.

14. Hodgson JM, Puddey IB, Mori TA, Burke V, Baker RI, Beilin LJ. Effects of regular ingestion of black tea on haemostasis and cell adhesion molecules in humans. Eur J Clin Nutr. 2001;55:881-886.

15. Steptoe A, Gibson EL, Vuononvirta R, et al. The effects of chronic tea intake on platelet activation and inflammation: a double-blind placebo controlled trial. Atherosclerosis. 2007;193:277-282.

16. Oyama J, Maeda T, Kouzuma K, et al. Green tea catechins improve human forearm endothelial dysfunction and have antiatherosclerotic effects in smokers. Circ J. 2010;74:578-588. 
17. de Maat MP, Pijl H, Kluft C, Princen HM. Consumption of black and green tea has no effect on inflammation, haemostasis and endothelial markers in smoking healthy individuals. Eur J Clin Nutr. 2000;54: 757-763.

18. Arts ICW, Hollman PCH, Feskens EJM, Bueno De Mesquita HB, Kromhout D. Catechin intake and associated dietary and lifestyle factors in a representative sample of Dutch men and women. Eur J Clin Nutr. 2001;55:76-81.

19. Hertog MGL, Hollman PCH, Katan MB, Kromhout D. Intake of potentially anticarcinogenic flavonoids and their determinants in adults in The Netherlands. Nutr Cancer. 1993;20:21-29.

20. Dower Jl, Geleijnse JM, Gijsbers L, Zock PL, Kromhout D, Hollman PCH. Effects of the pure flavonoids epicatechin and quercetin on vascular function and cardiometabolic health: a randomised doubleblind, placebo-controlled, crossover trial. Am J Clin Nutr. 2015;101:914-921.

21. Engler MB, Engler MM, Chen CY, et al. Flavonoid-rich dark chocolate improves endothelial function and increases plasma epicatechin concentrations in healthy adults. J Am Coll Nutr. 2004;23:197204.

22. Faridi Z, Njike VY, Dutta S, Ali A, Katz DL. Acute dark chocolate and cocoa ingestion and endothelial function: A randomized controlled crossover trial. Am J Clin Nutr. 2008;88:58-63.

23. Farouque HMO, Leung M, Hope SA, et al. Acute and chronic effects of flavanol-rich cocoa on vascular function in subjects with coronary artery disease: A randomized double-blind placebocontrolled study. Clin Sci. 2006;111:71-80.

24. Grassi D, Desideri G, Necozione S, et al. Blood pressure is reduced and insulin sensitivity increased in glucose-intolerant, hypertensive subjects after 15 days of consuming high-polyphenol dark chocolate. J Nutr. 2008;138:1671-1676.

25. van Bussel BCT, Henry RMA, Schalkwijk CG, et al. Fish consumption in healthy adults is associated with decreased circulating biomarkers of endothelial dysfunction and inflammation during a 6-year follow-Up. J Nutr. 2011;141:1719-1725.

26. de Jager J, Dekker JM, Kooy A, et al. Endothelial dysfunction and low-grade inflammation explain much of the excess cardiovascular mortality in individuals with type 2 diabetes: the Hoorn Study. Arterioscler Thromb Vasc Biol. 2006;26:1086-1093.

27. Yudkin JS, Stehouwer CDA, Emeis JJ, Coppack SW. C-reactive protein in healthy subjects: Associations with obesity, insulin resistance, and endothelial dysfunction: A potential role for cytokines originating from adipose tissue? Arterioscler Thromb Vasc Biol. 1999;19:972-978.

28. Eschen O, Christensen JH, Dethlefsen C, Schmidt EB. Cellular adhesion molecules in healthy subjects: short term variations and relations to flow mediated dilation. Biomark Insights. 2008;3:5762.

29. Osmancik P, Kvasnicka J, Widimsky P, Tarnok A. Diurnal variation of soluble E- and P-selectin, and intercellular adhesion molecule-1 in patients with and without coronary artery disease. Cardiology. 2004;102:194-199.

30. van Bussel BC, Schouten F, Henry RM, et al. Endothelial dysfunction and low-grade inflammation are associated with greater arterial stiffness over a 6-year period. Hypertension. 2011;58: 588-595. 
31. van Bussel BCT, Soedamah-Muthu SS, Henry RMA, et al. Unhealthy dietary patterns associated with inflammation and endothelial dysfunction in type 1 diabetes: the EURODIAB study. Nutr Metab Cardiovasc Dis. 2013;23:758-764.

32. Calder PC, Ahluwalia N, Albers R, et al. A consideration of biomarkers to be used for evaluation of inflammation in human nutritional studies. BrJ Nutr. 2013;109:S1-34.

33. Hwang SJ, Ballantyne CM, Sharrett AR, et al. Circulating adhesion molecules VCAM-1, ICAM-1, and E-selectin in carotid atherosclerosis and incident coronary heart disease cases: the Atherosclerosis Risk In Communities (ARIC) study. Circulation. 1997;96:4219-4225.

34. Hertog MGL, Hollman PCH, Van de Putte B. Content of potentially anticareinogenic flavonoids of tea infusions, wines, and fruit juices. J Agric Food Chem. 1993;41:1242-1246.

35. Song Y, Manson JE, Tinker L, et al. Circulating levels of endothelial adhesion molecules and risk of diabetes in an ethnically diverse cohort of women. Diabetes 2007;56:1898-1904.

36. Hak AE, Pols HAP, Stehouwer CDA, et al. Markers of inflammation and cellular adhesion molecules in relation to insulin resistance in nondiabetic elderly: the Rotterdam Study.J Clin Endocrinol Metab. 2001;86:4398-4405.

37. Matsumoto K, Miyake S, Yano M, Ueki Y, Tominaga Y. High serum concentrations of soluble E-selectin in patients with impaired glucose tolerance with hyperinsulinemia. Atherosclerosis. 2000;152:415-420.

38. Weyer C, Yudkin JS, Stehouwer CDA, Schalkwijk CG, Pratley RE, Tataranni PA. Humoral markers of inflammation and endothelial dysfunction in relation to adiposity and in vivo insulin action in Pima Indians. Atherosclerosis. 2002;161:233-242. 


Pure epicatechin and inflammatory gene expression profiles in circulating immune cells in (pre) hypertensive adults; a randomised, double-blind, placebo-controlled, crossover trial

\author{
Diederik Esser \\ James I Dower \\ Juri C Matualatupauw \\ Marianne Geleijnse \\ Daan Kromhout \\ Peter $\mathrm{CH}$ Hollman \\ Lydia A Afman
}

Manuscript in preparation 


\section{ABSTRACT}

\section{Background}

There is increasing evidence that consumption of cocoa products have a beneficial effect on cardiometabolic health, but the underlying mechanisms remain unclear. Cocoa contains a complex mixture of flavan-3-ols. Epicatechin, a major monomeric flavan-3-ol, is considered to contribute to the cardioprotective effects of cocoa. We investigated the effects of pure epicatechin supplementation on whole genome gene expression profiles of circulating immune cells.

\section{Methods}

In a randomised, double blind, placebo-controlled, cross-over trial, 37 (pre)hypertensive (40-80 years) subjects received two 4-week interventions; epicatechin (100mg/day) or placebo with a washout period of 4 weeks between both interventions. Whole genome gene expression profiles of peripheral blood mononuclear cells were determined before and after both interventions.

\section{Results}

After epicatechin supplementation 1180 genes were significantly regulated, of which 234 were also significantly regulated compared to placebo. Epicatechin supplementation upregulated gene sets involved in transcription/translation and tubulin folding and downregulated gene sets involved in inflammation. Only a few genes within these regulated gene sets were actually significantly changed upon epicatechin supplementation. Upstream regulators that were shown to be inhibited were classified as cytokine or inflammatory type molecules.

\section{Conclusions}

Pure epicatechin supplementation modestly reduced gene expression related to inflammation signalling routes in circulating immune cells. These routes are known to play a role in cardiovascular health. 


\section{INTRODUCTION}

Prospective cohort studies showed that higher levels of chocolate or cocoa consumption are associated with a lower risk of cardiometabolic disorders [1]. In addition, several randomised controlled intervention studies showed beneficial effects on intermediate markers of CVD, especially on blood pressure, flow mediated dilation (FMD) [a marker of endothelial function], but also on insulin resistance [2-4]. Based on this evidence, the European Food and Safety Authority (EFSA) approved a health claim that cocoa flavan3-ols help maintain normal endothelium-dependent vasodilation [5]. Although a causeand-effect relationship has been established between cocoa/chocolate consumption and these cardiometabolic health markers, the underlying mechanisms remain largely unknown. Recently, we demonstrated in a human intervention study that dark chocolate consumption improved FMD and also lowered adhesion molecules on leukocytes in the circulation [6]. These findings may suggest a role of immune cells in the cardioprotective effects of dark chocolate.

Cocoa is rich in flavan-3-ols. Epicatechin, its major monomeric flavan-3-ol, may be responsible for the beneficial effect of cocoa on FMD [7]. However, cocoa contains a complex mixture of many flavan-3-ols and other substances, and the specific role of epicatechin is less well studied in isolation. For this reason, we recently conducted a human intervention study to determine the effects of pure epicatechin supplementation on markers of cardiometabolic health $[8,9]$. Findings from that study suggested that epicatechin may, in part, contribute to the cardioprotective effects of cocoa by lowering sE-selectin, a leukocyte adhesion molecule and marker of endothelial function, and improving fasting insulin and insulin resistance $[8,9]$. This hypothesis is in line with a cocoa intervention study which showed that an improvement in endothelial function after 15 days of dark chocolate consumption was paralleled by a decrease in insulin resistance [3].

However, the underlying mechanisms by which epicatechin may affect endothelial function in humans remain largely unclear. Several in vitro experiments in human endothelial cells demonstrated that epicatechin stimulated the synthesis of nitric oxide (NO), an important mediator of vasodilation, and prevented the superoxide-mediated loss of NO $[10,11]$. Other factors known to be important in endothelial health, such as inflammation, leukocyte adhesion and coagulation, might also be affected by epicatechin, but are less extensively studied in vivo $[6,12]$. Peripheral blood mononuclear cells (PBMC) are immune cells which are easy to collect in human intervention studies. These cells play an important role in inflammation and endothelial function and react to changes in nutrient levels and inflammatory agents in blood. They are, therefore, valuable to study the potential cardioprotective effects of epicatechin in vivo [13,14]. A powerful and largely unbiased strategy to understand how nutrients and bioactive compounds may affect cellular 
processes is by using whole genome wide screening techniques, such as transcriptomics. We demonstrated that atherosclerotic-related gene expression changes can be detected in PBMCs in vivo upon consumption of different types of fatty acids [13,14]. Applying such

high throughput screening tools may increase our understanding of how epicatechin may affect immune cells and thereby might exert its cardioprotective effects. For this reason, we aimed to investigate the effects of 4-week supplementation of pure epicatechin on whole genome gene expression profiles of PBMCs using a randomised, double-blind, placebo-controlled, crossover trial.

\section{MATERIALS AND METHODS}

\section{Subjects}

We included 37 (pre-)hypertensive subjects (25 men, 12 women) between 40-80 years old from a previously reported study [8]. All subjects were non-smoking and free of chronic diseases. All subjects gave written informed consent and the study was approved by the local Medical Ethics Committee. The study was registered at clinicaltrials.gov as NCT01691404.

\section{Study Design}

The original study $[8,9]$ investigated the effects of epicatechin and quercetin-3-glucoside on markers of cardiometabolic health. Because epicatechin had more pronounced effects on these markers than quercetin, we selected only the epicatechin treatment for PBMC transcriptome analysis and compared these effects with the placebo group.

The study was a randomised, double blind, placebo-controlled, cross-over trial in which subjects received two 4-week interventions; epicatechin $(100 \mathrm{mg} /$ day) or placebo (microcrystalline cellulose). Details of the study have been described previously [8]. In brief, subjects received both interventions in random order with a washout period of 4 weeks between both interventions. Subjects consumed 2 capsules per day with a glass of water: one during breakfast and one during dinner. Subjects were asked to avoid consumption of epicatechin-rich foods throughout the study period. Fasting PBMCs were collected before (T0) and after each intervention period (T4). On the day prior to each study day, subjects received a standardised evening meal, refrained from alcohol consumption and strenuous exercise, and were not allowed to eat or drink anything except water after 22:00.

\section{PBMC and RNA isolation}

Fasting PBMCs were isolated before and after both intervention arms using BD Vacutainer Cell Preparation Tubes. RNA was isolated (RNeasy Micro kit, Qiagen, Venlo, the Netherlands), quantified (Nanodrop ND 1000, Nanodrop technologies, Wilmington, Delaware USA) and 
integrity was checked by an Agilent 2100 Bioanalyser with RNA 6000 microchips (Agilent Technologies, South Queensferry, UK). Samples were included for microarray analysis if the RNA integrity number (RIN) was $>7$.

\section{Microarray Processing}

PBMC samples from 32 subjects yielded enough RNA of sufficient quality at all collection points to perform microarray analysis. Microarray analysis was performed for each individual before and after 4 weeks supplementation of placebo and epicatechin, resulting in a total of 128 microarrays, which all passed the RNA quality control (RIN>7). Total RNA was labelled using a one-cycle cDNA labelling kit (MessageAmp ${ }^{\text {TM }}$ II-Biotin Enhanced Kit; Ambion Inc, Nieuwekerk a/d IJssel, Netherlands) and hybridised to GeneChip ${ }^{\circledR}$ Human Gene 1.1 ST Array targeting 19,738 unique gene identifiers (Affymetrix Inc. Santa Clara, CA). Sample labelling, hybridization to chips and image scanning were performed according to the manufacturers' instructions.

\section{Microarray Analysis}

MADMAX pipeline was used for statistical analysis of microarray data [15]. Microarrays were analysed using the reorganised oligonucleotide probes, which combine all individual probes for a gene [16]. Expression values were calculated using the robust multichip average (RMA) method and normalised by quantile normalisation [17, 18]. Genes with normalised signals $>20$ on $>10$ arrays were defined as expressed and selected for further analysis. Microarray data are registered as GSEXXXX in the Gene Expression Omnibus.

Differences in gene expression changes between intervention groups were calculated from the individual signal-to-log ratios (SLR). The change over time in gene expression due to the intervention ( $\Delta$ epicatechin or $\Delta$ placebo) was considered significant if the $p$-value in a paired t-test with Bayesian correction was $<0.05$ (Limma) [19]. The difference between the change during the epicatechin intervention and the placebo intervention ( $\Delta$ epicatechin vs. $\Delta$ placebo) was analysed in the same way. Data was further analysed with gene set enrichment analysis (GSEA) [20] to identify regulated gene sets and QIAGEN's Ingenuity Pathway Analysis (IPA®,QIAGEN Redwood City) to identify transcriptional regulators. Gene sets with a false discovery rate (FDR) Q-value $<0.25$ were defined as significantly regulated and further analysed in Cytoscape (Cytoscape 2.8.3) to visualise clusters of the most significantly changed gene sets. 


\section{RESULTS}

The mean age of the 32 subjects included in the analysis was $65.8 \pm 7.9$ years and the mean BMI was $26.7 \pm 3.5 \mathrm{~kg} / \mathrm{m}^{2}$ (Table 1). Epicatechin supplementation changed the expression of 1180 genes ( $\Delta$ epicatechin), and placebo changed the expression of 500 genes ( $\Delta$ placebo) (Figure 1). Expression of 465 genes changed significantly between the epicatechin and the placebo intervention ( $\Delta$ epicatechin vs. $\Delta$ placebo). Of these 465 genes, 234 genes also changed in expression upon epicatechin intervention ( $\Delta$ epicatechin) with an up-regulated expression of 95 genes and a down-regulated expression of 139 genes. To obtain a selection of robust responding genes upon epicatechin consumption ( $\Delta$ epicatechin), we selected the 20 genes with the lowest $p$-value. These selected genes ranked based upon SLR are visualised in an expression heatmap (Figure 2).

\section{Gene Set Enrichment Analysis}

To elucidate which gene sets were regulated by epicatechin supplementation we performed a GSEA. Significantly regulated gene sets between intervention arms ( $\Delta$ epicatechin vs. $\Delta$ placebo) and within epicatechin intervention( $\Delta$ epicatechin) included 35 upregulated gene sets and 21 down-regulated gene sets (FDRQ<0.25) (Supplemental Table 1 and 2). High ranking gene sets (ranked on normalised enrichment score (NES), FDR Q<0.1) that were affected after the epicatechin intervention and were also significantly changed between

TABLE 1. Baseline characteristics of 32 healthy subjects included in the analysis.

\begin{tabular}{lc}
\hline & $\mathrm{N}=32$ \\
\hline Male/female & $20 / 12$ \\
Age $(\mathrm{yrs})$ & $65.8 \pm 7.9$ \\
BMI $\left(\mathrm{kg} / \mathrm{m}^{2}\right)$ & $26.7 \pm 3.52$ \\
Office SBP $(\mathrm{mmHg})$ & $128.2 \pm 13.0$ \\
Office DBP $(\mathrm{mmHg})$ & $74.3 \pm 9.3$ \\
Plasma glucose (mmol/L) & $5.72 \pm 0.57$ \\
Serum insulin (mU/L) & $6.76 \pm 4.49$ \\
HOMA-IR & $1.74 \pm 1.16$ \\
Fasting serum lipids (mmol/L) & \\
Total cholesterol & $5.62 \pm 0.75$ \\
LDL cholesterol & $3.46 \pm 0.65$ \\
HDL cholesterol & $1.56 \pm 0.44$ \\
Triglycerides & $1.32 \pm 0.51$ \\
\hline
\end{tabular}

Values are mean \pm SD.

Abbreviations: BMI, body mass index; DBP, diastolic blood pressure; HDL, high-density lipoprotein; HOMA-IR, homeostatic model assessment of insulin resistance; LDL, low-density lipoprotein; SBP, systolic blood pressure. 


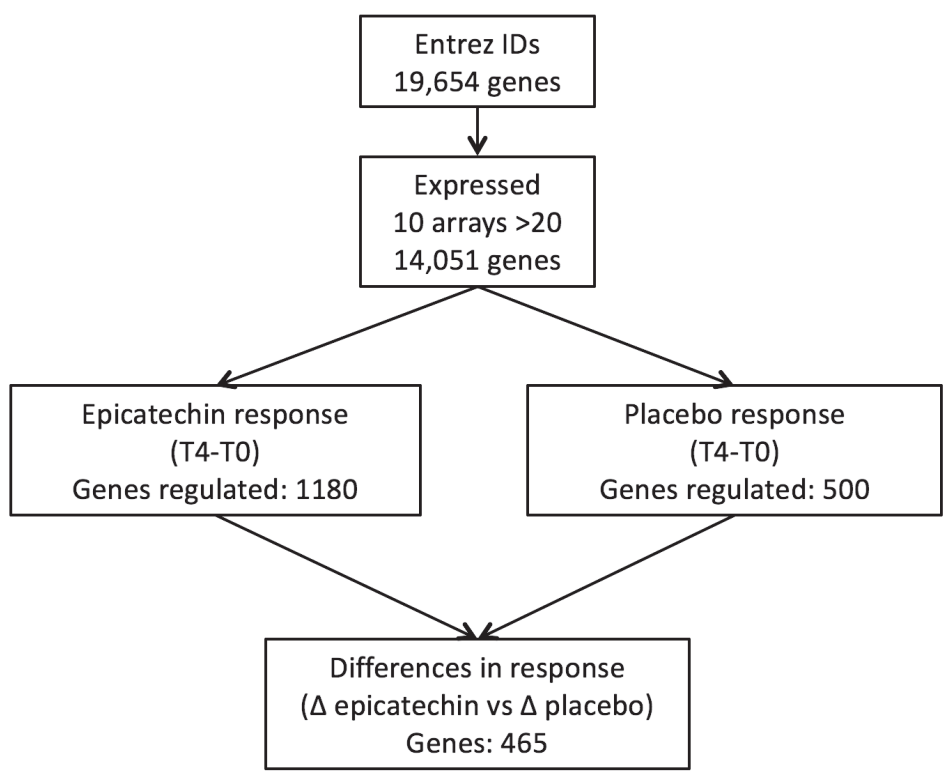

FIGURE 1. Flow diagram showing the number of genes of which the expression was changed after 4-week epicatechin or placebo supplementation and the number of genes that significantly changed in expression between the epicatechin or placebo intervention. A change was considered significant if $\mathrm{P}<0.05$.

the epicatechin and the placebo intervention ( $\Delta$ epicatechin vs. $\Delta$ placebo) are visualised in Figure 3. A cluster of gene sets with genes involved in transcription/translation was upregulated. Gene sets in this cluster largely included zinc finger proteins and ribosomal proteins. Other upregulated gene sets included genes involved in 'tubulin folding'. Changes of individual genes within these above described up-regulated gene sets showed a relatively large variation in response (Supplemental Figure 1). A down-regulated cluster included inflammatory gene clusters IL8-CXCR1/2 pathways and AMB2_neutrophil pathway, which are related to vascular health (Figure 3). Only a few genes within these significantly downregulated gene sets were changed significantly after the epicatechin intervention and between intervention arms ( $\Delta$ epicatechin vs. $\Delta$ placebo) (Supplemental Figure 1 ). In the current study we observed that epicatechin supplementation resulted in improved fasting insulin and insulin resistance [8]. We therefore specifically investigated if related pathways were affected. The insulin synthesis and processing pathway was upregulated (FDR q= 0.11 , supplemental table 1 ) but no genes within this gene set were changed significantly after the epicatechin intervention and between intervention arms ( $\Delta$ epicatechin vs. $\Delta$ placebo). The AMPK signalling pathway was down regulated (FDR $q=0.17$, supplemental table 1), but only the PLCB1 gene changed significantly after the epicatechin intervention and between intervention arms within this pathway. 


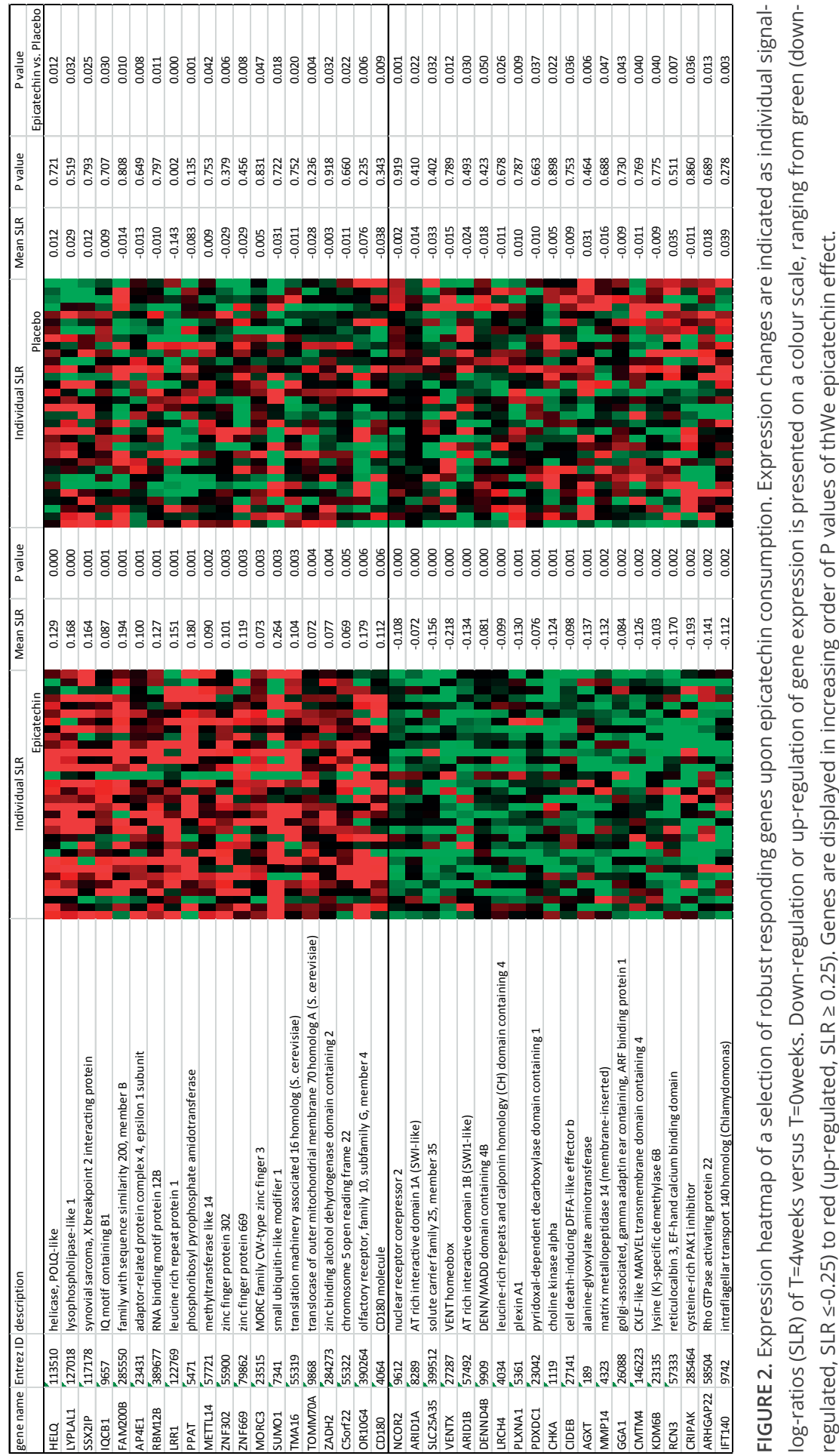




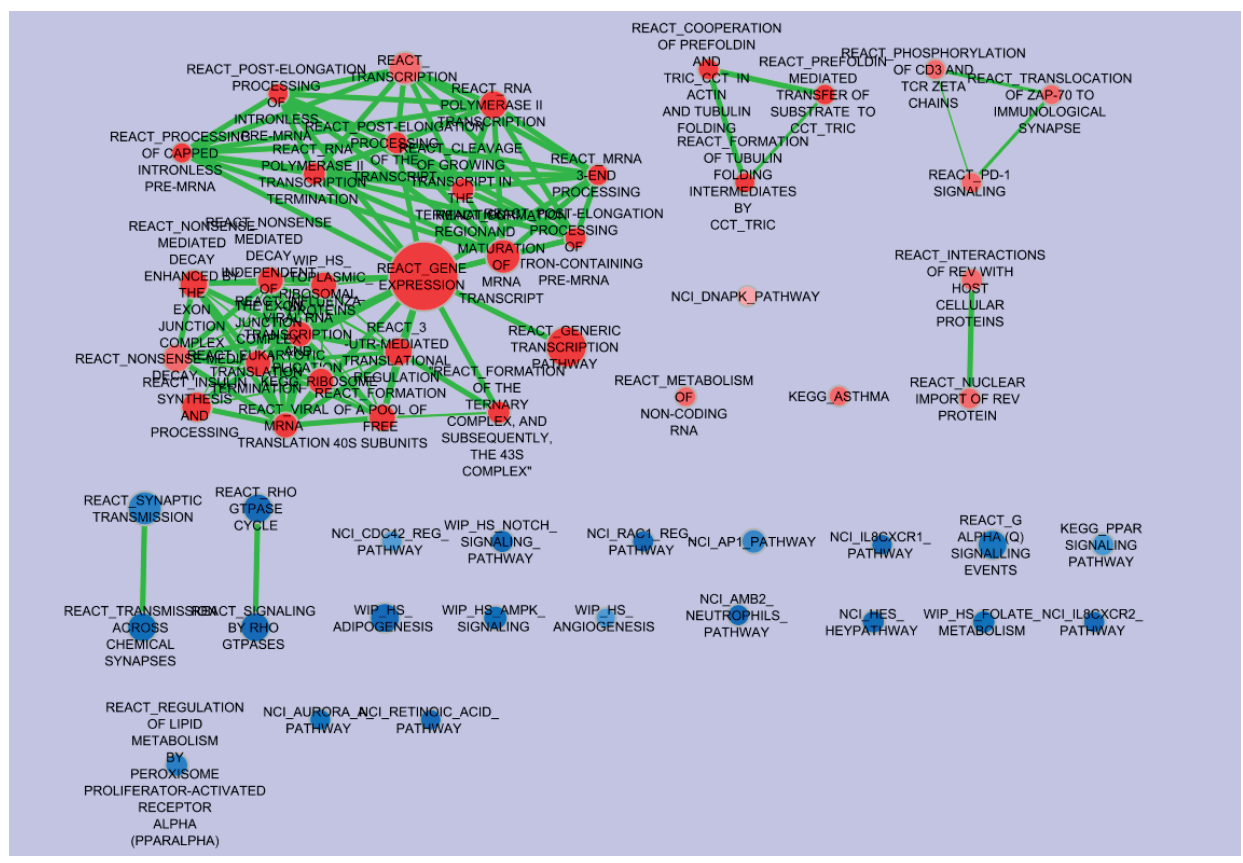

FIGURE 3. Enrichment map of gene sets (FDR Q< 0.25) that changed significantly after 4-week pure epicatechin supplementation ( $\Delta$ epicatechin ) and between the epicatechin and the placebo intervention ( $\Delta$ epicatechin vs. $\Delta$ placebo). Nodes represent gene sets, whereas lines indicate overlapping genes between the gene sets (overlap cut-off: 0.5). Colours in the nodes indicate if the gene set was upregulated (red), down-regulated (blue) after pure epicatechin supplementation. Abbreviations: BIOC, BioCarta Pathway Diagrams; KEGG, Kyoto Encyclopedia of Genes and Genomes database; NCl, Nature Pathway Interaction database; REACT, Reactome knowledgebase; WIP_HS, WikiPathways Homo Sapiens.

\section{Upstream Regulator Analysis}

In order to identify common upstream regulators of the affected genes we performed an upstream regulator analysis using Ingenuity Pathway Analysis. No significant potential upstream regulators were identified if we compared the epicatechin and the placebo intervention ( $\Delta$ epicatechin vs. $\Delta$ placebo). However, when analysing the effects upon epicatechin supplementation only, we identified 3 activated and 16 inhibited potential upstream regulators (Table 2). No significant upstream regulators were identified upon placebo supplementation. Upregulated upstream regulators were Hdac, miR-155-5p and JAG2. The majority of the inhibited upstream regulators upon epicatechin supplementation were classified as platelet-derived growth factor complex (PDGF BB), or as a cytokine (TNF, CCL5, IL1 $\beta$, IL1A, IL17A and IFNG) or other inflammatory type molecules (NF-kB, RELA (NFkB p65 subunit) and TLR7). 
TABLE 2. Predicted upstream regulators upon epicatechin supplementation ( $\Delta$ epicatechin)*.

\begin{tabular}{|c|c|c|c|c|}
\hline & & Predicted & & \\
\hline Upstream Regulator & Molecule Type & $\begin{array}{l}\text { Activation } \\
\text { State }\end{array}$ & $\begin{array}{l}\text { Activation } \\
\text { z-score }\end{array}$ & $\begin{array}{l}\mathrm{p} \text {-value of } \\
\text { overlap }\end{array}$ \\
\hline NUPR1 & transcription regulator & Inhibited & $-4,343$ & 0.000 \\
\hline TNF & cytokine & Inhibited & $-3,664$ & 0.013 \\
\hline PDGF BB & complex & Inhibited & $-3,606$ & 0.000 \\
\hline NFkB (complex) & complex & Inhibited & $-3,328$ & 0.045 \\
\hline RELA & transcription regulator & Inhibited & $-3,207$ & 0.007 \\
\hline STAT3 & transcription regulator & Inhibited & $-3,112$ & 0.006 \\
\hline SYVN1 & transporter & Inhibited & $-3,051$ & 0.035 \\
\hline TGM2 & enzyme & Inhibited & $-3,031$ & 0.019 \\
\hline CCL5 & cytokine & Inhibited & $-2,646$ & 0.007 \\
\hline IL1B & cytokine & Inhibited & $-2,589$ & 0.003 \\
\hline FOXL2 & transcription regulator & Inhibited & $-2,435$ & 0.002 \\
\hline EGFR & kinase & Inhibited & $-2,413$ & 0.003 \\
\hline IL1A & cytokine & Inhibited & $-2,394$ & 0.027 \\
\hline NCR2 & transmembrane receptor & Inhibited & $-2,213$ & 0.002 \\
\hline IL17A & cytokine & Inhibited & $-2,156$ & 0.040 \\
\hline ID1 & transcription regulator & Inhibited & $-2,000$ & 0.006 \\
\hline Hdac & group & Activated & 2,378 & 0.039 \\
\hline miR-155-5p & mature micro-rna & Activated & 2,425 & 0.004 \\
\hline JAG2 & growth factor & Activated & 2,804 & 0.000 \\
\hline
\end{tabular}

*No significant upstream regulators were identified upon placebo supplementation ( $\Delta$ placebo), or between the placebo or epicatechin intervention ( $\Delta$ epicatechin vs $\Delta$ placebo). ( $P$ value $<0.05$ and activation z-score $>2$ or $<-2$ ).

\section{DISCUSSION}

In a 4-week randomised, double-blind, placebo-controlled, crossover trial we demonstrated that epicatechin supplementation modestly affected PBMC gene expression profiles. Compared to placebo, epicatechin up-regulated gene sets involved in transcription/ translation and tubulin folding, and down-regulated gene sets involved in inflammation. However, within these regulated gene sets, expression of only a few genes was significantly changed upon epicatechin supplementation and significantly changed between the epicatechin and the placebo intervention ( $\Delta$ epicatechin vs. $\Delta$ placebo). 
The down-regulation of the clusters IL8 -CXCR1/2 and AMB2_neutrophil pathway points in the direction of an anti-inflammatory effect by epicatechin. Furthermore, a number of potential upstream regulators, including NF-KB, TNF and IL1 $\beta$ that have been classified as cytokine or inflammatory type molecules were inhibited upon epicatechin supplementation. These differences did not remain, however, when compared to placebo. If epicatechin does exert anti-inflammatory effects, we hypothesise that these effects may be mediated via the inhibition of MAPKs and the subsequent inhibition of inflammatory transcription factors such as NF-kB and AP-1 [21]. This hypothesis is supported by a previously published human intervention trial which showed that cocoa powder (28.2 mg epicatechin) significantly decreased NF-kB activation in PBMCs compared to baseline [22]. Similarly, Morrison et al. showed that pure epicatechin supplementation prevented dietinduced activation of aortic NF-KB in ApoE*3-Leiden mice fed an atherogenic diet [23]. The reduction in expression of genes involved in inflammation by epicatechin may be one of the contributing factors to the cardioprotective effects of cocoa [24]. However, it must be noted that the effects of epicatechin supplementation on plasma markers of endothelial dysfunction or inflammation in this intervention study were relatively mild; out of 11 plasma markers of inflammation or endothelial dysfunction, only sE-selectin was changed by epicatechin supplementation when compared to placebo [9]. Plasma markers reflect a systemic response coming from several organs. Because the current analysis focused specifically on the effects in circulating immune cells, comparisons with plasma markers should be made cautiously.

We previously reported in this intervention study that epicatechin supplementation improved insulin resistance [8]. Although an up-regulation of the insulin synthesis and processing pathway was observed, no genes within this gene set changed significantly between intervention arms. The current observed effects on gene expression in PBMCs are too variable between individuals to draw conclusions with respect to changes in glucose/ insulin regulatory pathways. As insulin signalling is especially of relevance in metabolically active organs, such as muscle, immune cells may not be the optimal cell-type to study the observed effects of epicatechin on insulin resistance. In addition, many changes in insulin signalling are regulated on the protein level by, for instance, phosphorylation [25].

Cardiometabolic health effects of pure epicatechin may also work via an increased NO bioavailability [26]. A hypothesised mechanism through which epicatechin may increase the bioavailability of NO is by protecting against oxidative damage via the transcription factor Nrf2 [27]. However, our results do not point towards this hypothesis. With our non-targeted approach, we identified up-regulated gene sets involved in transcription/ translation and tubulin folding upon epicatechin supplementation. These gene sets are involved in basic cellular functions. How epicatechin may affect these pathways in PBMCs is so far unclear. 
In the current study, 1180 genes were significantly regulated $(p<0.05)$ after epicatechin supplementation. However, after comparison to the placebo intervention we identified 465 genes to be significantly regulated. Only 234 of these genes were overlapping and were considered to be significantly regulated by epicatechin supplementation compared to the placebo. This number of genes and the magnitude of change were smaller than previously found for various fatty acids, also in PBMCs [14]. The small effect sizes and the large variation in individual responses may explain the relatively low number of genes significantly regulated. As a consequence, pure epicatechin, in concentrations achievable with dietary exposure, did not show consistent and robust effects on gene expression in immune cells. The molecular effects of (-)-epicatechin on immune cells will depend on the concentrations of epicatechin metabolites in the circulation available for interaction with membranes or inside cells [28]. In humans, epicatechin is absorbed by epithelial cells in the jejunum and completely metabolised upon absorption to (-)-epicatechin glucuronides, sulfates, and O-methyl sulfates [29]. The absorption and conjugation patterns may differ substantially between subjects [7] and may, therefore, affect receptors and nuclear factors differently. This could explain the large variation in gene expression response. Previous studies in our group on the effects of isoflavones demonstrated that the effects of isoflavones on whole-genome wide expression are more pronounced in adipose tissue [30] compared to PBMCs [31]. Similarly, the effect of epicatechin might be more pronounced in other cells, such as endothelial cells, adipose or muscle tissue and effects on PBMCs might be relatively modest [28].

The compliance in this relatively large cross-over study $(n=32)$ was high; $>98 \%$ of the distributed supplements were consumed, causing a marked increase in plasma epicatechin concentrations upon acute consumption of the capsules [8]. In the current design we compared the changes induced by 4-week supplementation of epicatechin to those induced by placebo supplementation. Only 234 of these genes were significantly regulated, even without false discovery rate controlling procedures. We considered genes changed if they were significantly changed after both the epicatechin intervention and between the epicatechin and the placebo intervention ( $\Delta$ epicatechin vs. $\Delta$ placebo). Such an approach is rather strict, but in our opinion it is also the most valid way of performing such analysis. Especially when considering that 500 genes were significantly changed by the placebo treatment.

In conclusion, pure epicatechin supplementation in (pre)hypertensive men and women affected gene expression profiles in PBMCs, but the effects were relatively small and the variation in individual responses was large. Results from this gene expression analysis, suggest that epicatechin may inhibit inflammation signalling routes which are known to play a role in cardiovascular health. 


\section{REFERENCES}

1. Buitrago-Lopez A, Sanderson J, Johnson L, et al. Chocolate consumption and cardiometabolic disorders: systematic review and meta-analysis. BMJ. 2011; 343.

2. Hooper L, Kay C, Abdelhamid A, et al. Effects of chocolate, cocoa, and flavan-3-ols on cardiovascular health: a systematic review and meta-analysis of randomized trials. Am J Clin Nutr. 2012;95:740751.

3. Grassi, D., Desideri, G., Necozione, S., Lippi, C., et al., Blood pressure is reduced and insulin sensitivity increased in glucose-intolerant, hypertensive subjects after 15 days of consuming highpolyphenol dark chocolate. J Nutr 2008, 138, 1671-1676.

4. Grassi D, Necozione S, Lippi C, et al, Cocoa reduces blood pressure and insulin resistance and improves endothelium-dependent vasodilation in hypertensives. Hypertension. 2005;46:398-405.

5. EFSA Panel on Dietetic Products NaAN. Scientific Opinion on the modification of the authorisation of a health claim related to cocoa flavanols and maintenance of normal endothelium-dependent vasodilation pursuant to Article 13(5) of Regulation (EC) No 1924/20061 following a request in accordance with Article 19 of Regulation (EC) No 1924/2006. EFSA Journal. 2014;12(5):3654.

6. Esser $D$, Mars $M$, Oosterink $E$, et al. Dark chocolate consumption improves leukocyte adhesion factors and vascular function in overweight men. FASEB J. 2014;28:1464-1473.

7. Schroeter $\mathrm{H}$, Heiss $\mathrm{C}$, Balzer J, et al. (-)-Epicatechin mediates beneficial effects of flavanol-rich cocoa on vascular function in humans. Proc Natl Acad Sci USA. 2006;103:1024-1029.

8. Dower JI, Geleijnse JM, Gijsbers L, et al. Effects of the pure flavonoids epicatechin and quercetin on vascular function and cardiometabolic health: a randomized, double-blind, placebo-controlled, crossover trial. Am J Clin Nutr. 2015;101:914-921.

9. Dower Jl, Geleijnse JM, Gijsbers L, et al. Supplementation of the Pure Flavonoids Epicatechin and Quercetin Affects Some Biomarkers of Endothelial Dysfunction and Inflammation in (Pre) Hypertensive Adults: A Randomized Double-Blind, Placebo-Controlled, Crossover Trial. J Nutr. 2015;145(7):1459-1463.

10. Steffen $Y$, Schewe T, Sies $H$. Epicatechin protects endothelial cells against oxidized LDL and maintains NO synthase. Biochem Biophys Res Commun. 2005;331:1277-1283.

11. Steffen Y, Schewe T, Sies H. (-)-Epicatechin elevates nitric oxide in endothelial cells via inhibition of NADPH oxidase. Biochem Biophys Res Commun. 2007;359: 828-833.

12. Katz DL, Doughty K, Ali A. Cocoa and chocolate in human health and disease. Antioxid Redox Signal. 2011;15:2779-2811.

13. Esser D, van Dijk SJ, Oosterink E, et al. High fat challenges with different fatty acids affect distinct atherogenic gene expression pathways in immune cells from lean and obese subjects. Mol Nutr Food Res. 2015;59(8):1563-72.

14. Bouwens $\mathrm{M}$, van de Rest $\mathrm{O}$, Dellschaft $\mathrm{N}$, et al. Fish-oil supplementation induces antiinflammatory gene expression profiles in human blood mononuclear cells. Am J Clin Nutr. 2009;90:415-424.

15. Lin K, Kools H, de Groot PJ, et al. MADMAX - Management and analysis database for multiple omics experiments. J Integr Bioinform. 2011;21;8(2):160 
16. Dai $M$, Wang $P$, Boyd $A D$, et al. Evolving gene/transcript definitions significantly alter the interpretation of GeneChip data. Nucleic Acids Res. 2005;33(20):e175.

17. Bolstad BM, Irizarry RA, Astrand M, Speed TP. A comparison of normalization methods for high density oligonucleotide array data based on variance and bias. Bioinformatics. 2003;19:185-193.

18. Irizarry RA, Bolstad BM, Collin F, et al. Summaries of Affymetrix GeneChip probe level data. Nucleic Acids Res. 2003;31:e15.

19. Smyth GK. Linear models and empirical bayes methods for assessing differential expression in microarray experiments. Stat Appl Genet Mol Biol. 2004;3:3.

20. Subramanian A, Tamayo P, Mootha VK, et al. Gene set enrichment analysis: a knowledgebased approach for interpreting genome-wide expression profiles. Proc Natl Acad Sci USA. 2005;102:15545-15550.

21. Ali F, Ismail A, Kersten S. Molecular mechanisms underlying the potential antiobesity-related diseases effect of cocoa polyphenols. Mol Nutr Food Res. 2014;58:33-48.

22. Vazquez-Agell M, Urpi-Sarda M, Sacanella E, et al. Cocoa consumption reduces NF-kappaB activation in peripheral blood mononuclear cells in humans. Nutr Metab Cardiovasc Dis. 2013;23:257-263.

23. Morrison $M$, van der Heijden $R$, Heeringa $P$, et al. Epicatechin attenuates atherosclerosis and exerts anti-inflammatory effects on diet-induced human-CRP and NFkappaB in vivo. Atherosclerosis. 2014;233:149-156.

24. Libby P. Inflammation and cardiovascular disease mechanisms. Am J Clin Nutr. 2006; 83:456S-460S.

25. Lizcano JM, Alessi DR. The insulin signalling pathway. Curr Biol. 2002;12: R236-238.

26. Loke WM, Hodgson JM, Proudfoot JM, et al. Pure dietary flavonoids quercetin and (-)-epicatechin augment nitric oxide products and reduce endothelin-1 acutely in healthy men. Am J Clin Nutr. 2008;88:1018-1025.

27. Mann GE, Rowlands DJ, Li FY, de Winter P, Siow RC. Activation of endothelial nitric oxide synthase by dietary isoflavones: role of NO in Nrf2-mediated antioxidant gene expression. Cardiovasc Res. 2007;75:261-274.

28. Rodriguez-Mateos A, Toro-Funes N, Cifuentes-Gomez T, et al. Uptake and metabolism of (-)-epicatechin in endothelial cells. Arch Biochem Biophys. 2014;559:17-23.

29. Actis-Goretta L, Leveques A, Giuffrida F, et al. Elucidation of (-)-epicatechin metabolites after ingestion of chocolate by healthy humans. Free Radic Biol Med. 2012;53:787-795.

30. van der Velpen V, Geelen A, Hollman PC, et al. Isoflavone supplement composition and equol producer status affect gene expression in adipose tissue: a double-blind, randomized, placebocontrolled crossover trial in postmenopausal women. Am J Clin Nutr. 2014;100:1269-1277.

31. van der Velpen V, Geelen A, Schouten EG, et al. Estrogen receptor-mediated effects of isoflavone supplementation were not observed in whole-genome gene expression profiles of peripheral blood mononuclear cells in postmenopausal, equol-producing women. J Nutr. 2013;143:774-780. 
SUPPLEMENTAL TABLE 1: Significantly up-regulated gene sets in both within the epicatechin intervention ( $\Delta$ epicatechin) and between intervention arms ( $\Delta$ epicatechin vs. $\Delta$ placebo).

\begin{tabular}{|c|c|c|c|}
\hline NAME & $\begin{array}{c}\text { SIZE } \\
\text { (\# genes) }\end{array}$ & NES & $\begin{array}{l}\text { FDR } \\
\text { q-value }\end{array}$ \\
\hline KEGG_RIBOSOME & 74 & 2 & 0.14 \\
\hline REACT_FORMATION OF A POOL OF FREE 4OS SUBUNITS & 79 & 1.9 & 0.15 \\
\hline $\begin{array}{l}\text { REACT_FORMATION OF THE TERNARY COMPLEX, AND } \\
\text { SUBSEQUENTLY, THE } 43 \text { S COMPLEX }\end{array}$ & 41 & 1.9 & 0.12 \\
\hline REACT_INSULIN SYNTHESIS AND PROCESSING & 109 & 1.9 & 0.11 \\
\hline $\begin{array}{l}\text { REACT_POST-ELONGATION PROCESSING OF INTRONLESS PRE- } \\
\text { MRNA }\end{array}$ & 22 & 1.9 & 0.1 \\
\hline REACT_VIRAL MRNA TRANSLATION & 68 & 1.9 & 0.09 \\
\hline REACT_EUKARYOTIC TRANSLATION TERMINATION & 70 & 1.9 & 0.08 \\
\hline $\begin{array}{l}\text { REACT_INFLUENZA VIRAL RNA TRANSCRIPTION AND } \\
\text { REPLICATION }\end{array}$ & 68 & 1.9 & 0.07 \\
\hline $\begin{array}{l}\text { REACT_NONSENSE MEDIATED DECAY INDEPENDENT OF THE } \\
\text { EXON JUNCTION COMPLEX }\end{array}$ & 75 & 1.9 & 0.07 \\
\hline REACT_PROCESSING OF CAPPED INTRONLESS PRE-MRNA & 22 & 1.9 & 0.06 \\
\hline WIP_HS_CYTOPLASMIC_RIBOSOMAL_PROTEINS & 74 & 1.9 & 0.07 \\
\hline REACT_RNA POLYMERASE II TRANSCRIPTION TERMINATION & 40 & 1.9 & 0.06 \\
\hline $\begin{array}{l}\text { REACT_CLEAVAGE OF GROWING TRANSCRIPT IN THE } \\
\text { TERMINATION REGION }\end{array}$ & 40 & 1.8 & 0.06 \\
\hline REACT_POST-ELONGATION PROCESSING OF THE TRANSCRIPT & 40 & 1.8 & 0.06 \\
\hline REACT_GENE EXPRESSION & 492 & 1.8 & 0.06 \\
\hline $\begin{array}{l}\text { REACT_FORMATION OF TUBULIN FOLDING INTERMEDIATES BY } \\
\text { CCT_TRIC }\end{array}$ & 19 & 1.8 & 0.06 \\
\hline $\begin{array}{l}\text { REACT_COOPERATION OF PREFOLDIN AND TRIC_CCT IN ACTIN } \\
\text { AND TUBULIN FOLDING }\end{array}$ & 26 & 1.8 & 0.06 \\
\hline REACT_GENERIC TRANSCRIPTION PATHWAY & 204 & 1.8 & 0.08 \\
\hline $\begin{array}{l}\text { REACT_POST-ELONGATION PROCESSING OF INTRON- } \\
\text { CONTAINING PRE-MRNA }\end{array}$ & 31 & 1.8 & 0.08 \\
\hline REACT_MRNA 3-END PROCESSING & 31 & 1.8 & 0.08 \\
\hline REACT_3 -UTR-MEDIATED TRANSLATIONAL REGULATION & 88 & 1.7 & 0.08 \\
\hline $\begin{array}{l}\text { REACT_PREFOLDIN MEDIATED TRANSFER OF SUBSTRATE TO } \\
\text { CCT_TRIC }\end{array}$ & 25 & 1.7 & 0.07 \\
\hline REACT_RNA POLYMERASE II TRANSCRIPTION & 92 & 1.7 & 0.08 \\
\hline REACT_PD-1 SIGNALING & 25 & 1.6 & 0.13 \\
\hline KEGG_ASTHMA & 19 & 1.6 & 0.13 \\
\hline $\begin{array}{l}\text { REACT_NONSENSE MEDIATED DECAY ENHANCED BY THE EXON } \\
\text { JUNCTION COMPLEX }\end{array}$ & 92 & 1.6 & 0.13 \\
\hline
\end{tabular}


SUPPLEMENTAL TABLE 1. Continued

\begin{tabular}{lccc}
\hline NAME & $\begin{array}{c}\text { SIZE } \\
\text { \# genes) }\end{array}$ & $\begin{array}{c}\text { FDR } \\
\text { q-value }\end{array}$ \\
\hline REACT_NONSENSE-MEDIATED DECAY & 92 & 1.6 & 0.15 \\
REACT_PHOSPHORYLATION OF CD3 AND TCR ZETA CHAINS & 22 & 1.6 & 0.16 \\
REACT_INTERACTIONS OF REV WITH HOST CELLULAR PROTEINS & 32 & 1.6 & 0.16 \\
REACT_FORMATION AND MATURATION OF MRNA TRANSCRIPT & 146 & 1.5 & 0.17 \\
REACT_TRANSCRIPTION & 131 & 1.5 & 0.18 \\
REACT_NUCLEAR IMPORT OF REV PROTEIN & 31 & 1.5 & 0.18 \\
REACT_TRANSLOCATION OF ZAP-70 TO IMMUNOLOGICAL & 20 & 1.5 & 0.2 \\
SYNAPSE & & 15 & 0.2 \\
NCI_DNAPK_PATHWAY & 21 & 1.5 \\
REACT_METABOLISM OF NON-CODING RNA & 15 & 0.2 \\
\hline
\end{tabular}

Ranking based on normalised enrichment score (NES). Abbreviations: KEGG, Kyoto Encyclopedia of Genes and Genomes database; NCl, Nature Pathway Interaction database; REACT, Reactome knowledgebase; WIP_HS, WikiPathways Homo Sapiens. 
SUPPLEMENTAL TABLE 2. Significantly down-regulated gene sets within the epicatechin intervention $(\Delta$ epicatechin) and between intervention arms ( $\Delta$ epicatechin vs. $\Delta$ placebo)

\begin{tabular}{|c|c|c|c|}
\hline NAME & $\begin{array}{c}\text { SIZE } \\
\text { (\# genes) }\end{array}$ & NES & $\begin{array}{c}\text { FDR } \\
\text { q-value }\end{array}$ \\
\hline WIP_HS_NOTCH_SIGNALING_PATHWAY & 42 & -2.3 & 0.00 \\
\hline NCI_RETINOIC_ACID_PATHWAY & 23 & -2.2 & 0.01 \\
\hline NCI_AURORA_A_PATHWAY & 29 & -2.0 & 0.05 \\
\hline REACT_SIGNALING BY RHO GTPASES & 102 & -2.0 & 0.06 \\
\hline NCI_IL8CXCR2_PATHWAY & 31 & -1.9 & 0.05 \\
\hline REACT_RHO GTPASE CYCLE & 102 & -1.9 & 0.04 \\
\hline NCI_IL8CXCR1_PATHWAY & 25 & -1.9 & 0.04 \\
\hline NCI_RAC1_REG_PATHWAY & 32 & -1.9 & 0.06 \\
\hline WIP_HS_ADIPOGENESIS & 103 & -1.9 & 0.06 \\
\hline NCI_AMB2_NEUTROPHILS_PATHWAY & 30 & -1.8 & 0.06 \\
\hline WIP_HS_FOLATE_METABOLISM & 44 & -1.8 & 0.09 \\
\hline NCI_HES_HEYPATHWAY & 40 & -1.7 & 0.13 \\
\hline KEGG_PPAR SIGNALING PATHWAY & 41 & -1.6 & 0.15 \\
\hline NCI_AP1_PATHWAY & 55 & -1.6 & 0.16 \\
\hline WIP_HS_ANGIOGENESIS & 17 & -1.6 & 0.16 \\
\hline WIP_HS_AMPK_SIGNALING & 54 & -1.6 & 0.17 \\
\hline REACT_REGULATION OF LIPID METABOLISM BY PPAR & 41 & -1.5 & 0.21 \\
\hline REACT_TRANSMISSION ACROSS CHEMICAL SYNAPSES & 103 & -1.5 & 0.20 \\
\hline REACT_SYNAPTIC TRANSMISSION & 143 & -1.5 & 0.20 \\
\hline NCI_CDC42_REG_PATHWAY & 26 & -1.5 & 0.24 \\
\hline REACT_G ALPHA (Q) SIGNALLING EVENTS & 106 & -1.4 & 0.25 \\
\hline
\end{tabular}

Ranking based on normalised enrichment score (NES). Abbreviations: KEGG, Kyoto Encyclopedia of Genes and Genomes database; $\mathrm{NCl}$, Nature Pathway Interaction database; REACT, Reactome knowledgebase; WIP_HS, WikiPathways Homo Sapiens. 


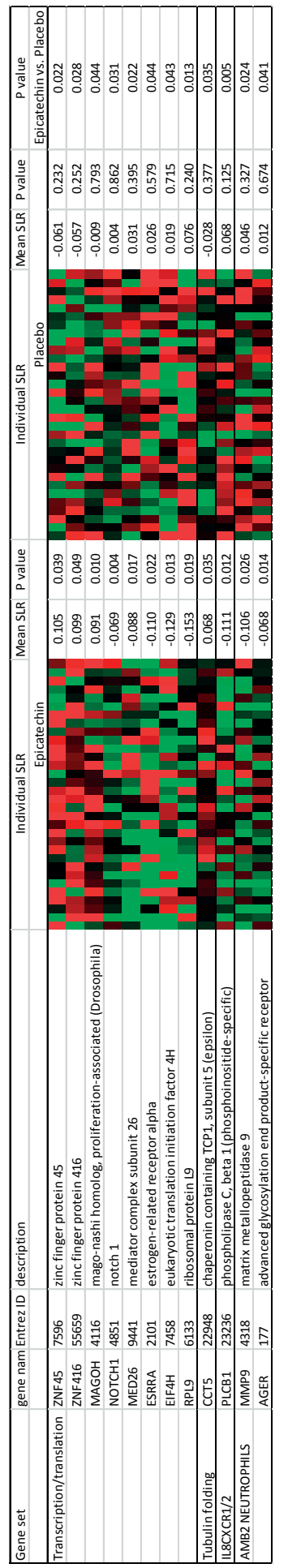

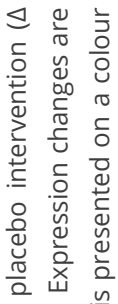

昱 完 은

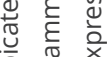

응 한

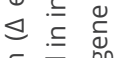

들 뭉

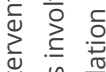

$\stackrel{\square}{\leftrightarrows}$

号

점

워월 음

든 흔

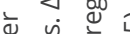

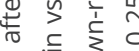

选运

盛

व 웜

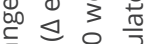

ป ᄃ

ते

矢 焉

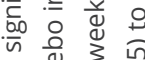

4 प च ?

은 닌

है

๖

든

ग

य 임 $\frac{1}{\frac{1}{10}}$

-

山्丶

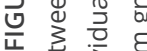

它起 总

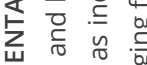

出完递

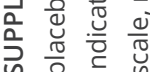






\title{
Does epicatechin contribute to the acute vascular function effects of dark chocolate? A randomised, crossover study
}

\author{
James I Dower \\ Johanna M Geleijnse \\ Paul A Kroon \\ Mark Philo \\ Marco Mensink \\ Daan Kromhout \\ Peter $\mathrm{CH}$ Hollman
}

Under review 


\section{ABSTRACT}

\section{Background}

Cocoa, rich in flavan-3-ols, improves vascular function, but the contribution of specific flavan-3-ols is unknown. Epicatechin, a major flavan-3-ol in cocoa, may play an important role. We compared the effects of pure epicatechin and chocolate in a randomised crossover study.

\section{Methods}

Twenty apparently healthy men aged 40-80 years completed the study. Treatments were: 1 ) $70 \mathrm{~g}$ dark chocolate (150 mg epicatechin) with two placebo capsules; 2) two pure epicatechin capsules (100 mg epicatechin) with $75 \mathrm{~g}$ white chocolate and 3) two placebo capsules with $75 \mathrm{~g}$ white chocolate (0 mg epicatechin). Flow-mediated dilation (FMD), augmentation index (AIx) and additional markers of vascular function were measured before and 2 hours after interventions. These changes were compared between intervention and placebo ( $\Delta$ intervention- $\Delta$ placebo) with linear mixed models for repeated measures. Epicatechin metabolites were measured in blood samples taken repeatedly, and the area under the concentration-time curve (AUC) was calculated to determine bioavailability.

\section{Results}

There was no significant difference in improvement in FMD $(\Delta 0.21 \% ; p=0.65)$ or Alx $(\Delta$ $2.4 \% ; p=0.20$ ) between pure epicatechin and dark chocolate. The absolute changes in FMD $(+0.75 \% ; p=0.10)$ and Alx $(-2.2 \% ; p=0.23)$ after pure epicatechin were not significant. Dark chocolate improved FMD (+0.96\%; $p=0.04)$ and Alx (-4.6\%; $p=0.02)$. Standardised per 100mg of epicatechin, the AUC did not differ $(p=0.14)$ between pure epicatechin $(18.9 \mu \mathrm{M} . \mathrm{h})$ and dark chocolate (16.2 $\mu$ M.h).

\section{Conclusion}

The acute improvements in FMD and Alx after pure epicatechin and dark chocolate were similar and the bioavailability of epicatechin did not differ. This suggests that epicatechin may contribute to the vascular effects of cocoa. 


\section{INTRODUCTION}

Cocoa consumption is associated with a lower risk of cardiovascular disease (CVD). In a meta-analysis of prospective cohort studies, subjects $(n=114,009)$ with the highest level of chocolate consumption had a 37\% lower risk of CVD, compared to the lowest level [1]. Human randomised controlled trials (RCTs) showed that consumption of flavonoid-rich cocoa/chocolate improved risk factors of CVD, such as blood pressure [2] and insulin resistance (HOMA-IR) [3], as well as flow-mediated dilation (FMD) - a measure of endothelial function. RCTs showed that acute cocoa/chocolate consumption increased FMD by $3.2 \%$ [3]. In addition, chocolate consumption improved vascular function by reducing arterial stiffness acutely (2-3 hours), as measured by augmentation index (Alx) [4, 5]. Potential mechanisms point to an increase in nitric oxide (NO), a vasodilator, after chocolate consumption and a decrease in endothelin-1, a vasoconstrictor [6].

Cocoa is notably rich in flavan-3-ols, and contains a mixture of monomers and oligomers (up to 10 units). Ottaviani et al. showed that only monomeric flavan-3-ols, but not oligomers contributed to the plasma pool of flavan-3-ols in humans [7]. Cocoa contains two monomeric flavan-3-ols; epicatechin and catechin. The content of epicatechin in cocoa is approximately three times higher than that of catechins [8]. A study in rats also showed that epicatechin was more bioavailable than catechins [9]. The relatively high bioavailability and high natural occurrence of epicatechin in cocoa suggests that epicatechin may contribute directly to the cardioprotective effects of cocoa. In a study with 10 subjects, Schroeter et al. showed that changes in FMD after acute cocoa consumption correlated with changes in plasma epicatechin concentrations [10]. Furthermore, Loke et al. showed that $200 \mathrm{mg}$ of pure epicatechin increased NO and decreased endothelin-1 concentrations acutely [11].

Effects of other compounds in cocoa such as theobromine and magnesium on vascular function have not yet been studied [12], and to our knowledge, the bioavailability of pure epicatechin and epicatechin from chocolate has also not yet been compared. As such, the contribution of epicatechin to the vascular effects of cocoa is still unclear. In the present study we aimed to compare the acute effects of pure epicatechin (in supplement form) and dark chocolate on vascular function in a randomised, assessor-blind, crossover study. In addition, we compared the bioavailability of pure epicatechin and epicatechin in dark chocolate. 


\section{METHODS}

\section{Subjects}

Apparently healthy, non-smoking, men aged 40 to 80 years and with a BMI between 20 and $30 \mathrm{~kg} / \mathrm{m} 2$ were recruited from the area of Wageningen and surroundings, in the Netherlands. Exclusion criteria included presence of diabetes mellitus, cardiovascular, gastrointestinal or liver diseases as well as usage of anti-hypertensive or cholesterol-lowering medication, adherence to a prescribed diet, unstable weight in the last two months and high levels of moderate physical activity (>10hrs/week). All participants (Table 1) gave written informed consent and the study was approved by the Medical Ethics Committee of Wageningen University (NL 4843308114). The trial was registered at ClinicalTrials.gov (registration no: NCT02221791).

\section{Study Design}

The study was conducted as an acute randomised, placebo-controlled, crossover intervention in September and October 2014. Subjects received three treatments, encoded $A, B$, and C. Subjects were allocated to one of six possible intervention sequences using computer-generated block randomization. The three treatments were: 1) $70 \mathrm{~g}$ of dark chocolate (150 mg epicatechin) with two placebo capsules; 2) pure epicatechin (100mg) in two capsules with $75 \mathrm{~g}$ of white chocolate and 3) two placebo capsules with $75 \mathrm{~g}$ of white chocolate (0 mg epicatechin). Epicatechin capsules contained $50 \mathrm{mg}$ of (-)-epicatechin (purity 96.2\%) and microcrystalline cellulose as an excipient. Placebo capsules contained only microcrystalline cellulose [13]. Treatments were provided in sealed envelopes by a member of staff not involved in the study, leaving researchers blind to treatment allocation. Subjects were blinded to the type of capsule $(A, B$, or $C)$ but not to the type of chocolate.

TABLE 1. Composition of the chocolates.

\begin{tabular}{lcc}
\hline & Dark chocolate (70g) & White chocolate $(75 \mathrm{~g})$ \\
\hline (-)-Epicatechin (mg) & 150 & 0 \\
$(+)$-Catechin (mg) & 42 & 0 \\
Energy (kcal) & 397 & 415 \\
Total fat (g) & 30 & 25 \\
Saturated fat (g) & 18 & 16 \\
Carbohydrates (g) & 22 & 42 \\
Sugars (g) & 19 & 42 \\
Protein (g) & 5 & 6 \\
Magnesium (mg) & 114 & 5 \\
\hline
\end{tabular}


Participants visited the university on three measurement days, which were each separated by a two-week washout period. For the 24-hours prior to each measurement day, subjects were asked to avoid physical activity and alcohol consumption and in the evening consumed a standardised low-flavonoid meal provided by the research team. One week prior to the start of the study and throughout the study period, subjects were asked to avoid consumption of flavonoid-rich foods (cocoa products, red wine and apples) and to drink no more than one cup of tea per day.

Baseline vascular function (FMD and Alx) was measured in a fasting state $(T=0)$, at the beginning of each measurement day (Figure 1). Immediately after baseline measurements, subjects consumed the chocolate and capsules with a glass of water. Vascular function measurements were repeated two hours after chocolate consumption $(T=2)$. To determine bioavailability, blood samples were taken by means of an intravenous catheter (venflon) at baseline $(\mathrm{T}=0)$ as well as 1 hour, 2, 3, 4, 6 and 8 hours after chocolate consumption. Participants received a flavonoid-free breakfast consisting of bread, cheese, honey, water and milk after all vascular function measurements were completed (after T=2).

\section{Chocolate Composition}

The dark and white chocolate were matched for energy, fat, saturated fat and protein (Table 1). The dark chocolate was obtained from Barry Callebaut ${ }^{\circledR}$ (CHD-070-ACTICOA--558) and the white chocolate was a commercially available brand (Verkade). The flavan-3-ol monomer concentrations of the two types of chocolate were determined by means of reversed phase HPLC with fluorescence detection [14]. Samples of NIST Baking Chocolate (NIST2384) were analysed as a certified reference sample, and the estimated epicatechin content for the NIST Baking Chocolate was close to the certified value and within the certified range. The daily dose of dark chocolate contained $150 \mathrm{mg}$ of (-)-epicatechin and $42 \mathrm{mg}$ of (+)-catechin. The white chocolate contained no (-)-epicatechin or (+)-catechin. The dark chocolate provided $19 \mathrm{~g}$ of sugar and $114 \mathrm{mg}$ of magnesium, compared to $42 \mathrm{~g}$ of sugar and $5 \mathrm{mg}$ of magnesium for the white chocolate.

\begin{tabular}{|c|c|c|c|c|c|c|c|c|c|c|c|c|c|c|c|c|c|c|c|c|c|c|c|c|}
\hline \multirow[b]{2}{*}{ Time (hrs) } & \multicolumn{7}{|c|}{ Dark chocolate } & \multirow[t]{2}{*}{$\begin{array}{l}\text { Washout } \\
\text { (2 weeks) }\end{array}$} & \multicolumn{7}{|c|}{ Epicatechin } & \multirow{2}{*}{$\begin{array}{l}\text { Washout } \\
\text { (2 weeks) }\end{array}$} & \multicolumn{8}{|c|}{ Placebo } \\
\hline & 0 & 1 & 23 & 4 & 5 & 6 & 7 & & & 12 & 23 & 4 & 5 & 67 & 8 & & 0 & 1 & 2 & 3 & 45 & 56 & 7 & - 8 \\
\hline Blood sample & $\uparrow$ & $\uparrow$ & $\uparrow \uparrow$ & $\uparrow$ & & $\uparrow$ & & & & $\uparrow \uparrow$ & $\uparrow \uparrow$ & $\uparrow$ & 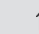 & $\uparrow$ & & & $\uparrow$ & $\uparrow$ & 1 & $\uparrow$ & $\uparrow$ & $\uparrow$ & & $\uparrow$ \\
\hline Vascular Function & $\uparrow$ & & $\uparrow$ & & & & & & $\uparrow$ & 1 & $\uparrow$ & & & & & & $\uparrow$ & & $\uparrow$ & & & & & \\
\hline Breakfast & & & 1 & 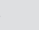 & & & & & & & $\uparrow$ & & & & & & & & & $\uparrow$ & & & & \\
\hline
\end{tabular}

FIGURE 1. Timeline of intervention study. Participants received interventions (dark chocolate, epicatechin and placebo) in random order. The chocolate was consumed immediately after the baseline measurements ( $T=0 \mathrm{hrs}$ ) were completed. Each intervention was separated by a 2-week washout period. Vascular function measurements included flow-mediated dilation and pulse wave analysis. 


\section{Vascular Function}

Endothelial function (FMD) was measured non-invasively in the right brachial artery by the same researcher, who was blinded to treatment allocation. An ultrasound transducer (7.5 MHz) was positioned proximal to the antecubital fossa. Baseline arterial diameter was measured for 3 mins. Subsequently, reactive hyperaemia was induced by 5 mins of lower arm occlusion through inflation of a cuff to $200 \mathrm{mmHg}$. FMD-images were processed automatically using custom-written software (MyFMD, Prof. A.P.G. Hoeks, Department of Biomedical Engineering, Maastricht University). FMD was calculated as peak change in arterial diameter following reactive hyperaemia relative to baseline. Endotheliumindependent vasodilation was calculated as peak change in arterial diameter over a 5 minute period following sublingual administration of $400 \mu \mathrm{g}$ of glyceryl trinitrate (GTN) and did not differ between the interventions.

Arterial stiffness was measured as Alx corrected for a heart rate of $75 \mathrm{bpm}$. Measurements were taken in triplicate by means of applanation tonometry using the SphygmoCor system (version 8: Atcor Medical, Sydney, Australia). Central aortic waveforms were derived using a validated transfer function $[15,16]$. Subsequently, HR-corrected central Alx, subendocardial viability ratio (SEVR) and ejection duration were estimated using integrated software. Office BP was measured as the mean of the last three of four measurements using an automated oscillometric device (Dinamap Pro 100). All measurements were taken in a temperaturecontrolled room $\left(20-24^{\circ} \mathrm{C}\right)$, in the supine position, after 10 minutes of rest.

\section{Blood Parameters}

Heparin-plasma samples were taken at baseline $(T=0)$ and two hours after chocolate consumption ( $\mathrm{T}=2$ ) to determine plasma NOx concentrations by chemiluminescence of NO formed after release from NO2, NO2- and nitrosated and nitrosylated species [17]. To minimize NOx contamination, measurements of NOx were performed only when atmospheric NOx concentrations were below $40 \mu \mathrm{g} / \mathrm{m} 3$. Detection limit was $10 \mathrm{nmol} / \mathrm{L}$ and the intra-assay coefficient of variation was $8.3 \%$. Endothelin-1 was measured by an electrochemiluminescence detection system using multiarray technology (SECTOR Imager 2400, Meso Scale Discovery) in EDTA-plasma.

To determine epicatechin bioavailability, EDTA-plasma samples were taken at all 7 timepoints throughout the day. Monomeric (epi)catechin metabolites were determined using a slightly modified procedure as described previously [18]. In brief, after centrifugation, plasma samples were mixed with a storage solution of 0.4M NaH2PO4 buffer containing $20 \%$ ascorbic acid and $0.1 \%$ EDTA, and stored at $-80^{\circ} \mathrm{C}$ until further analysis. For analysis, plasma samples were thawed and mixed with taxifolin as internal standard. Proteins were precipated with trichloroacetic acid and dimethylformadide. UPLC-MS/MS analysis was used to determine sulfated, glucuronidated and methylated metabolites of (-)-epicatechin 
and (+)-catechin including di-conjugated metabolites. For each type of (epi)catechin metabolite (e.g. monosulfate, monoglucuronide, etc.), a number of isomers with distinct retention times were observed, and the peak areas of all isomers were summed for the purposes of calculating total (epi)catechin metabolites.

\section{Statistical Analysis}

FMD was defined as the primary outcome and the power calculation was based on previous cocoa studies3. Assuming an SD in absolute FMD change of 2.5\%, 16 participants would provide sufficient power to detect an absolute change of $2.1 \%$ (2-sided a of 5\%, power = $80 \%$ ). All analyses were performed according to a pre-defined statistical analysis plan using SAS software version 9.3 (SAS Institute, Cary, NC) prior to de-blinding. The change over time from baseline to 2-hour post intervention was calculated for each vascular function parameter. Treatment effect was defined as the difference between the change over time after each intervention compared to placebo ( $\Delta$ intervention - $\Delta$ placebo). Histograms of treatment effects were visually inspected and all treatment effects were judged to be normally distributed. Linear mixed models for repeated measures (SAS, PROC MIXED) were used to test the treatment effects. 'Treatment' and 'period' were set as fixed effects and 'subject' as random effect. Compound symmetry was used as covariant structure as this resulted in the best fit according to a likelihood ratio test. Treatment effects were expressed as least squares mean with $95 \%$ confidence intervals $(95 \% \mathrm{Cl})$. Statistical significance was set at a two-sided a-level of 0.05 . Bioavailability was calculated as the area under the curve (AUC) for total (epi)catechin metabolites over the 8-hour period, and was calculated according to the trapezoidal rule.

\section{RESULTS}

\section{Study Population}

The mean age of the 20 randomised men who all completed the study was $61.8 \pm 9.3$ years. The mean baseline BMI was $25.1 \pm 2.1 \mathrm{~kg} / \mathrm{m}^{2}$ and the mean SBP/DBP was $121 / 74 \mathrm{~mm} \mathrm{Hg}$ (Table 2). Body weight remained stable throughout the study period and subjects did not report adverse events.

\section{Vascular Function}

The change in FMD was not different between dark chocolate and pure epicatechin $(\Delta 0.21 \%$; $\mathrm{p}=0.65)$. Pure epicatechin supplementation increased FMD by $0.75 \%(95 \% \mathrm{Cl}:-0.18,1.69$; $\mathrm{p}=0.10$ ) when compared to placebo, but the effect was not statistically significant. Dark chocolate significantly increased FMD by $0.96 \%(95 \% \mathrm{Cl}: 0.02-1.90 ; \mathrm{p}=0.04)$ when compared to placebo (Table 3). 
TABLE 2. Baseline characteristics of 20 subjects randomised at the start of the study.

\begin{tabular}{lc}
\hline & Mean \pm SD \\
\hline Age $(\mathrm{yrs})$ & $61.8 \pm 9.3$ \\
BMI $\left(\mathrm{kg} / \mathrm{m}^{2}\right)$ & $25.1 \pm 2.1$ \\
Office SBP $(\mathrm{mmHg})$ & $121.5 \pm 15.1$ \\
Office DBP $(\mathrm{mmHg})$ & $74.0 \pm 6.3$ \\
FMD $(\%)$ & $3.0 \pm 1.6$ \\
Alx $(\%)$ & $19.3 \pm 11.9$ \\
Nitric oxide $(\mathrm{nmol} / \mathrm{L})$ & $79.0 \pm 23.2$ \\
Endothelin-1 $(\mathrm{pg} / \mathrm{ml})$ & $1.46 \pm 0.30$ \\
\hline
\end{tabular}

Data are given as mean \pm SD.

Abbreviations: Alx, augmentation index corrected for heart rate of 75 bpm; BMI, body mass index, DBP, diastolic blood pressure; FMD, flow-mediated dilation; SBP, systolic blood pressure.

TABLE 3. Treatment effects of pure epicatechin (100mg) and dark chocolate (150mg epicatechin) supplementation on markers of vascular function in healthy subjects.

\begin{tabular}{|c|c|c|c|c|c|c|c|c|c|}
\hline \multirow[b]{3}{*}{ FMD $(\%)^{\ddagger}$} & \multicolumn{3}{|c|}{ Pure epicatechin $(n=20)$} & \multicolumn{3}{|c|}{ Dark chocolate $(n=20)$} & \multicolumn{3}{|c|}{ Difference $^{\dagger}$} \\
\hline & \multicolumn{2}{|c|}{$\begin{array}{l}\text { Treatment effect } \\
\qquad(95 \% \mathrm{Cl})\end{array}$} & \multirow{2}{*}{$\begin{array}{c}\begin{array}{c}\mathrm{p}- \\
\text { value }\end{array} \\
0.10\end{array}$} & \multicolumn{2}{|c|}{$\begin{array}{l}\text { Treatment effect* } \\
\qquad(95 \% \mathrm{Cl})\end{array}$} & \multirow{2}{*}{$\begin{array}{c}\begin{array}{c}\mathrm{p}- \\
\text { value }\end{array} \\
0.04\end{array}$} & \multicolumn{2}{|c|}{$\begin{array}{l}\text { Difference } \\
(95 \% \mathrm{Cl})\end{array}$} & \multirow{2}{*}{$\begin{array}{c}\begin{array}{c}\mathrm{p}- \\
\text { value }\end{array} \\
0.65\end{array}$} \\
\hline & 0.75 & $\begin{array}{c}(-0.18 \\
1.69)\end{array}$ & & 0.96 & $\begin{array}{l}(0.02 \\
1.90)\end{array}$ & & 0.21 & $\begin{array}{c}(-0.72 \\
1.13)\end{array}$ & \\
\hline \multicolumn{10}{|l|}{ Pulse Wave Analysis ${ }^{\ddagger}$} \\
\hline Alx (\%) & -2.2 & $(-5.9,1.5)$ & 0.23 & -4.6 & $(-8.2,-0.9)$ & 0.02 & -2.4 & $(-6.1,1.3)$ & 0.20 \\
\hline SEVR (\%) & -0.4 & $(-9.7,8.8)$ & 0.92 & -1.5 & $(-10.8,7.8)$ & 0.74 & -1.1 & $(-10.4,8.2)$ & 0.81 \\
\hline $\begin{array}{l}\text { Ejection duration } \\
\text { (ms) }\end{array}$ & 5.2 & $(-8.9,19.3)$ & 0.46 & 5.5 & $(-8.6,19.6)$ & 0.43 & 0.4 & $\begin{array}{c}(-12.7 \\
13.4)\end{array}$ & 0.96 \\
\hline Systolic BP (mmHg) & 1.3 & $(-3.6,6.2)$ & 0.84 & -0.5 & $(-5.4,4.4)$ & 0.60 & -1.8 & $(-6.7,3.1)$ & 0.47 \\
\hline Diastolic BP (mmHg) & 0.3 & $(-2.8,3.5)$ & 0.94 & 0.1 & $(-3.0,3.3)$ & 0.82 & -0.2 & $(-3.4,2.9)$ & 0.88 \\
\hline Nitric oxide (nmol/L) & -8.7 & $(-21.7,4.3)$ & 0.18 & 18.1 & $(5.1,31.1)$ & 0.008 & 26.8 & $(13.8,39.7)$ & $<0.001$ \\
\hline Endothelin-1 (pg/ml) & 0.07 & $(-0.14,0.29)$ & 0.50 & 0.45 & $(0.24,0.67)$ & $<0.001$ & 0.38 & $(0.16,0.60)$ & 0.001 \\
\hline
\end{tabular}

${ }^{*}$ Treatment effect, $\Delta_{\text {intervention }}-\Delta_{\text {placebo }}=$ (value parameter at end treatment - value at start treatment) (value parameter at end placebo - value at start placebo)

${ }^{\dagger}$ Difference in treatment effect between dark chocolate and pure epicatechin $\left(\Delta_{\text {chocolate }}-\Delta_{\text {epicatechin }}\right)$.

${ }^{\ddagger}$ Absolute difference.

Abbreviations: Alx, augmentation index corrected for a heart rate of 75 bpm; DBP, diastolic blood pressure; FMD, Flow-mediated dilation; BP, blood pressure; SEVR = subendocardial viability ratio.

Data are least square means $(95 \% \mathrm{Cl})$ from linear mixed model for repeated measures with compound symmetry as covariant structure. 
The change in Alx was not different between dark chocolate and pure epicatechin $(\Delta-2.4 \%$; $\mathrm{p}=0.20)$. Pure epicatechin lowered Alx by $2.2 \%(95 \% \mathrm{Cl}:-5.9,1.5 ; \mathrm{p}=0.23)$, but the effect was not statistically significant. Dark chocolate lowered Alx by $4.6 \%(95 \% \mathrm{Cl}:-8.2,-0.9 ; \mathrm{p}<0.05)$ when compared to placebo. Ejection duration and SEVR did not change following either pure epicatechin or dark chocolate supplementation.

The increase in plasma NO was higher after dark chocolate than after pure epicatechin $(\Delta 26.8 \mathrm{nmol} / \mathrm{L} ; \mathrm{p}<0.001)$. Pure epicatechin did not change plasma NO levels when compared to placebo. Dark chocolate increased plasma NO when compared to placebo $(\Delta 18.1 \mathrm{nmol} / \mathrm{L} ; 95 \% \mathrm{Cl}: 5.1,31.1 ; \mathrm{p}<0.01)$. The increase in plasma endothelin-1 was higher after dark chocolate than after pure epicatechin $(\Delta 0.38 \mathrm{pg} / \mathrm{ml} ; \mathrm{p}=0.001)$. Pure epicatechin had no effect on endothelin-1, however, dark chocolate increased endothelin-1 by 0.45 pg/ $\mathrm{ml}(95 \% \mathrm{Cl}: 0.24,0.67 ; \mathrm{p}<0.01)$ compared to placebo.

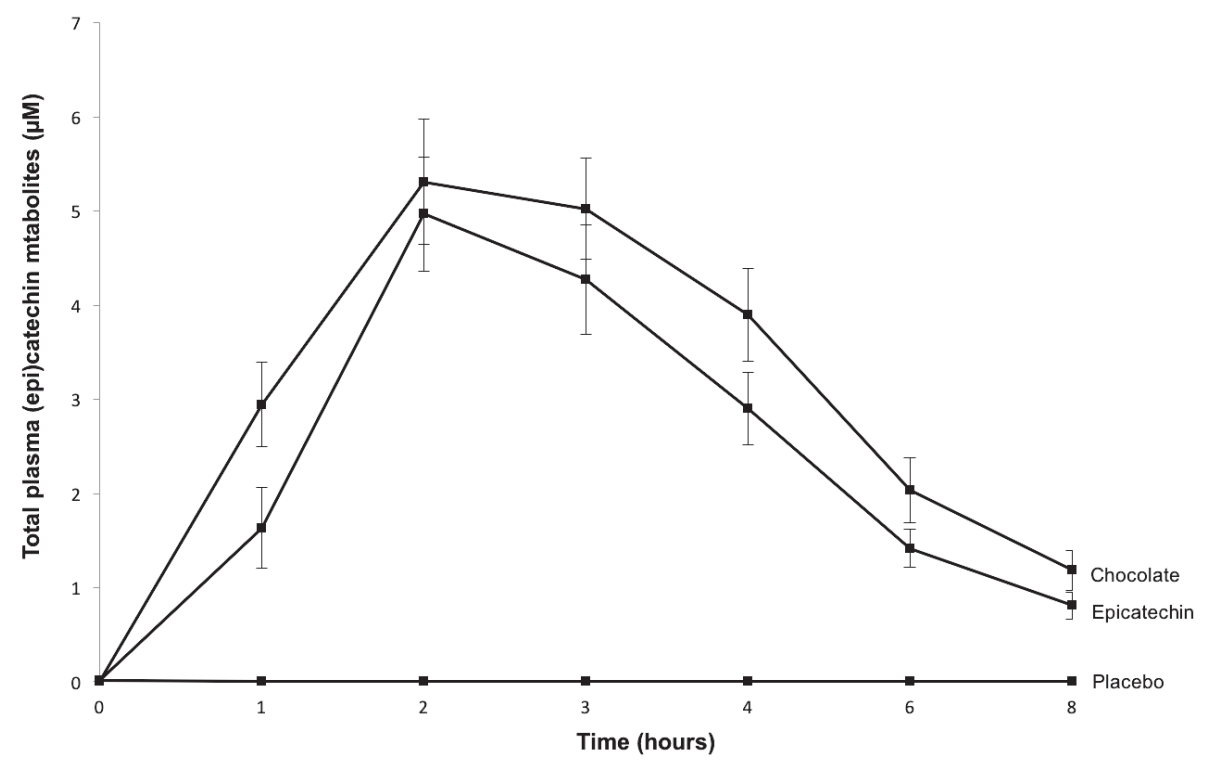

FIGURE 2. Time course of plasma (epi)catechin metabolite concentrations following consumption of 1) $70 \mathrm{~g}$ dark chocolate (150 mg epicatechin) +2 placebo capsules); 2 ) pure epicatechin (100mg) in 2 capsules $+75 \mathrm{~g}$ of white chocolate) and; 3 ) placebo (75g of white chocolate +2 placebo capsules). Data are mean \pm SEM. 


\section{Bioavailability}

Both epicatechin and dark chocolate increased (epi)catechin metabolite concentrations, with a peak seen after 2 hours (Figure 2). The placebo intervention did not increase (epi) catechin metabolite concentrations at any time point (total AUC $=0.03 \mu \mathrm{M}$.h). After pure epicatechin supplementation the AUC was $18.9 \mu \mathrm{M} . \mathrm{h}$, and higher after dark chocolate consumption: $24.4 \mu \mathrm{M}$.h. This difference was statistically significant $(p=0.03)$. Taking into account the difference in epicatechin dosage between the dark chocolate and the epicatechin supplement, the AUC after dark chocolate was $16.2 \mu \mathrm{M}$.h, per $100 \mathrm{mg}$ of epicatechin. This was not significantly lower than the AUC for pure epicatechin of 18. 9 $\mu \mathrm{M} . \mathrm{h}(\Delta 2.8 \mu \mathrm{M} . \mathrm{h} ; \mathrm{p}=0.14)$.

\section{DISCUSSION}

In this acute study of 20 healthy adult men, the increase of FMD after pure epicatechin and dark chocolate was similar, but not statistically significant for pure epicatechin. In contrast to dark chocolate, pure epicatechin did not significantly affect Alx, NO, or endothelin-1. The bioavailability of pure epicatechin and epicatechin from chocolate was similar.

Pure epicatechin increased FMD and decreased Alx, however, in both cases the effect was not significant. In contrast, dark chocolate increased FMD and decreased Alx. There was no significant difference, however, between the effects of pure epicatechin and dark chocolate on FMD and Alx. The increase in FMD of 0.96\% (absolute) after dark chocolate consumption is lower than the increase of 3.2\% (95\% Cl: $2.04,4.33)$ reported in a metaanalysis of acute cocoa RCTs which used similar dosages of about $100 \mathrm{mg}$ of epicatechin [3]. Our study population was, on average, older than the majority of study populations included in the meta-analysis. Because FMD is known to decrease with age [19], this could have influenced the results of our study. Whether age also plays a role in the improvement of FMD has not been sufficiently studied. Recently, Heiss et al. showed, however, that improvements in FMD (absolute) were similar in young and elderly healthy men [20]. Besides FMD, dark chocolate also decreased Aix by $4.6 \%$, which is in line with previous acute RCTs which showed decreases of $5 \% 4$ and $7.8 \%$ [5].

The fact that dark chocolate significantly improved FMD and Alx while pure epicatechin did not, could be explained by differences in dosage. The chocolate used in the present study had a certified minimum flavan-3-ol content of $1 \%$. The content of epicatechin was not, however, specified. In a previous study, this chocolate had a reported content of 96-119 mg of epicatechin [4]. When designing the trial we, therefore, decided to use this chocolate. Unfortunately, after chemical analysis, we found that the batch used in our study had a higher epicatechin content (150 mg), and thus the comparison between the chocolate and the pure epicatechin was less well-balanced concerning dosage. Possibly the 
$100 \mathrm{mg}$ in the epicatechin supplements was not high enough to elicit significant changes in vascular function. Standardised for the epicatechin content of the dark chocolate, there was no significant difference in the AUC for (epi)catechin metabolites between pure epicatechin and dark chocolate. Besides (-)-epicatechin, the dark chocolate also contained $(+)$-catechin. Because metabolites of (+)-catechin and (-)-epicatechin cannot be separated in the chromatographic system, both (-)-epicatechin and (+)-catechin are likely to have contributed to the (epi)catechin metabolites of the AUC. A study in rats showed that the bioavailability of (+)-catechin is approximately $40 \%$ lower than that of (-)-epicatechin [9]. Nevertheless, (+)-catechin will also have contributed to the AUC of dark chocolate. This suggests that epicatechin from dark chocolate is less bioavailable than pure epicatechin, and dismisses a bioavailability issue of the pure epicatechin supplement.

To match for the energy and fat content of the dark chocolate, which otherwise would have affected vascular function [21, 22], we used white chocolate during the epicatechin and placebo interventions. This introduced imbalance in other nutrients and bioactive compounds. The higher sugar content of the white chocolate (42g vs. $19 \mathrm{~g}$ ) may have suppressed the effects of pure epicatechin on FMD, as a previous study showed that sugar consumption ( $\leq 75 \mathrm{~g}$ glucose) reduced FMD acutely [22]. The effects of theobromine (which is present in dark chocolate) on FMD and Alx are unknown [12]. Besides theobromine, the dark chocolate also contained $114 \mathrm{mg}$ of $\mathrm{Mg}$ - almost one half of the recommended daily allowance of $300 \mathrm{mg} /$ day for male adults. The white chocolate only contained a minor quantity of $\mathrm{Mg}$. To our knowledge, acute effects of $\mathrm{Mg}$ have not been studied. Previous RCTs reported that chronic supplementation of about $350 \mathrm{mg}$ of $\mathrm{Mg}$ increased FMD by $5.1 \%$ [23] and $11.1 \%$ [24] in cardiometabolic patients, but not in a healthy population [25]. It is possible, therefore, that sugar and $\mathrm{Mg}$ could play a role in the effects of chocolate on endothelial function.

The improvements in vascular function are thought to be mediated through changes in vasoactive compounds such as NO (vasodilator) and endothelin-1 (vasoconstrictor). Results from RCTs showed that cocoa consumption increased NO acutely [10, 26]. In our acute study, dark chocolate also increased NO, which confirms the established beneficial effects of dark chocolate on vascular function. A recent study showed that cocoa flavan-3ols dose-dependently decreased endothelin-1 production in healthy volunteers6. To our knowledge, our study is the first to show an increase in endothelin-1 after dark chocolate consumption, which could be a chance finding. Previously, Loke et al. showed that acute consumption of $200 \mathrm{mg}$ of epicatechin dissolved in water increased plasma nitrite concentrations and decreased plasma endothelin-1 [11]. In our study, pure epicatechin supplementation had no effect on NO or endothelin-1. This again suggests that a higher dosage may be required to elicit changes in NO and endothelin-1. Thus, dose-response relations should be studied. 
To conclude, there was no difference in FMD or Alx between pure epicatechin and dark chocolate. The bioavailability of epicatechin did not differ between pure epicatechin dark chocolate. This suggests that epicatechin may contribute to the vascular effects of cocoa.

\section{ACKNOWLEDGEMENTS}

We thank Harrie Robins, for practical assistance in carrying out the study and Dini Venema for biochemical analyses. We are also grateful to Prof. dr. Hendriek Boshuizen for statistical advice and Barry Callebaut for providing the chocolate. 


\section{REFERENCES}

1. Buitrago-Lopez A, Sanderson J, Johnson L, Warnakula S, Wood A, Di Angelantonio E, Franco OH. Chocolate consumption and cardiometabolic disorders: Systematic review and meta-analysis. BMJ (Online). 2011;343

2. Ried K, Sullivan TR, Fakler P, Frank OR, Stocks NP. Effect of cocoa on blood pressure. Cochrane Database Syst Rev. 2012;8

3. Hooper L, Kay C, Abdelhamid A, Kroon PA, Cohn JS, Rimm EB, Cassidy A. Effects of chocolate, cocoa, and flavan-3-ols on cardiovascular health: A systematic review and meta-analysis of randomized trials. Am J Clin Nutr. 2012;95:740-751

4. Esser DM, M; Oosterink, E; Stalmach, A; Muller, M; Afman, L. Dark chocolate consumption improves leukocyte adhesion factors and vascular function in overweight men. FASEB J. 2013;28:1464-1473

5. Vlachopoulos C, Aznaouridis K, Alexopoulos N, Economou E, Andreadou I, Stefanadis C. Effect of dark chocolate on arterial function in healthy individuals. Am J Hypertens. 2005;18:785-791

6. Grassi D, Desideri G, Necozione S, Di Giosia P, Barnabei R, Allegaert L, Bernaert H, Ferri C. Cocoa consumption dose-dependently improves flow-mediated dilation and arterial stiffness decreasing blood pressure in healthy individuals. J Hypertens. 2015;33:294-303

7. Ottaviani Jl, Kwik-Uribe C, Keen CL, Schroeter $\mathrm{H}$. Intake of dietary procyanidins does not contribute to the pool of circulating flavanols in humans. Am J Clin Nutr. 2012;95:851-858

8. Arts ICW, Van De Putte B, Hollman PCH. Catechin contents of foods commonly consumed in the netherlands. 1. Fruits, vegetables, staple foods, and processed foods. J Agric Food Chem. 2000;48:1746-1751

9. Ottaviani Jl, Momma TY, Heiss C, Kwik-Uribe C, Schroeter H, Keen CL. The stereochemical configuration of flavanols influences the level and metabolism of flavanols in humans and their biological activity in vivo. Free Radic Biol Med. 2011;50:237-244

10. Schroeter H, Heiss C, Balzer J, Kleinbongard P, Keen CL, Hollenberg NK, Sies H, Kwik-Uribe C, Schmitz HH, Kelm M. (-)-epicatechin mediates beneficial effects of flavanol-rich cocoa on vascular function in humans. Proc Natl Acad Sci U S A. 2006;103:1024-1029

11. Loke WM, Hodgson JM, Proudfoot JM, McKinley AJ, Puddey IB, Croft KD. Pure dietary flavonoids quercetin and (-)-epicatechin augment nitric oxide products and reduce endothelin-1 acutely in healthy men. Am J Clin Nutr. 2008;88:1018-1025

12. Berends LM, Van Der Velpen V, Cassidy A. Flavan-3-ols, theobromine, and the effects of cocoa and chocolate on cardiometabolic risk factors. Curr Opin Lipidol. 2015;26:10-19

13. Dower Jl, Geleijnse JM, Gijsbers L, Zock PL, Kromhout D, Hollman PCH. Effects of the pure flavonoids epicatechin and quercetin on vascular function and cardiometabolic health: A randomized, double-blind, placebo-controlled, crossover trial. Am J Clin Nutr. 2015;101:914-921

14. Hollands WJ, Hart DJ, Dainty JR, Hasselwander O, Tiihonen K, Wood R, Kroon PA. Bioavailability of epicatechin and effects on nitric oxide metabolites of an apple flavanol-rich extract supplemented beverage compared to a whole apple puree: A randomized, placebo-controlled, crossover trial. Mol Nutr Food Res. 2013;57:1209-1217 
15. Karamanoglu M, O'Rourke MF, Avolio AP, Kelly RP. An analysis of the relationship between central aortic and peripheral upper limb pressure waves in man. Eur Heart J. 1993;14:160-167

16. Pauca AL, O'Rourke MF, Kon ND. Prospective evaluation of a method for estimating ascending aortic pressure from the radial artery pressure waveform. Hypertension. 2001;38:932-937

17. Appeldoorn MM, Venema DP, Peters THF, Koenen ME, Arts ICW, Vincken JP, Gruppen H, Keuer J, Hollman PCH. Some phenolic compounds increase the nitric oxide level in endothelial cells in vitro. J Agric Food Chem. 2009;57:7693-7699

18. Saha S, Hollands W, Needs PW, Ostertag LM, De Roos B, Duthie GG, Kroon PA. Human o-sulfated metabolites of (-)-epicatechin and methyl-(-)-epicatechin are poor substrates for commercial aryl-sulfatases: Implications for studies concerned with quantifying epicatechin bioavailability. Pharmacol Res. 2012;65:592-602

19. Heiss C, Keymel S, Niesler U, Ziemann J, Kelm M, Kalka C. Impaired progenitor cell activity in agerelated endothelial dysfunction. J Am Coll Cardiol. 2005;45:1441-1448

20. Heiss C, Sansone R, Karimi H, Krabbe M, Schuler D, Rodriguez-Mateos A, Kraemer T, Cortese-Krott MM, Kuhnle GGC, Spencer JPE, Schroeter H, Merx MW, Kelm M. Impact of cocoa flavanol intake on age-dependent vascular stiffness in healthy men: A randomized, controlled, double-masked trial. Age. 2015;37:56

21. Nicholls SJ, Lundman P, Harmer JA, Cutri B, Griffiths KA, Rye KA, Barter PJ, Celermajer DS. Consumption of saturated fat impairs the anti-inflammatory properties of high-density lipoproteins and endothelial function. J Am Coll Cardiol. 2006;48:715-720

22. Van Oostrom AJHHM, Sijmonsma TP, Verseyden C, Jansen EHJM, De Koning EJP, Rabelink TJ, Cabezas MC. Postprandial recruitment of neutrophils may contribute to endothelial dysfunction. J Lipid Res. 2003;44:576-583

23. Barbagallo M, Dominguez LJ, Galioto A, Pineo A, Belvedere M. Oral magnesium supplementation improves vascular function in elderly diabetic patients. Magnes Res. 2010;23:131-137

24. Shechter M, Sharir M, Paul MJ, James L, Burton F, Noel SC, Merz B. Oral magnesium therapy improves endothelial function in patients with coronary artery disease. Circulation. 2000;102:23532358

25. Cosaro E, Bonafini S, Montagnana M, Danese E, Trettene MS, Minuz P, Delva P, Fava C. Effects of magnesium supplements on blood pressure, endothelial function and metabolic parameters in healthy young men with a family history of metabolic syndrome. Nutr Metab Cardiovasc Dis. 2014;24:1213-1220

26. Heiss C, Finis D, Kleinbongard P, Hoffmann A, Rassaf T, Kelm M, Sies H. Sustained increase in flow-mediated dilation after daily intake of high-flavanol cocoa drink over 1 week. J Cardiovasc Pharmacol. 2007;49:74-80 


General Discussion 
Cocoa and tea intake are associated with a lower risk of cardiovascular disease (CVD) [1, 2]. This may be due to the high intake of flavonoids from cocoa and tea. In this thesis, the effects of epicatechin (the main flavan-3-ol in cocoa, but also substantially present in tea) and quercetin (the main flavonol in tea) on cardiovascular health were investigated. This was done by means of an epidemiological analysis, randomised-controlled trials (RCTs) in humans, and gene expression analyses.

The association between epicatechin intake and CVD mortality was studied using data from the Zutphen Elderly Study, a cohort of elderly Dutch men who were followed for a period of 25-years. Men in the highest tertile of epicatechin intake had a 38\% lower risk of coronary heart disease (CHD) mortality compared to men in the lowest tertile. For men with prevalent CVD, the risk of CVD mortality was $46 \%$ lower for men in the highest tertile of intake, compared to men in the lowest tertile.

In a chronic randomised-controlled trial (RCT) we showed that 4-week supplementation of pure epicatechin improved insulin resistance, sE-selectin (a biomarker of endothelial function), and had a borderline significant effect on endothelial function. Epicatechin did not improve blood pressure, arterial stiffness or biomarkers of inflammation. Pure quercetin supplementation (4 weeks) did not improve endothelial function, blood pressure or insulin resistance but did improve IL-1 $\beta$ (a biomarker of inflammation) and sE-selectin. To investigate the effects of epicatechin on gene expression, we carried out whole genome analyses of peripheral blood mononuclear cells which were collected in the chronic RCT. Expression of 465 genes changed significantly between the epicatechin and the placebo intervention. Epicatechin down-regulated gene sets involved in inflammation. Only a few genes within these regulated gene sets were actually significantly changed upon epicatechin supplementation. Upstream regulators that were inhibited were classified as cytokine or inflammatory-type molecules.

In an acute RCT, we showed that there was no difference in response of endothelial function (FMD and Alx) between epicatechin (100 mg) and dark chocolate (150 mg epicatechin). Only dark chocolate significantly improved FMD and Alx. The bioavailability of epicatechin did not differ between the supplement of pure epicatechin and the dark chocolate.

These results will be interpreted and methodological issues will be considered. Lastly, the main findings from the studies will be integrated so that a final conclusion about the cardioprotective effects of epicatechin and quercetin can be made. 


\section{INTERPTREATION OF MAIN FINDINGS}

\section{Epicatechin, quercetin and cardiovascular disease mortality}

To investigate the association between epicatechin intake and CVD mortality, we conducted a prospective cohort analysis. In the Zutphen Elderly Study we found that the risk of CHD mortality was inversely associated with epicatechin intake. Elderly men who consumed more than $18 \mathrm{mg} / \mathrm{d}$ of epicatechin had 38\% lower risk of CHD mortality compared to men who consumed less than $11 \mathrm{mg} / \mathrm{d}$ (Chapter 2). Higher epicatechin intake was also associated with a $46 \%$ lower risk of CVD mortality in men with prevalent CVD.

The association of quercetin intake with CHD mortality has already been studied in a number of prospective cohort studies, and the results were inconclusive. In the Finnish Mobile Clinic Health Examination Survey, subjects in the highest quartile of quercetin intake had a $21 \%$ lower risk of CHD mortality compared to the lowest quartile [3]. In two other cohort studies quercetin intake was also associated with a lower risk of CHD mortality, however, the associations were not statistically significant [4, 5]. In the Health Professionals Follow-up Study, quercetin intake was not associated with nonfatal CHD [6].

In Europe in general, tea contributes more than $20 \%$ of quercetin intake [7]. In the Zutphen Elderly Study, tea contributed $50 \%$ of epicatechin intake (Chapter 2). As a result, strong correlations between epicatechin, quercetin and tea intake will be present. This makes it difficult to separate the effects of epicatechin and quercetin from those of tea. For this reason, RCTs are critical for unravelling the roles of epicatechin and quercetin in the aetiology of CVD.

\section{Chronic effects of pure epicatechin and quercetin on markers of cardiometabolic health}

To establish a cause-effect relationship of epicatechin and quercetin with CVD risk, two RCTs were carried out. In the first RCT, the daily consumption of pure epicatechin (100mg) for 4 weeks improved flow mediated dilation (FMD) by $1.1 \%(95 \% \mathrm{Cl}:-0.1,2.3 ; \mathrm{p}=0.07)$ in (pre) hypertensive adults, when compared to placebo. The effect was, however, only borderline statistically significant, but was supported by the effect of pure epicatechin on sE-selectin, a biomarker of endothelial function. To our knowledge, this is the first human RCT to investigate the chronic effects of pure epicatechin on FMD, using an upper dietary dose of $100 \mathrm{mg}$. A meta-analysis of cocoa RCTs reported that the chronic daily consumption of epicatechin-rich cocoa (46 - 203 mg epicatechin) improved FMD by 1.3\% [8]. This suggests that the magnitude of the effect of pure epicatechin in our study was comparable with that of epicatechin-rich cocoa.

In our RCT, epicatechin did not change arterial stiffness, which was assessed by measuring the augmentation index (Alx) and pulse wave velocity (PWV). No previous RCTs have 
investigated the effects of pure epicatechin on Alx or PWV, and results from chronic cocoa RCTs are limited. One trial reported that consuming a cocoa drink (25 mg epicatechin) for 3 weeks had no effect on Alx and increased PWV [9]. In contrast, however, Grassi et al. reported that cocoa dose-dependently (42-168 mg epicatechin) decreased PWV when consumed for 1 week [10].

Vascular function markers such as arterial stiffness and FMD are indicators of the proper functioning of blood vessels, and both are closely linked to blood pressure [11-14]. In our trial, pure epicatechin did not significantly lower 24-hour blood pressure, which is consistent with the fact that pure epicatechin did not change arterial stiffness, NO (vasodilator) or endothelin-1 (vasoconstrictor). This is, however, in contrast to results from cocoa RCTs. A meta-analysis of 13 RCTs showed that cocoa/chocolate consumption decreased blood pressure [15]. Other chronic RCTs reported that cocoa/chocolate increased NO [16, 17], and decreased endothelin-1 [10]. Of the cocoa RCTs which reported the epicatechin content of the cocoa/chocolate used, most had an epicatechin content between 46 and $107 \mathrm{mg} / \mathrm{d}$ [18-21]. This suggests that the dose of epicatechin used in our RCT (100 mg/d) probably was sufficient. An alternative explanation could be that the bioavailability of pure epicatechin is less than that of epicatechin from cocoa/chocolate. However, this was not evident when we compared the bioavailability of the pure epicatechin in the capsules and the epicatechin from dark chocolate (Chapter 6). Possibly other flavan-3-ols or other bioactive compounds in cocoa also contribute to the vascular effects of cocoa. As will be discussed in more detail later on, cocoa contains many more flavan-3-ols, especially oligomeric flavan-3-ol. Oligomeric flavan-3-ols cannot be absorbed from the cocoa as such, but first have to be converted into smaller molecules by the microbiota of the colon. A potentially interesting group of colonic metabolites are the valerolactons [22], which inhibited angiotensin 1-converting enzyme (ACE) and reduced blood pressure in rats [23].

Results from our trial did show that pure epicatechin improved insulin resistance, as measured by the homeostatic model assessment of insulin resistance (HOMA-IR). This is in line with a meta-analysis of cocoa RCTs which found that chronic cocoa consumption improved HOMA-IR [8]. With the exception of a positive effect on sE-selectin, pure epicatechin did not significantly change other biomarkers of endothelial function or inflammation.

Pure quercetin supplementation did not affect FMD, blood pressure, arterial stiffness, insulin resistance, NO or endothelin-1. Previous chronic RCTs have reported that pure quercetin improved blood pressure [24-27], however, these RCTs have used very high doses (150-730 $\mathrm{mg}$ aglycone/d) of quercetin. If a dose-response relationship exists, then possibly the dose used in our study (100 mg aglycone/d) was not high enough to elicit significant changes in blood pressure and other markers of cardiometabolic health. In our study, we chose to use quercetin-3-glucoside because of its superior bioavailability in 
comparison to quercetin aglycone [28]. It is unlikely, therefore, that poor bioavailability of the supplement is an explanation for the lack of an effect seen in our trial.

Pure quercetin did significantly lower sE-selectin and IL-1 3 (a biomarker of inflammation) when compared to placebo. The few published tea trials on inflammation or endothelial dysfunction markers have reported inconclusive results. One RCT reported that consuming 4 cups/day of black tea for 6 weeks decreased plasma CRP [29], while other trials reported that consuming tea (polyphenols) for 4 weeks had no effect on biomarkers of inflammation [30] or endothelial dysfunction [31].

\section{Chronic effects of pure epicatechin on gene expression}

Advances in technologies and reductions in costs have made gene expression analyses more feasible. Although often labour intensive and statistically complex, a comprehensive nutrigenomics approach may be useful in defining more subtle intervention-related changes in cardiometabolic health [32]. In our chronic RCT, pure epicatechin supplementation for 4-weeks down-regulated gene sets involved in inflammation in circulating immune cells (Chapter 5). NF-KB was identified as a possible upstream regulator to be inhibited upon epicatechin supplementation. In a previous RCT, cocoa powder significantly decreased NF-kB activation compared to baseline [33]. Similarly, pure epicatechin supplementation prevented diet-induced activation of NF- KB in ApoE*3-Leiden mice fed an atherogenic diet [34]. Also the inflammatory gene clusters IL8 -CXCR1/2 pathways and AMB2_neutrophil pathway were down-regulated upon epicatechin supplementation.

It has also been suggested that flavonoids may exert cardioprotective effects by increasing NO bioavailability through the regulation of oxidative damage via the transcription factor Nrf2 [35]. This was not, however, evident in our analysis of PBMC whole gene expression. Taken together, the effects of pure epicatechin on gene expression were modest compared to other nutritional interventions such as fatty acids. Previous analyses suggested that the effects of isoflavones on whole-genome wide expression are more pronounced in adipose tissue [36] than in PBMCs [37]. Possibly PBMCs are less adequate for investigating the effects of epicatechin on cardiometabolic health compared to other cell types such as endothelial cells and adipose tissue [38].

\section{Acute effects of pure epicatechin compared to chocolate}

Because of the consistent vascular effects of cocoa in RCTs and the modest effects of pure epicatechin found in our trial, we directly compared the effects of pure epicatechin and dark chocolate on vascular function in an acute RCT. There was no statistically significant difference in FMD or arterial stiffness between pure epicatechin and dark chocolate. Compared to placebo (white chocolate), pure epicatechin supplementation (in capsule form) did not significantly change FMD, arterial stiffness (Alx) and nitric oxide (NO), whereas dark chocolate did have a beneficial effect. To rule out differences in bioavailability 
between epicatechin in the chocolate and the epicatechin supplement, we measured plasma (epi)catechin metabolite concentrations over a period of 8 hours. Unexpectedly, the dark chocolate used in this study contained more epicatechin than in the capsules (150mg vs. 100mg). After adjustment for the difference in epicatechin content, there was no statistically significant difference between the bioavailability of epicatechin from dark chocolate and the pure epicatechin in the capsules. Possibly the dose of epicatechin in the capsules was not high enough to elicit significant changes in vascular function.

\section{Conclusions of the main findings}

Combining our results from the epidemiological analysis as well as from the RCTs and gene expression analyses, it appears that epicatechin contributes to the cardioprotective effects of cocoa and tea. Epicatechin intake was associated with a 38\% lower risk of CHD mortality in elderly Dutch men and with a 46\% lower risk of CVD mortality in men with prevalent CVD. Results from the chronic RCT using pure epicatechin pointed towards improvements in insulin resistance and endothelial function. However, the effects of pure epicatechin on PBMC gene expression profiles were modest, with only a few changes seen in genes related to inflammation. The acute effects of pure epicatechin $(100 \mathrm{mg} / \mathrm{d})$ were also less pronounced than the effects of cocoa (150 mg/d epicatechin), suggesting that the dose may play an important role in the cardioprotective effects of epicatechin. Quercetin, on the other hand, does not appear to contribute to the cardioprotective effects of tea. Results from the chronic RCT showed that pure quercetin did not beneficially affect markers of endothelial function, or insulin resistance but may have a minor effect on inflammation.

\section{METHODOLOGICAL CONSIDERATIONS}

\section{Assessment of the intake of flavonoids}

Accurate dietary assessment is critical in nutritional epidemiology. A major strength of the Zutphen Elderly Study is the use of a cross check dietary history method as a dietary assessment tool. This method assesses the habitual dietary intake and has been shown to be a reproducible and valid dietary assessment tool [39]. It should be noted, however, that no dietary assessment tool currently exists that has been validated to assess the intake of flavonoids. For this reason, we cannot exclude the possibility of misclassification of epicatechin intake which could influence the results. Ideally, future studies should aim to validate tools for assessing the intake of flavonoids, however, this does pose a great challenge.

Firstly, it is important to note that the reported flavonoid content of foods can vary between studies due to the use of different flavonoid databases. For example, two commonly used flavonoid databases are the USDA Database [40] and the PhenolExplorer Database [41]. The average (-)-epicatechin content of black tea is $2.13 \mathrm{mg} / 100 \mathrm{~mL}$ according to the 
USDA database, compared to $3.94 \mathrm{mg} / 100 \mathrm{~mL}$ according to the PhenolExplorer database. These differences reflect variation in tea cultivars, growth conditions (climate and soil), crop management (irrigation, fertilisation, pest management), post-harvest handling, storage, and preparation of the tea infusion, and to a lesser extent also differences in analytical methods. With the exception of flavan-3-ols, it is also important to realise that PhenolExplorer reports flavonoids as the original glycosides present in the foods, whereas USDA only reports aglycone values. A failure to recognise this, may lead to different and incomparable flavonoid intakes. This means that when assessing flavonoid intake, it is important to use the flavonoid contents of foods consumed in the local area whenever possible. In our cohort study we used data of foods sampled in the Netherlands from at least three selling locations or three major brands, which were combined per product to a composite reflecting sales [42]. For example, the flavonoid content of black tea used in our studies was based on a weighted average of the most common brands of tea consumed in the Netherlands.

Ideally, dietary assessment methods should be validated against objective biomarkers. Analysing flavonoid concentrations in body fluids like plasma and urine is a complex process since most flavonoids are metabolised into glucuronides, sulfates, and O-methyl sulfates, resulting in a variety of circulating metabolites. For this reason, valid biomarkers do not currently exist for assessing flavonoid intake. Moreover, flavonoids are rapidly excreted after ingestion, which results in highly fluctuating plasma concentrations that only postprandially relate to intake. Measuring 24-h urine samples would be the best choice, but these kind of samples are often not available in cohort studies. For this reason, using biomarkers to validate the intake of individual flavonoids is currently unfeasible. The best available measure of validity for flavonoid intake is to determine the reproducibility of repeated measurements. In the Zutphen Elderly Study we used repeated assessments of epicatechin intake and the 5-year repeated estimate of epicatechin intake was strongly correlated $(r=0.59)$. This suggests that the method used to determine epicatechin intake was reproducible. Advances in metabolomics may, however, offer new validation opportunities in the future [43].

\section{Residual confounding in cohort studies}

Another important point to consider in cohort studies is the possibility of residual confounding. Residual confounding is a result of inadequate adjustment for confounders, which can lead to distortion of the observed association between an exposure and outcome. Adequate adjustment for confounders is especially important in nutritional research since (un)healthy habits tend to correlate. For example, smokers generally have a lower intake of $\beta$-carotene which is a marker of fruit and vegetable consumption [44]. Also, sedentary behaviour is associated with a less healthy diet [45]. In our cohort studies, subjects with a higher epicatechin intake also had a higher intake of protein, calcium and fibre and were generally more physically active and less likely to smoke. To minimise the 
potential confounding of other dietary components or lifestyle factors on the outcome, it is important to adjust for these potential confounders. Although we adjusted for a wide range of potential confounders, we cannot exclude the possibility of residual confounding - either due to missing confounders or due to measurement error of the confounders included.

\section{Epicatechin and other dietary components in cohort studies}

In the Zutphen Elderly Study, the main dietary source of epicatechin was tea, followed by apples and cocoa. Tea contributed 50\% of epicatechin intake and hence there was a high correlation between tea consumption and total epicatechin intake. This makes it difficult to separate the effects of epicatechin from that of tea. Besides epicatechin, tea contains a wide range of other compounds including other flavonoids as well as theaflavins, caffeine and potassium. Hence, we cannot exclude the possibility that compounds in tea other than epicatechin also contribute to the cardioprotective effects of tea, and that epicatechin intake acts as a surrogate marker of tea intake.

\section{Relevance of cardiometabolic markers}

Effects of dietary interventions on cardiometabolic health should ideally be assessed by means of an RCT using clinical endpoints such as CVD morbidity and/or mortality. However, due to the large sample sizes and long durations required, such interventions would be prohibitively expensive. Therefore, surrogate markers of cardiometabolic health have to be used.

In both RCTs that we conducted, the primary outcome was the change in FMD - which is considered the best available measure of endothelial function [46]. Studies showed that FMD is reduced in subjects with CVD risk factors and that FMD acts as an independent predictor of CVD events - every 1\% increase in FMD is associated with an 8-13\% lower risk of future CVD events $[47,48]$. It has also been suggested that the prognostic value of FMD is stronger in patients with established CVD and more modest in asymptomatic subjects [49].

It is important to note that FMD is a sensitive measurement which can be influenced by minor changes in methodology (Chapter 3, supplemental material 2). For example, it has been shown that there is a diurnal variation in FMD, with higher values seen in the afternoon than in the morning $[50,51]$. Also the placement of the cuff/probe (distal or proximal to the antecubital fossa) [52], as well as duration of cuff inflation can influence the magnitude of FMD [53]. Differences in ultrasound transducer could influence the measurement of FMD $[49,54]$. In our studies we used an ultrasound transducer of $7.5 \mathrm{MHz}$ which is in line with two commonly used guidelines which state that a minimum frequency of 7-7.5 $\mathrm{MHz}$ is required $[49,54]$. As a consequence of advances in technology, however, transducers with a higher frequency (10-14 MHz) are now often used. Other external 
factors such as exercise [55], caffeine consumption, and tobacco use can also influence the accuracy of FMD [56]. These differences could explain why studies have reported varying degrees of within-subject variability, between $7 \%$ and 50\% [32]. In our study, we followed a strict protocol, adhering to two commonly used guidelines for FMD measurements $[49,54]$. Nevertheless, there still often exists variation in methodology and apparatus between studies.

Differences in study population could also influence the observed effects. Our study population was fairly heterogeneous with large differences in age, BMI, and blood pressure. Nevertheless, the effects of cocoa consumption on FMD have been reported in studies with similar populations, even when using smaller sample sizes. For example, Grassi et al. showed that cocoa dose-dependently improved FMD in only 20 participants aged 18-70, with a BMI between 19 and $30 \mathrm{~kg} / \mathrm{m}^{2}$ [10]. Similar results were obtained by Davison et al. with 16 participants [57]. The aforementioned differences in methodology and differences in study population could, however, partly explain the variation in FMD response between cocoa RCTs, with studies reporting a change in FMD of between 0.4 and $7.1 \%$ (absolute) after acute cocoa consumption [8]. Indeed, in our study, FMD increased by $1.0 \%$ after acute cocoa consumption, which is lower than the $3.2 \%$ reported in a meta-analysis of acute cocoa RCTs [8]. For this reason, caution should be taken when comparing the magnitude of effect sizes of FMD between studies.

Besides FMD, we also measured blood pressure, arterial stiffness and a comprehensive set of biomarkers for endothelial function and inflammation. The measurement of 24-hour blood pressure was a major strength of our study (Chapter 3) as 24-hour blood pressure has been shown to hold a greater prognostic value than office blood pressure [58]. In our study, we did not see an effect of epicatechin or quercetin supplementation on 24hour blood pressure. Epicatechin supplementation did reduce 24-hour SBP by $2.4 \mathrm{mmHg}$ and DBP by $1.5 \mathrm{mmHg}$, however, the effects were not statistically significant. Based on a power calculation to detect a change in the primary outcome (FMD) of $1.5 \%$, we included 37 subjects in the study. To detect a significant change in SBP of $3 \mathrm{mmHg}$ we would have needed to include 88 subjects. In addition, the mean baseline SBP of the 37 subjects included in the study was $129 \mathrm{mmHg}$ which may have been too low to warrant a significant decrease in blood pressure.

Advances in computer technology have made it possible to quickly and accurately measure arterial stiffness in a non-invasive manner. In our studies, we measured pulse wave velocity (PWV) and augmentation index (AIx), two separate methods for measuring arterial stiffness. Despite the fact that blood pressure and arterial stiffness are closely linked, indices of arterial stiffness do have additional predictive value [59]. Cohort studies showed that PWV is a strong predictor of future CVD events - every $1 \mathrm{~m} / \mathrm{s}$ increase in PWV is associated with a $14 \%$ higher risk of CVD mortality [60]. Likewise, a 10\% (absolute) increase in central 
Alx is associated with a 32\% higher risk of cardiovascular events [61]. Importantly, these measurements can be considered diet-sensitive markers of arterial stiffness as studies have shown that nutritional interventions using omega-3 fatty acids and soy isoflavone supplements are able to improve both PWV and Alx [62].

The duration of a study may play an important role in the effect of a dietary intervention on arterial stiffness. It is thought that PWV may represent more long-term changes in vascular function. In contrast, studies have shown that cocoa intake improves Alx acutely by approximately $5 \%[63,64]$, which we confirmed for chocolate in our acute intervention study (Chapter 6). It has been suggested that acute changes in arterial stiffness are likely to be a result of changes in functional mechanisms that regulate arterial stiffness, such as changes in the bioavailability of NO or reductions in inflammation [62].

In chapter 4 we investigated the effects of pure epicatechin and quercetin on a comprehensive set of biomarkers of endothelial dysfunction and inflammation. The assessment of these biomarkers can be useful in nutritional research as they are relatively easily accessible and are closely associated with CVD [65-68]. Based on pre-defined clusters we calculated Z-scores for markers of endothelial dysfunction and inflammation. We found that epicatechin had a borderline significant effect on the z-score for endothelial dysfunction. The calculation of a z-score can be useful for calculating the effects on a group of biomarkers, however, the assumption that all biomarkers carry the same weight may not be valid. As such, we consider the calculation of the z-scores a useful indication but are apprehensive about drawing firm conclusions about the effects of pure flavonoids on endothelial dysfunction and inflammation based on the z-scores.

In Chapter 3, we found that epicatechin supplementation improved fasting insulin and insulin resistance. This is in line with the meta-analysis of Hooper et al. which showed that flavonoid-rich cocoa improved insulin resistance [8]. However, based on results of the gene expression analysis, there was no apparent effect of epicatechin on mechanisms involved in insulin resistance. Since PBMCs are immune cells, they may not be the optimal cell-type for investigating changes in gene expression profiles related to insulin signalling. Other metabolically active tissues such as adipose or muscle tissue, or endothelial cells may be more relevant. We cannot, however, exclude the possibility that the effect of epicatechin supplementation on insulin resistance was a chance finding. It should also be noted that the measurement of insulin resistance based on fasting glucose and insulin concentrations is an indirect measure of insulin resistance and may not optimally reflect glucose and insulin metabolism. To get a more accurate view, future studies should look to investigate the effects of pure epicatechin on more direct markers of glucose and insulin metabolism such as a hyperglycemic clamp. 


\section{Cocoa flavan-3-ol bioavailability, and potential additional bioactive compounds of cocoa}

Cocoa contains many flavan-3-ols including monomers such as epicatechin and catechin, as well as oligomers called procyanidins. As an example, a cocoa extract used in an intervention study contained $64 \mathrm{mg}$ of epicatechin, $7 \mathrm{mg}$ of catechin and $377 \mathrm{mg}$ of procyanidins [69]. In this thesis, we chose epicatechin as a flavan-3-ol of interest due to its high natural occurrence in cocoa, its relatively high bioavailability as a monomer as opposed to procyanidins, and its relatively high bioactivity (see Chapter 1 ). Ottaviani et al. showed that the vasodilatory effect of (-)-epicatechin was 5 times higher than that of (+)-catechin in rats [70]. In the same study, they showed that the bioavailability of epicatechin was approximately $25 \%$ higher than that of catechin [70]. Another rat study showed that the bioavailability of a procyanidin dimer tested was only $1 \%$ that of epicatechin, whereas trimers were not absorbed [71]. This shows that direct effects of procyanidins on vascular function can be neglected. Although minor, we cannot, however, completely exclude the possibility that catechin contributes to the cardioprotective effects of cocoa.

Besides flavan-3-ols, cocoa also contains a number of other bioactive compounds such as magnesium and theobromine. Effects of magnesium on vascular function are unclear with two RCTs reporting that magnesium improved FMD $[72,73]$, and another reporting no change [74]. Theobromine could contribute to the cardioprotective effects of cocoa by reducing arterial stiffness and central blood pressure [9]. The effects of theobromine on FMD are currently unknown. Future studies should establish the effects of magnesium and theobromine on vascular function.

In our two RCTs we provided pure epicatechin in capsule form. In reality, however, flavonoids are not consumed in pure form but enclosed within a food matrix. Possibly the bioavailability of flavonoids could be influenced by fats, sugars and protein, which raises questions about the bioavailability of the pure flavonoid supplements. In Chapter 6 we compared the bioavailability of epicatechin from dark chocolate and pure epicatechin. To match for energy, fat and protein we provided white chocolate with the epicatechin supplements. We did not observe a difference in bioavailability of epicatechin from the dark chocolate or the pure epicatechin supplement, when consumed in combination with white chocolate. This suggests that the chocolate matrix itself did not influence bioavailability.

Because we used white chocolate, we cannot exclude the possibility that the bioavailability of epicatechin was influenced by the sugar, fat or protein content of white chocolate. The effects of such nutrients on flavan-3-ol bioavailability are, however, unclear. For example, cocoa powder dissolved in milk had no significant effect on plasma epicatechin concentrations when compared to a water-based cocoa drink $[75,76]$. On the other hand, Serafini et al. showed that consuming milk with chocolate inhibited the absorption of epicatechin [77]. Ideally we would have included an additional intervention arm in our 
study with only pure epicatechin (no white chocolate), however, logistically this was not feasible. Future studies should consider using a sugar-free, water-based cocoa drink as an alternative to chocolate as this would eliminate the potential effects of sugar and fats which are present in chocolate.

\section{The effect of epicatechin dose and duration}

Chronic cocoa RCTs have consistently shown improvements in blood pressure, endothelial function and insulin resistance after the daily consumption of cocoa typically containing between 46 and 107 mg of epicatechin [18-21]. In the meta-analysis of Hooper et al. cocoa containing $>50 \mathrm{mg} / \mathrm{d}$ of epicatechin resulted in the greatest improvements in systolic and diastolic blood pressure [8]. This is almost three times as high as the highest category of epicatechin intake in the epidemiological study - the highest category of intake corresponded to a median epicatechin intake of approximately $20 \mathrm{mg} / \mathrm{d}$.

Besides a difference in dose, epidemiological studies and RCTs also inevitably differ in the duration of exposure. Most chronic cocoa RCTs lasted between 2 and 18 weeks. In contrast, the median follow-up time in the Zutphen Elderly Study was 10.7 years. This suggests that the beneficial effects of epicatechin may be achieved from relatively low levels of intake, which can be attained from a normal diet, when consumed over a sufficiently long period of time. Currently, there are no studies that systematically explored this dose-duration effect. Remarkably, in the cocoa RCT with the longest duration of 18 weeks, a relatively low habitual intake of dark chocolate $(6.3 \mathrm{~g} / \mathrm{d}$ chocolate; $5.1 \mathrm{mg} / \mathrm{d}$ epicatechin) resulted in significant reductions in systolic and diastolic blood pressure as well as an increase in NO bioavailability [17]. More long-term RCTs are required in order to investigate the effects of habitual intake of low levels of dark chocolate and epicatechin on cardiometabolic health.

\section{FINAL CONCLUSIONS AND FUTURE DIRECTIONS}

In this thesis we aimed to investigate the effects of epicatechin and quercetin on cardiovascular health by means of epidemiological analysis, human intervention studies and whole genome analyses.

In the Zutphen Elderly Study we found that a higher epicatechin intake was associated with a lower risk of CHD mortality in a population of elderly Dutch men, and with CVD mortality in men with prevalent CVD. More and larger cohort studies are required to confirm the association of epicatechin intake with CVD mortality, possibly with a focus on populations with a high risk of CVD.

In the chronic RCT that we conducted, we found that pure epicatechin improved insulin resistance and sE-selectin, and had a borderline significant effect on FMD when compared 
to placebo. This suggested that epicatechin contributes to the cardioprotective effects of cocoa and tea. Larger long-term RCTs are required to confirm the effects of pure epicatechin on insulin resistance and to further investigate the effects on endothelial function and inflammation. To investigate the effects of pure epicatechin on glucose and insulin metabolism, more established methods such as a hyperglycemic clamp are also needed. With the exception of sE-selectin, IL-1 $\beta$ and the z-score for inflammation, quercetin did not beneficially affect any marker of cardiometabolic health. This suggests that quercetin is unlikely to play a major role in the cardioprotective effects of tea but may help to lower inflammation.

In the acute RCT, we found that the cardioprotective effects of dark chocolate were higher than that of pure epicatechin, which could be explained by differences in the dose of epicatechin. Alternatively, other compounds in chocolate could also contribute to the cardioprotective effects of dark chocolate. Future studies should look to assess the cardioprotective effects of other compounds in chocolate such as colonic metabolites of procyanidins, magnesium and theobromine. More studies are needed to compare the cardioprotective effects of pure epicatechin and cocoa, with a focus on the effects of doseresponse and duration of epicatechin. Future studies could also consider using a cocoa drink instead of chocolate, as this would exclude the effects of sugar and fat which are also present in chocolate.

TABLE 1. Summary of effects of epicatechin, quercetin and dark chocolate/cocoa on cardiovascular mortality and cardiometabolic risk factors, based on results from this thesis.

\begin{tabular}{lccccccccccc}
\hline & \multicolumn{3}{c}{ Mortality } & & \multicolumn{1}{c}{ Functional Markers } & & \multicolumn{3}{c}{ Biomarkers } \\
\hline & & & & & & & HOMA- & Inflam- & Endothelial \\
& CVD & CHD & Stroke & FMD & Alx & BP & IR & mation & function ${ }^{2}$ \\
\hline Epicatechin & ++ & ++ & $\leftrightarrow$ & + & $\leftrightarrow$ & $\leftrightarrow$ & ++ & $\leftrightarrow$ & + \\
Quercetin & N/D & N/D & N/D & $\leftrightarrow$ & $\leftrightarrow$ & $\leftrightarrow$ & $\leftrightarrow$ & + & & $\leftrightarrow$ \\
$\begin{array}{l}\text { Dark Chocolate/ } \\
\text { Cocoa }\end{array}$ & $\leftrightarrow$ & $\leftrightarrow$ & $\leftrightarrow$ & ++ & ++ & N/D & N/D & N/D & ++ \\
\hline
\end{tabular}

++ Significant improvement $(p<0.05)$

+ Borderline improvement $(0.05<\mathrm{p} \leq 0.10)$

$\leftrightarrow$ No significant change $(p>0.10)$

N/D Not determined

1 Epicatechin intake associated with a lower risk of CVD mortality in subjects with prevalent CVD.

2 Endothelial function for dark chocolate/cocoa based only on nitric oxide.

Abbreviations: Alx: augmentation index; BP: blood pressure; CHD: coronary heart disease; CVD: cardiovascular disease; FMD: flow-mediated dilation; HOMA-IR: homeostatic model assessment of insulin resistance. 
To conclude, based on the results of this thesis, we can say that epicatechin contributes to the cardioprotective effects of cocoa and tea (Table 1). The cardioprotective effects of epicatechin are likely mediated through improvements in insulin resistance and possibly endothelial function. In contrast, quercetin is unlikely to play a major role in the cardioprotective effects of tea. Results from cohort studies on quercetin are inconclusive, and based on the results of our chronic RCT, quercetin does not appear to contribute to the effects of tea on vascular function or insulin resistance, but may have a beneficial effect on inflammation. Evidence of the role that individual flavonoids play in the aetiology of CVD is, however, still limited and more studies with pure flavonoids are required to elucidate their role. 


\section{REFERENCES}

1. Arab L, Liu W, Elashoff D. Green and black tea consumption and risk of stroke: A meta-analysis. Stroke. 2009;40(5):1786-1792.

2. Buitrago-Lopez A, Sanderson J, Johnson L, et al. Chocolate consumption and cardiometabolic disorders: Systematic review and meta-analysis. BMJ (Online). 2011;343.

3. Knekt $P$, Kumpulainen J, Järvinen $R$, et al. Flavonoid intake and risk of chronic diseases. Am J Clin Nutr. 2002;76(3):560-568.

4. Lin J, Rexrode KM, Hu F, et al. Dietary intakes of flavonols and flavones and coronary heart disease in US women. Am J Epidemiol. 2007;165(11):1305-1313.

5. Yochum L, Kushi LH, Meyer K, Folsom AR. Dietary flavonoid intake and risk of cardiovascular disease in postmenopausal women. Am J Epidemiol. 1999;149(10):943-949.

6. Rimm EB, Katan MB, Ascherio A, Stampfer MJ, Willett WC. Relation between Intake of Flavonoids and Risk for Coronary Heart Disease in Male Health Professionals. Ann Intern Med. 1996;125(5):384389.

7. Zamora-Ros R, Forouhi NG, Sharp SJ, et al. Dietary intakes of individual flavanols and flavonols are inversely associated with incident type 2 diabetes in European populations.J Nutr. 2014;144(3):335343.

8. Hooper L, Kay C, Abdelhamid A, et al. Effects of chocolate, cocoa, and flavan-3-ols on cardiovascular health: A systematic review and meta-analysis of randomized trials. Am J Clin Nutr. 2012;95(3):740751.

9. Van Den Bogaard B, Draijer R, Westerhof BE, Van Den Meiracker AH, Van Montfrans GA, Van Den Born $\mathrm{BJH}$. Effects on peripheral and central blood pressure of cocoa with natural or high-dose theobromine: A randomized, double-blind crossover trial. Hypertension. 2010;56(5):839-846.

10. Grassi D, Desideri G, Necozione S, et al. Cocoa consumption dose-dependently improves flowmediated dilation and arterial stiffness decreasing blood pressure in healthy individuals. J Hypertens. 2015;33(2):294-303.

11. Franklin SS. Arterial stiffness and hypertension: A two-way street? Hypertension. 2005;45(3):349351.

12. Gokce N, Holbrook M, Duffy SJ, et al. Effects of race and hypertension on flow-mediated and nitroglycerin-mediated dilation of the brachial artery. Hypertension. 2001;38(6):1349-1354.

13. Maruhashi T, Soga J, Fujimura N, et al. Relationship between flow-mediated vasodilation and cardiovascular risk factors in a large community-based study. Heart. 2013;99(24):1837-1842.

14. Spronck B, Heusinkveld MHG, Vanmolkot FH, et al. Pressure-dependence of arterial stiffness: Potential clinical implications. J Hypertens. 2015;33(2):330-338.

15. Ried K, Sullivan T, Fakler P, Frank OR, Stocks NP. Does chocolate reduce blood pressure? A metaanalysis. BMC Med. 2010;8(39).

16. Heiss C, Jahn S, Taylor M, et al. Improvement of endothelial function with dietary flavanols is associated with mobilization of circulating angiogenic cells in patients with coronary artery disease. J Am Coll Cardiol. 2010;56(3):218-224. 
17. Taubert D, Roesen R, Lehmann C, Jung N, Schömig E. Effects of low habitual cocoa intake on blood pressure and bioactive nitric oxide: A randomized controlled trial. JAMA. 2007;298(1):49-60.

18. Engler MB, Engler MM, Chen CY, et al. Flavonoid-rich dark chocolate improves endothelial function and increases plasma epicatechin concentrations in healthy adults. J Am Coll Nutr. 2004;23(3):197204.

19. Faridi Z, Njike VY, Dutta S, Ali A, Katz DL. Acute dark chocolate and cocoa ingestion and endothelial function: A randomized controlled crossover trial. Am J Clin Nutr. 2008;88(1):58-63.

20. Farouque HMO, Leung M, Hope SA, et al. Acute and chronic effects of flavanol-rich cocoa on vascular function in subjects with coronary artery disease: A randomized double-blind placebocontrolled study. Clin Sci. 2006;111(1):71-80.

21. Grassi D, Desideri G, Necozione $S$, et al. Blood pressure is reduced and insulin sensitivity increased in glucose-intolerant, hypertensive subjects after 15 days of consuming high-polyphenol dark chocolate. J Nutr. 2008;138(9):1671-1676.

22. Rodriguez-Mateos A, Cifuentes-Gomez T, Gonzalez-Salvador I, et al. Influence of age on the absorption, metabolism, and excretion of cocoa flavanols in healthy subjects. Mol Nutr Food Res. 2015;59(8):1504-1512.

23. Takagaki A, Nanjo F. Effects of Metabolites Produced from (-)-Epigallocatechin Gallate by Rat Intestinal Bacteria on Angiotensin I-Converting Enzyme Activity and Blood Pressure in Spontaneously Hypertensive Rats. J Agric Food Chem. 2015;63(37):8262-8266.

24. Edwards RL, Lyon T, Litwin SE, Rabovsky A, Symons JD, Jalili T. Quercetin reduces blood pressure in hypertensive subjects. J Nutr. 2007;137(11):2405-2411.

25. Egert S, Bosy-Westphal A, Seiberl J, et al. Quercetin reduces systolic blood pressure and plasma oxidised low-density lipoprotein concentrations in overweight subjects with a high-cardiovascular disease risk phenotype: A double-blinded, placebo-controlled cross-over study. Br J Nutr. 2009;102(7):1065-1074.

26. Pfeuffer $M$, Auinger A, Bley $U$, et al. Effect of quercetin on traits of the metabolic syndrome, endothelial function and inflammation in men with different APOE isoforms. Nutr Metab Cardiovasc Dis. 2013;23(5):403-9.

27. Zahedi M, Ghiasvand R, Feizi A, Asgari G, Darvish L. Does quercetin improve cardiovascular risk factors and inflammatory biomarkers in women with type 2 diabetes: A double-blind randomized controlled clinical trial. Int J Prev Med. 2013;4(7):777-785.

28. Hollman PCH, Bijsman MNCP, Van Gameren Y, Cnossen EPJ, De Vries JHM, Katan MB. The sugar moiety is a major determinant of the absorption of dietary flavonoid glycosides in man. Free Radic Res. 1999;31(6):569-573.

29. Steptoe A, Gibson EL, Vuononvirta R, et al. The effects of chronic tea intake on platelet activation and inflammation: A double-blind placebo controlled trial. Atherosclerosis. 2007;193(2):277-282.

30. De Maat MPM, Pijl H, Kluft C, Princen HMG. Consumption of black and green tea has no effect on inflammation, haemostasis and endothelial markers in smoking healthy individuals. Eur J Clin Nutr. 2000;54(10):757-763.

31. Hodgson JM, Puddey IB, Mori TA, Burke V, Baker RI, Beilin LJ. Effects of regular ingestion of black tea on haemostasis and cell adhesion molecules in humans. Eur J Clin Nutr. 2001;55(10):881-886. 
32. McCall DO, McKinley MC, Noad R, et al. The assessment of vascular function during dietary intervention trials in human subjects. Br J Nutr. 2011;106(7):981-994.

33. Vázquez-Agell M, Urpi-Sarda M, Sacanella E, et al. Cocoa consumption reduces NF-kB activation in peripheral blood mononuclear cells in humans. Nutr Metab Cardiovasc Dis. 2013;23(3):257-263.

34. Morrison M, van der Heijden R, Heeringa $\mathrm{P}$, et al. Epicatechin attenuates atherosclerosis and exerts anti-inflammatory effects on diet-induced human-CRP and NFKB invivo. Atherosclerosis. 2014;233(1):149-156.

35. Mann GE, Rowlands DJ, Li FY, de Winter P, Siow RC. Activation of endothelial nitric oxide synthase by dietary isoflavones: role of NO in Nrf2-mediated antioxidant gene expression. Cardiovasc Res. 2007;75(2):261-74.

36. Van Der Velpen V, Geelen A, Hollman PCH, Schouten EG, Van 't Veer P, Afman LA. Isoflavone supplement composition and equol producer status affect gene expression in adipose tissue: A double-blind, randomized, placebo-controlled crossover trial in postmenopausal women. Am J Clin Nutr. 2014;100(5):1269-1277.

37. van Der Velpen V, Geelen A, Schouten EG, Hollman PC, Afman LA, van't Veer P. Estrogen receptormediated effects of isoflavone supplementation were not observed in whole-genome gene expression profiles of peripheral blood mononuclear cells in postmenopausal, equol-producing women. J Nutr. 2013;143(6):774-780.

38. Rodriguez-Mateos A, Toro-Funes N, Cifuentes-Gomez T, Cortese-Krott M, Heiss C, Spencer JP. Uptake and metabolism of (-)-epicatechin in endothelial cells. Arch Biochem Biophys. 2014;5591723.

39. Bloemberg BPM, Kromhout D, Obermann-De Boer GL, Van Kampen-Donker M. The reproducibility of dietary intake data assessed with the cross-check dietary history method. Am J Epidemiol. 1989;130(5):1047-1056.

40. Bhagwat S, Haytowitz DB, Holden JM. USDA Database for the Flavonoid Content of Selected Foods - Release 3.1 Beltsville, Maryland: USDA, 2013.

41. Rothwell JA, Perez-Jimenez J, Neveu V, et al. Phenol-Explorer 3.0: a major update of the PhenolExplorer database to incorporate data on the effects of food processing on polyphenol content. 2013;2013.

42. Arts ICW, Van De Putte B, Hollman PCH. Catechin contents of foods commonly consumed in The Netherlands. 1. Fruits, vegetables, staple foods, and processed foods. J Agric Food Chem. 2000;48(5):1746-1751.

43. Scalbert A, Brennan L, Manach C, et al. The food metabolome: a window over dietary exposure. The American journal of clinical nutrition. 2014;99(6):1286-308.

44. Stram DO, Huberman M, Wu AH. Is residual confounding a reasonable explanation for the apparent protective effects of beta-carotene found in epidemiologic studies of lung cancer in smokers? Am J Epidemiol. 2002;155(7):622-628.

45. Pearson N, Biddle SJH. Sedentary behavior and dietary intake in children, adolescents, and adults: A systematic review. Am J Prev Med. 2011;41(2):178-188.

46. Deanfield JE, Halcox JP, Rabelink TJ. Endothelial function and dysfunction: Testing and clinical relevance. Circulation. 2007;115(10):1285-1295. 
47. Inaba Y, Chen JA, Bergmann SR. Prediction of future cardiovascular outcomes by flow-mediated vasodilatation of brachial artery: A meta-analysis. Int J Cardiovasc Imaging. 2010;26(6):631-640.

48. Ras RT, Streppel MT, Draijer R, Zock PL. Flow-mediated dilation and cardiovascular risk prediction: A systematic review with meta-analysis. Int J Cardiol. 2013;168(1):344-351.

49. Thijssen DHJ, Black MA, Pyke KE, et al. Assessment of flow-mediated dilation in humans: A methodological and physiological guideline. Am J Physiol Heart Circ Physiol. 2011;300(1):H2-H12.

50. Jones H, Green DJ, George K, Atkinson G. Intermittent exercise abolishes the diurnal variation in endothelial-dependent flow-mediated dilation in humans. Am J Physiol Regul Integr Comp Physiol. 2010;298(2):R427-R432.

51. Otto ME, Svatikova A, De Mattos Barretto RB, et al. Early morning attenuation of endothelial function in healthy humans. Circulation. 2004;109(21):2507-2510.

52. Betik AC, Luckham VB, Hughson RL. Flow-mediated dilation in human brachial artery after different circulatory occlusion conditions. Am J Physiol Heart Circ Physiol. 2004;286(1 55-1):H442-H448.

53. Padilla J, Johnson BD, Newcomer SC, et al. Normalization of flow-mediated dilation to shear stress area under the curve eliminates the impact of variable hyperemic stimulus. Cardiovasc Ultrasound. 2008;6.

54. Corretti MC, Anderson TJ, Benjamin EJ, et al. Guidelines for the ultrasound assessment of endothelial-dependent flow-mediated vasodilation of the brachial artery: A report of the international brachial artery reactivity task force. J Am Coll Cardiol. 2002;39(2):257-265.

55. Dawson EA, Whyte GP, Black MA, et al. Changes in vascular and cardiac function after prolonged strenuous exercise in humans. J Appl Physiol. 2008;105(5):1562-1568.

56. Harris RA, Nishiyama SK, Wray DW, Richardson RS. Ultrasound assessment of flow-mediated dilation. Hypertension. 2010;55(5):1075-1085.

57. Davison K, Coates AM, Buckley JD, Howe PRC. Effect of cocoa flavanols and exercise on cardiometabolic risk factors in overweight and obese subjects. Int J Obes. 2008;32(8):1289-1296.

58. Dolan E, Stanton A, Thijs L, et al. Superiority of ambulatory over clinic blood pressure measurement in predicting mortality: The Dublin outcome study. Hypertension. 2005;46(1):156-161.

59. Hansen TW, Staessen JA, Torp-Pedersen C, et al. Prognostic value of aortic pulse wave velocity as index of arterial stiffness in the general population. Circulation. 2006;113(5):664-670.

60. Vlachopoulos C, Aznaouridis K, Stefanadis C. Prediction of Cardiovascular Events and All-Cause Mortality With Arterial Stiffness. A Systematic Review and Meta-Analysis. J Am Coll Cardiol. 2010;55(13):1318-1327.

61. Vlachopoulos C, Aznaouridis K, O'Rourke MF, Safar ME, Baou K, Stefanadis C. Prediction of cardiovascular events and all-cause mortality with central haemodynamics: A systematic review and meta-analysis. Eur Heart J. 2010;31(15):1865-1871.

62. Pase MP, Grima NA, Sarris J. The effects of dietary and nutrient interventions on arterial stiffness: A systematic review. Am J Clin Nutr. 2011;93(2):446-454.

63. Esser DM, M; Oosterink, E; Stalmach, A; Muller, M; Afman, L. Dark chocolate consumption improves leukocyte adhesion factors and vascular function in overweight men. FASEB J. 2013;28(3):14641473. 
64. Vlachopoulos C, Aznaouridis K, Alexopoulos N, Economou E, Andreadou I, Stefanadis C. Effect of dark chocolate on arterial function in healthy individuals. Am J Hypertens. 2005;18(6):785-791.

65. Blankenberg S, Rupprecht HJ, Bickel C, et al. Circulating cell adhesion molecules and death in patients with coronary artery disease. Circulation. 2001;104(12):1336-1342.

66. De Jager J, Dekker JM, Kooy A, et al. Endothelial dysfunction and low-grade inflammation explain much of the excess cardiovascular mortality in individuals with type 2 diabetes: The Hoorn study. Arterioscler Thromb Vasc Biol. 2006;26(5):1086-1093.

67. Jager A, Van Hinsbergh VWM, Kostense PJ, et al. von Willebrand factor, C-reactive protein, and 5-year mortality in diabetic and nondiabetic subjects: The Hoorn study. 1999;19(12):3071-3078.

68. Ridker PM, Hennekens CH, Buring JE, Rifai N. C-reactive protein and other markers of inflammation in the prediction of cardiovascular disease in women. N Engl J Med. 2000;342(12):836-843.

69. Sansone R, Rodriguez-Mateos A, Heuel J, et al. Cocoa flavanol intake improves endothelial function and Framingham Risk Score in healthy men and women: a randomised, controlled, doublemasked trial: the Flaviola Health Study. Br J Nutr. 2015;114(8):1246-55.

70. Ottaviani Jl, Momma TY, Heiss C, Kwik-Uribe C, Schroeter H, Keen CL. The stereochemical configuration of flavanols influences the level and metabolism of flavanols in humans and their biological activity in vivo. Free Radic Biol Med. 2011;50(2):237-244.

71. Appeldoorn MM, Vincken JP, Gruppen H, Hollman PCH. Procyanidin dimers A1, A2, and B2 are absorbed without conjugation or methylation from the small intestine of rats. J Nutr. 2009;139(8):1469-1473.

72. Barbagallo M, Dominguez LJ, Galioto A, Pineo A, Belvedere M. Oral magnesium supplementation improves vascular function in elderly diabetic patients. Magnes Res. 2010;23(3):131-137.

73. Shechter M, Sharir M, Paul MJ, et al. Oral magnesium therapy improves endothelial function in patients with coronary artery disease. Circulation. 2000;102(19 SUPPL.):2353-2358.

74. Cosaro E, Bonafini S, Montagnana M, et al. Effects of magnesium supplements on blood pressure, endothelial function and metabolic parameters in healthy young men with a family history of metabolic syndrome. Nutr Metab Cardiovasc Dis. 2014;24(11):1213-1220.

75. Roura E, Andrés-Lacueva C, Estruch R, et al. Milk does not affect the bioavailability of cocoa powder flavonoid in healthy human. Ann Nutr Metab. 2007;51(6):493-498.

76. Schroeter H, Holt RR, Orozco TJ, Schmitzt HH, Keen CL. Milk and absorption of dietary flavanols. Nature. 2003;426(6968):787-788.

77. Serafini M, Bugianesi R, Maiani G, Valtuena S, De Santis S, Crozier A. Plasma antioxidants from chocolate. Nature. 2003;424(6952):1013. 



\section{English Summary}


Epidemiological studies showed that the consumption of flavonoid-rich foods such as cocoa and tea is associated with a lower risk of cardiovascular disease (CVD). Randomised controlled trials (RCTs) showed that cocoa and tea improved markers of cardiometabolic health including blood pressure, endothelial function, insulin resistance, arterial stiffness and inflammation.

Cocoa is particularly rich in the flavan-3-ol epicatechin and tea is the main dietary source of epicatechin and of the major flavonol quercetin. However, evidence on the individual roles of epicatechin and quercetin in the health effects of cocoa and tea is still scarce. Therefore, we estimated the strength of the association between epicatechin intake and CVD mortality in a prospective cohort study. Furthermore, we also investigated the effects of epicatechin and quercetin on markers of cardiometabolic health and gene expression, by means of two RCTs.

In Chapter 2, the association between epicatechin intake and CVD mortality was studied using data from the Zutphen Elderly Study, a cohort of 744 elderly Dutch men. During 25 years of follow-up, 329 men died from CVD and 148 from coronary heart disease (CHD). Results from this study showed that men in the highest tertile of epicatechin intake had a $38 \%$ lower risk of CHD mortality compared to men in the lowest tertile. For men with prevalent CVD, the risk of CVD mortality was $46 \%$ lower for men in the highest tertile of intake, compared to men in the lowest tertile. This is the first epidemiological study to have investigated the association between epicatechin intake and CVD mortality. Hence, more and larger cohort studies are required to confirm this association, possibly with a focus on populations with a high risk of CVD.

In Chapter 3, the chronic effects of pure epicatechin and quercetin on markers of cardiometabolic health were investigated by means of a RCT. Thirty-seven apparently healthy men and women aged 40-80 years consumed (-)-epicatechin (100 mg/d), quercetin3-glucoside $(160 \mathrm{mg} / \mathrm{d})$, or placebo capsules for 4 weeks, in random order. Markers of cardiometabolic health were measured before and after each 4-week intervention. The results of this study showed that epicatechin improved insulin resistance and had a borderline significant effect on endothelial function. This suggests that epicatechin contributes to the cardioprotective effects of cocoa and tea, however, larger long-term RCTs are required to confirm these effects. Pure quercetin supplementation did not affect any of these markers of cardiometabolic health.

Using data from the same study, we investigated the effects of supplementation of pure epicatechin and quercetin on a comprehensive set of biomarkers of endothelial dysfunction and inflammation (Chapter 4). With the exception of sE-selectin (a biomarker of endothelial dysfunction), epicatechin supplementation did not beneficially influence 
any of the biomarkers, suggesting a lack of evidence for a role of epicatechin in inflammation. Quercetin also lowered sE-selectin as well as the inflammatory biomarker IL-1 $\beta$ and the overall z-score for inflammation. This suggests that quercetin may contribute to the cardioprotective effects of tea by reducing inflammation and possibly by improving endothelial function.

In the same study, the effects of pure epicatechin supplementation on whole genome gene expression profiles of circulating immune cells were also assessed (Chapter 5). Pure epicatechin supplementation modestly reduced gene expression related to inflammation signalling routes in circulating immune cells - routes which are known to play a role in cardiovascular health. However, there was no evidence that epicatechin affected pathways related to insulin resistance or endothelial function.

To directly compare the acute effects of pure epicatechin and epicatechin from dark chocolate on vascular function, we carried out an acute RCT in 20 apparently healthy men aged 40-80 years (Chapter 6 ). On three separate occasions, subjects consumed: 1) 70g dark chocolate (150 mg epicatechin) with two placebo capsules; 2 ) two pure epicatechin capsules (100 mg epicatechin) with 75g white chocolate and 3) two placebo capsules with $75 \mathrm{~g}$ white chocolate (0 $\mathrm{mg}$ epicatechin). Endothelial function and arterial stiffness were measured before and two hours after each intervention. To determine epicatechin bioavailability, epicatechin metabolites were measured in blood samples taken at repeated intervals over a period of 8 hours. There was no significant difference in improvement in endothelial function or arterial stiffness between pure epicatechin and dark chocolate. There was also no difference in bioavailability of pure epicatechin and epicatechin from dark chocolate, when standardised per $100 \mathrm{mg}$ of epicatechin. This suggests that epicatechin may contribute to the vascular effects of cocoa and that the bioavailability of pure epicatechin and epicatechin from dark chocolate is similar.

In the general discussion (Chapter 7), the main findings of this thesis were first summarised. Methodological considerations related to cohort studies, such as the assessment of flavonoid intake and the possibility of residual confounding were also discussed. Issues related to the relevance of cardiometabolic markers in RCTs and the effect of cocoa flavan-3-ol bioavailability were addressed. Finally, suggestions for future research were put forward.

In conclusion, the results of this thesis suggest that epicatechin contributes to the cardioprotective effects of cocoa and tea. Epicatechin intake was inversely related to CHD mortality in elderly men, and to CVD mortality in men with prevalent CVD. The cardioprotective effects of epicatechin are likely mediated through improvements in insulin resistance and possibly endothelial function. In contrast, quercetin is unlikely to play a 
major role in the cardioprotective effects of tea. Results for quercetin from cohort studies are inconclusive, and based on the results of our chronic RCT, quercetin did not affect vascular function or insulin resistance, but may help to lower inflammation. Evidence of the role that individual flavonoids play in the aetiology of CVD is still limited. More studies with pure flavonoids are required to elucidate their role. 


Dankwoord 
En nu tijd voor het meest belangrijke (en waarschijnlijk meest gelezen) stuk - het dankwoord! Want één ding is zeker, alleen was dit zeker nooit gelukt. Het is niet altijd even makkelijk geweest, en daarom ben ik een aantal mensen enorm dankbaar voor alle steun die ik de afgelopen jaren heb gekregen.

Om te beginnen, mijn promotors - Daan en Marianne. Ik zou niet weten hoeveel meetings we door de jaren heen hebben gehad. Soms waren dat nogal pittige bijeenkomsten, maar de mix van inhoudelijke discussies en leuke verhalen en anekdotes (want die waren er genoeg!) maakte deze meetings niet alleen leerzaam, maar ook erg plezierig. En wie had gedacht dat ik ooit een epidemiologisch onderzoek zou doen? Ik in ieder geval niet! Het zal geen verassing zijn als ik zeg dat epidemiologisch onderzoek niet mijn passie is, maar met jullie begeleiding ben ik er doorheen gekomen en daarvoor ben ik jullie enorm dankbaar. En Marianne, wat leuk dat we je sinds kort ook Professor mogen noemen en dat je 27 juni mijn promotor mag zijn!

Eén van de meest belangrijke personen in dit proces was natuurlijk onze flavo-expert. Peter, ik vond het erg fijn om met jou samen te werken, vooral omdat ik altijd met mijn vragen bij jou terecht kon. Je hebt er van begin af aan veel tijd en energie in gestoken en dat waardeer ik zeer. Ik vermoed dat het flavo-verhaal nog niet helemaal af is, maar later dit jaar neem je in ieder geval wel een stapje terug. Ik wens je alvast een hele fijne tijd na je pensionering!

Twee mensen die ik ook nog in het bijzonder wil bedanken zijn Sabita en Janette. Op verschillende momenten tijdens mijn PhD-project heb ik het genoegen gehad om met jullie samen te mogen werken. Jullie hebben mij allebei goed geholpen met de epi-analyses en ik heb met plezier met jullie samen gewerkt tijdens het begeleiden van MSc-studenten. En Janette, je bent nog niet helemaal van me af - ik zie je over een paar maanden weer bij Nutricia!

Talking about MSc-students... Morgan and Mia, thank you for all the hard work you put in during your thesis. Mia, I know it couldn't have been easy put up with us (Harry, Fabian, Christoph and myself), especially so early in the morning. But you were always there every morning and I really appreciate that. I hope you've managed to recover from the trauma by now!

Eén van de eerste dingen die ik heb geleerd tijdens mijn PhD-project was hoeveel werk het uitvoeren van een interventiestudie inhield. Gelukkig waren er veel mensen die hebben geholpen tijdens de interventiestudies. Ik ben iedereen dankbaar voor hun inzet en ondersteuning. Als eerste Harry en Fabian, bedankt voor alle hulp tijdens de FLAVO-1 (en Harry ook tijdens de FLAVO-2). Het was echt lachen om samen met jullie te werken! 
Ook iedereen van het bloedprikteam: Anita, Henriette, Jantien, Diana en Christoph, bedankt voor alle hulp en ook begeleiding tijdens de interventiestudies. Ik heb veel geleerd tijdens het uitvoeren van deze studies en dat kwam mede door jullie begeleiding. Daarnaast vond ik het ook een erg plezierig team om in te werken. Na het bloedprikken komen natuurlijk de analyses. Dini, bedankt voor alle tijd en moeite die je hieraan hebt besteed!

Een speciale plek wil ik bewaren voor alle deelnemers die hebben deelgenomen aan beide interventiestudies. Zonder jullie was dit allemaal niet mogelijk geweest en hiermee hebben jullie een belangrijke bijdrage geleverd aan dit proefschrift.

Op 27 juni mag ik op het podium staan, in de Aula in Wageningen, om dit proefschrift te verdedigen. Dit zou uiteraard niet mogelijk zijn zonder de opponenten. Ilja Arts, Aalt Bast en Jaap Keijer - bedankt voor het lezen en beoordelen van dit manuscript en voor het optreden als opponent. A special word of thanks also needs to be reserved for Aiden Cassidy - thank you so much that you were willing to make the journey from England to act as opponent for my PhD-defence.

Naast de opponenten staan er ook twee bijzondere mensen op het podium. Rob en Femke, wat fijn dat jullie mijn paranimfen wilden zijn. Rob, je hebt door de jaren heen aardig wat meegekregen van alles en je had altijd een goed luisterend oor. Meestal wel met een koud biertje in de hand en een voetbalwedstrijd op de achtergrond, dat helpt altijd! Het is voor mij een beetje afkicken geweest sinds ik in Hoorn woon, zo weinig voetbal - daar moeten we maar eens verandering in zien te brengen!

En Femke, wat was je een top roomy - ik had echt niet beter kunnen wensen! Het was altijd gezellig op het werk en je was er ook altijd om te praten - of het nou was om bij te kletsen na het weekend, of om alle frustraties te uiten - het maakte niet uit. Onze werkplek was ook regelmatig versierd, dat is iets wat me altijd zal bijblijven. Uiteraard niet alleen als roomy heb je het geweldig gedaan, maar ook als voorzitter van de kamer 116-feestcommissie ;) Ik heb echt genoten van alle uitjes en tripjes die we gezamenlijk hebben gemaakt.

Kamer 116 is door de jaren heen steeds iets veranderd, maar de harde kern kregen ze niet zomaar weg - zelfs niet toen ze een nieuw gebouw wilden bouwen ;) Lieke, Susanne, Eveline en Harry - samen met Femke hebben we veel mooie momenten meegemaakt en ik hoop dat we elkaar nog regelmatig zullen zien. Susanne onze reis door Australië, samen met Femke, was voor mij echt één van de hoogtepunten van mijn PhD-tijd. Lieke, mijn TIFN-buddy - ik vond het erg leuk om samen met jou de interventiestudies uit te voeren en wie weet, misschien dat we binnenkort weer collega's worden! Eveline, bedankt voor alle gezelligheid en ook alle data;) Ik beloof je dat ik je nooit meer zal vragen om een nieuwe 
flavo-tabel. And Harry......what can I say....? You pikey, je was echt geweldig! Soms leek het voor anderen misschien een beetje chaotisch, maar je kreeg altijd alles voor elkaar. Ik heb echt van je geleerd dat hoe dan ook, altijd alles goed komt. Wat ik niet van je heb geleerd is....hoe je worcestershiresaus uitspreekt ;)

Naast de harde kern, zijn er door de jaren heen veel mensen die (tijdelijk) in kamer 116 hebben gebivakkeerd. Jaike, Sabine, Sifra, Danielle, Rianne, Claudia, Laura - bedankt voor alle gezelligheid en gekkigheid in kamer 116 !

Buiten Wageningen om zijn er ook een aantal mensen die hebben bijgedragen aan het project. ledereen vanuit TIFN die heeft meegeholpen aan het project - Ronald, Peter, Arno, Richard, Casper, Peter, Yvo en Jos bedankt voor jullie inzet en levendige discussies die we door de jaren heen hebben gehad. Diederik, thanks voor alle geduld met het uitleggen van de genexpressie data!

Als laatste wil ik een plek reserveren voor een aantal belangrijke mensen die misschien niet direct betrokken waren bij het project, maar veel steun hebben geboden tijdens de afgelopen jaren. Mum, Dad, Steve, Myriam en Yuhwi - het was misschien niet altijd even duidelijk wat ik allemaal aan het doen was in Wageningen, maar het feit dat ik altijd zo een fijne thuisbasis had om op terug te vallen heeft me door de jaren heen enorm geholpen. En natuurlijk hoort de schoonfamilie daar ook bij - Martje, Johan, Jaap, Sylvia, Sanne en Hein bedankt voor alle interesse en betrokkenheid vanaf de zijlijn de afgelopen jaren! Tot slot, een paar woorden voor het homefront. Lieve Lotte, je bent echt een rots voor me geweest! Toen het even zwaar was, wist je me altijd op de juiste manier te steunen - soms met wat goedgekozen wijze woorden, soms met een echte kick-up-the-backside.... Op een bepaalde manier wist je altijd wat ik nodig had. Sinds kort heeft onze leven samen een nieuwe, spannende wending gekregen. Lotte en Sebas, ik ben zeer trots op jullie allebei en ik weet zeker dat we een mooie toekomst tegemoet gaan! 


About the Author

Curriculum Vitae

List of Publications

Overview of Completed

Training Activities 


\section{CURRICULUM VITAE}

James Dower was born on $16^{\text {th }}$ February 1987 in Bridgwater, England. At the age of eight he moved to the Netherlands where he attended the European School of Bergen. After graduating with a European Baccalaureate in 2005, he started a BSc degree in Sports and Exercise Sciences at Loughborough University (England) which he completed in 2008. Following his BSc degree he started an MSc degree in Human Nutrition at Wageningen University, the Netherlands. In 2010, James completed his MSc thesis entitled 'Salivary IgA: reproducibility and response to endurance exercise'. After his MSc thesis, he did an internship at the department of Nutrition and Dietetics at the University of Newcastle in Australia. During his internship he provided practical assistance for a number of weight loss studies for men, and investigated the implementation of behavior change frameworks in weight loss programs. After completing his MSc degree, James started as a PhD student at the Division of Human Nutrition, Wageningen University. His PhD-thesis focused on the role of dietary flavonoids on cardiovascular health and disease. During the course of his PhD-project, he attended several conferences and courses with the education program of the VLAG graduate school. In March 2016, James started as a Clinical Studies Researcher for the Clinical Research Platform of Nutricia Research. 


\section{LIST OF PUBLICATIONS}

Dower JI, Geleijnse JM, Gijsbers L, Zock PL, Kromhout D, Hollman PCH. Effects of the pure flavonoids epicatechin and quercetin on vascular function and cardiometabolic health: a randomised double-blind, placebo-controlled, crossover trial. AJCN 2015.

Gijsbers L, Dower JI, Mensink M, Siebelink E, Bakker SJ, Geleijnse JM. Effects of sodium and potassium supplementation on blood pressure and arterial stiffness: a fully controlled dietary intervention study. J Hum Hypertens 2015.

Dower JI, Geleijnse JM, Gijsbers L, Schalkwijk C, Kromhout D, Hollman PCH. Supplementation of the pure flavonoids epicatechin and quercetin improves some biomarkers of endothelial function and inflammation in (pre)hypertensive adults: a randomised double-blind, placebo-controlled, crossover trial. J Nutr 2015.

Gijsbers L., Dower JI, Schalkwijk C, Kuster YH, Bakker SJ, Hollman PCH, Geleijnse JM. Effects of sodium and potassium supplementation on endothelial function: a fully controlled dietary intervention study. Br J Nutr 2015. 


\section{OVERVIEW OF COMPLETED TRAINING ACTIVITIES}

\section{Discipline specific activities}

- Symposium: Nutritional Sciences - The Future is ours, Wageningen University, Wageningen, the Netherlands, 2015

- Annual meeting of NWO Nutrition, Nationale Academie van Voedingswetenschappen, Deurne, the Netherlands, 2012

- World Congress on Polyphenols Applications, ISANH Polyphenols, Lisbon, Portugal, 2014

- Molecular Epidemiology of Chronic Disease, MUMC, Maastricht, the Netherlands, 2014

- TIFN Information Patent Workshop, TIFN, Wageningen, the Netherlands, 2013

- Annual meeting of NWO Nutrition, Nationale Academie van Voedingswetenschappen, Deurne, the Netherlands, 2012

- Regression Analysis; Erasmus Summer Programme, Netherlands Institute for Health Sciences (NIHES), Rotterdam, the Netherlands, 2012

- NuGo-week, NuGo, Wageningen, the Netherlands, 2011

- Nutrigenomics Masterclass, Graduate School VLAG, Wageningen, the Netherlands, 2011

- Clinical Trials; Erasmus Summer Programme, Netherlands Institute for Health Sciences (NIHES), Rotterdam, the Netherlands, 2011

- Introduction to Global Public Health; Erasmus Summer Programme, Netherlands Institute for Health Sciences (NIHES), Rotterdam, the Netherlands, 2011

- Methods of Clinical Research; Erasmus Summer Programme, Netherlands Institute for Health Sciences (NIHES), Rotterdam, the Netherlands, 2011

- Markers and Prognostic Research; Erasmus Summer Programme, Netherlands Institute for Health Sciences (NIHES), Rotterdam, the Netherlands, 2011

- Vascular Biology (PhD- training course, ), Dutch Heart Foundation, Arnhem, The Netherlands, 2011 


\section{General courses}

- Career Orientation, Wageningen Graduate School, Wageningen, the Netherlands, 2015

- Philosophy and Ethics of Food Science and Technology, Graduate School VLAG, Wageningen, the Netherlands, 2015

- Masterclass: Visi-omics, Graduate School VLAG, Wageningen, the Netherlands, 2014

- Techniques for Writing and Presenting a Scientific Paper, Wageningen Graduate School, Wageningen, the Netherlands, 2014

- Masterclass: Confounding in Epidemiological Research, Graduate School VLAG, Wageningen, the Netherlands, 2013

- Techniques for Writing a Scientific Paper, Wageningen Business School, Wageningen, the Netherlands, 2011

\section{Optionals}

- TIFN midterm review, TIFN, Wageningen, the Netherlands, 2014

- PhD study tour, Division of Human Nutrition, Melbourne/Sydney, Australia, 2013

- Analytical Epidemiology, Division of Human Nutrition, Wageningen, the Netherlands, 2013

- Preparation of research proposal, Wageningen, the Netherlands, 2012

- TIFN team workshop, TIFN, Wageningen, the Netherlands, 2011 
The studies presented in this thesis were performed within the framework of TI Food and Nutrition (TIFN).

Financial support from Wageningen University for printing this thesis is gratefully acknowledged.

Cover design: Joska Sesink, Persoonlijk Proefschrift

Layout design: Joska Sesink Persoonlijk Proefschrift

Printed by: Ipskamp Printing, Nijmegen 





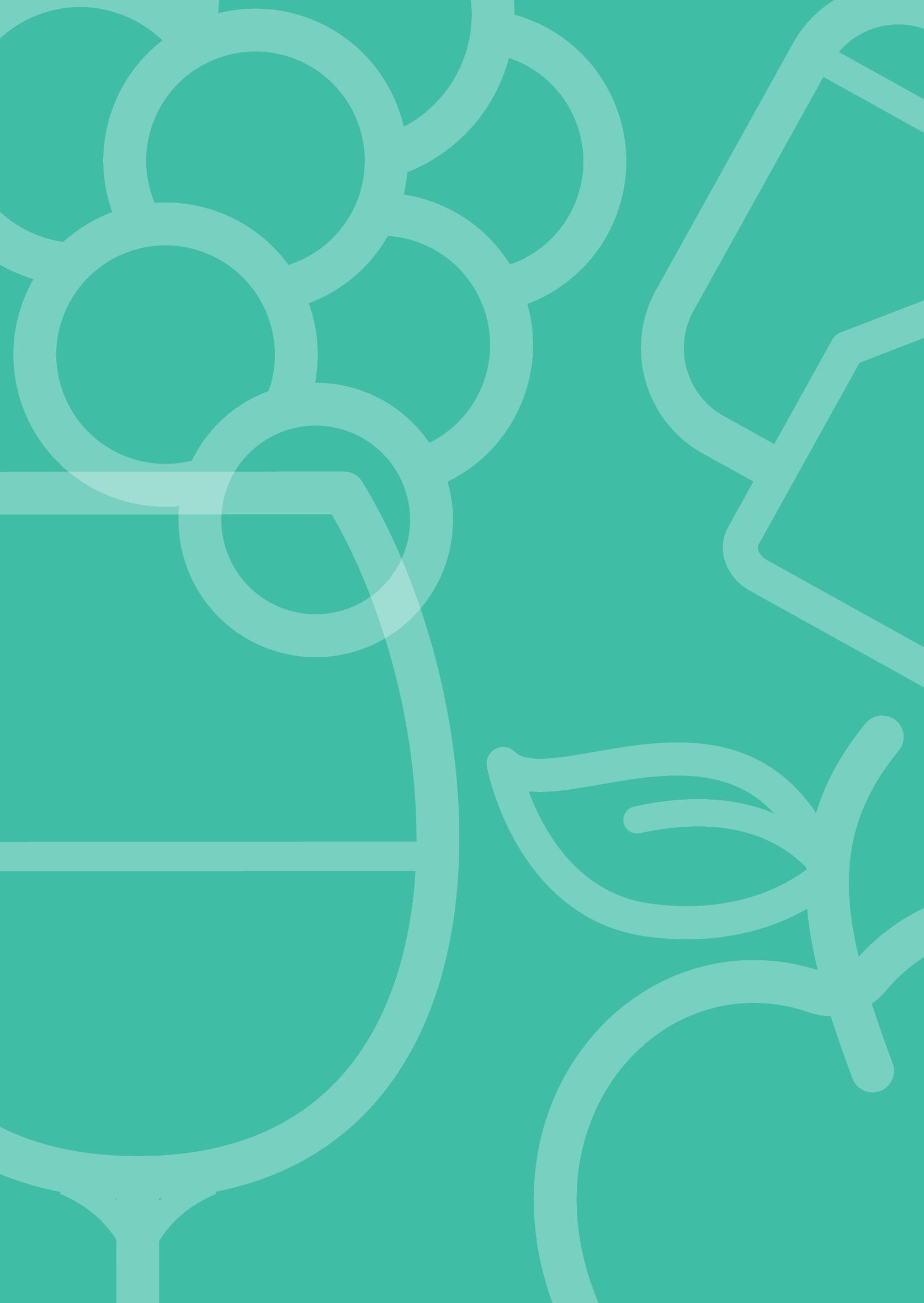

